\title{
National Ignition Facility Quarterly Status Report- Second Quarter 2000, Jan-Mar 2000
}

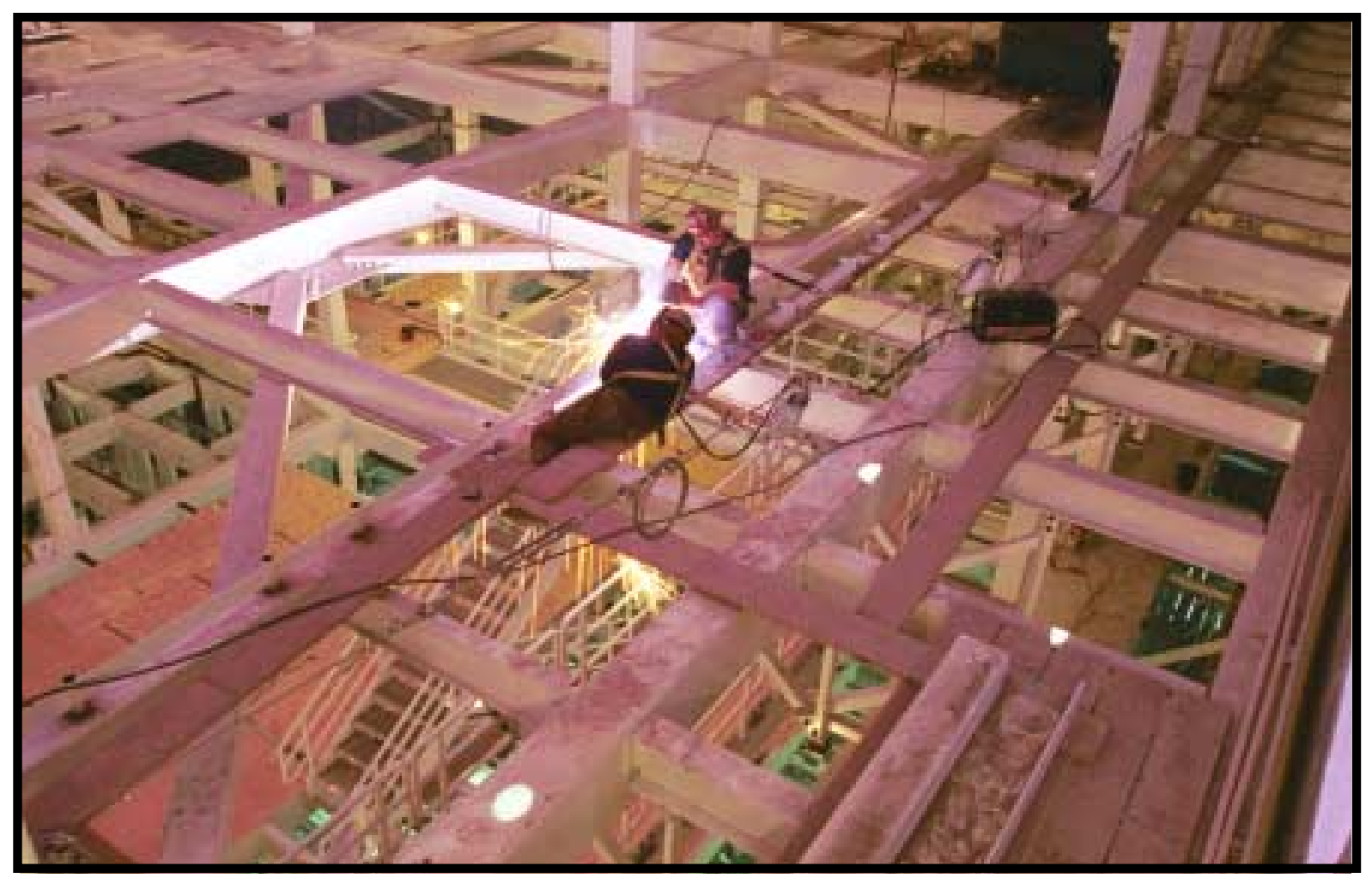

April 30, 2000

Edward I. Moses

Project Manager

Law rence Livermore National Laboratory

7000 East Avenue

Livermore, CA 94550 
This document was prepared as an account of work sponsored by an agency of the United States Government. Neither the United States Government nor the University of California nor any of their employees, makes any warranty, express or implied, or assumes any legal liability or responsibility for the accuracy, completeness, or usefulness of any information, apparatus, product, or process disclosed, or represents that its use would not infringe privately owned rights. Reference herein to any specific commercial products, process, or service by trade name, trademark, manufacturer, or otherwise, does not necessarily constitute or imply its endorsement, recommendation, or favoring by the United States Government or the University of California. The views and opinions of authors expressed herein do not necessarily state or reflect those of the United States Government or the University of California, and shall not be used for advertising or product endorsement purposes.

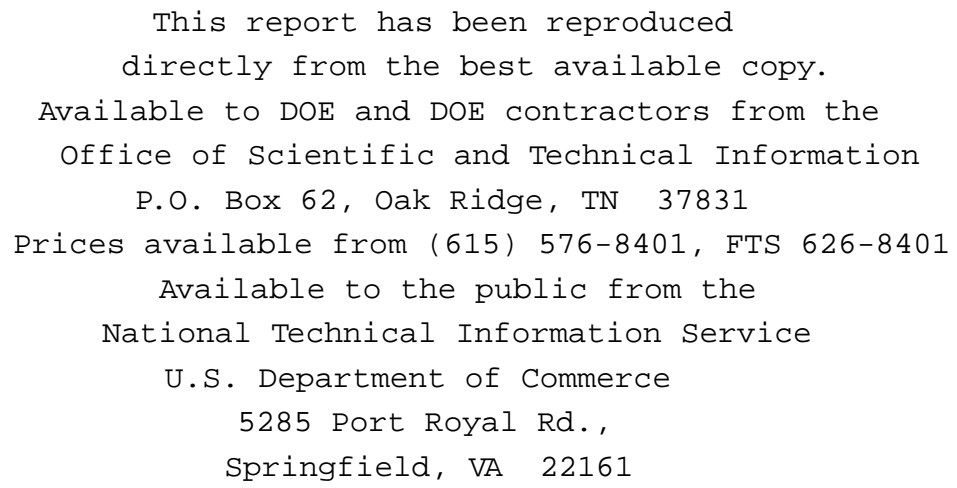

This work performed under the auspices of the U.S. Department of Energy by University of California Lawrence Livermore National Laboratory under Contract No. W-7405-Eng-48. 


\section{NATIONAL IGNITION \\ FACIUTY \\ Q UARTERLY STATUS \\ REPORT SUMMARY \\ MARCH 2000}

WBS 1.1 PROJECT

O FFICE

W BS 1.2 SITE AND CONVENTIONAL FACIUTIES

W BS 1.3 LASER SYSTEMS

\section{TABle OF Contents}

NATIONAL IGNITION FACIUTY QUARTERLY STATUS REPORT

MARCH 2000

NIF Project Manager's Assessment ...................................................... 2

Overall Project Assessment ................................................................. 2

Second Quarter Rebaseline Activities .......................................... 3

Second Quarter Activities Highlights ................................................. 4

Third Quarter Scheduled Activities ............................................... 5

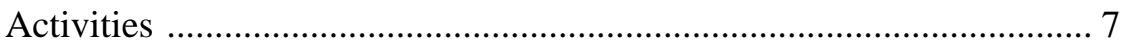

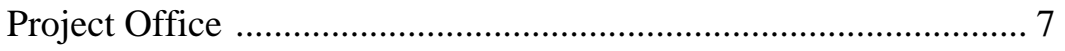

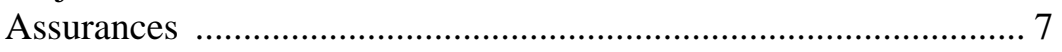

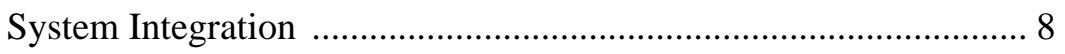

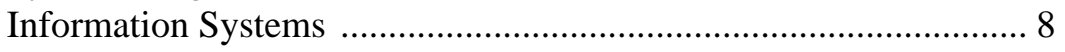

System Performance, Mission, and Risk Analysis ......................... 8

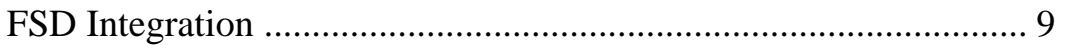

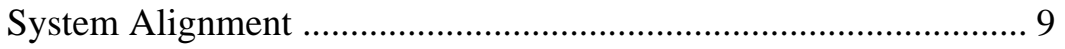

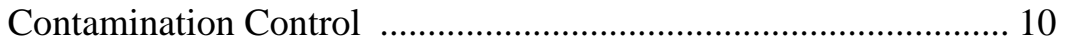

Confirguration Management, Change Control Actions .................. 11

Problems/Impacts/Corrective Actions ................................................. 14

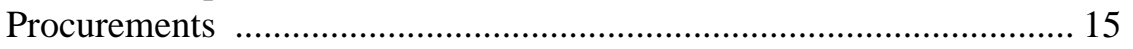

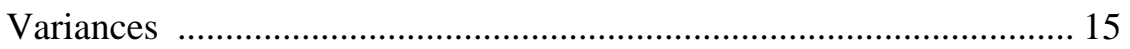

Upcoming Major Activities ............................................................ 15

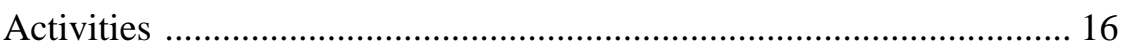

Problems/Impacts/Corrective Actions ............................................... 17

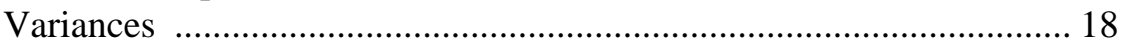

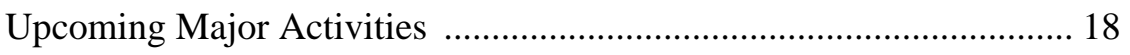

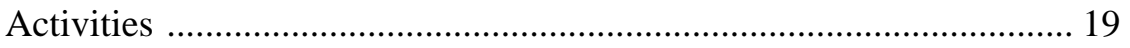

Optical Pulse Generation System ............................................... 19

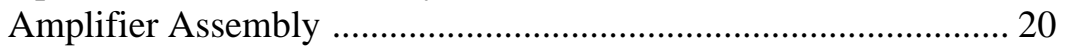

Amplifier Power Conditioning System (PCS) ……....................... 20

Problems/Impacts/Corrective Actions ................................................. 20

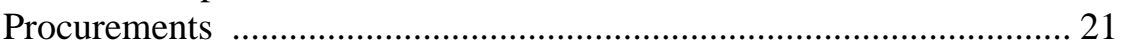

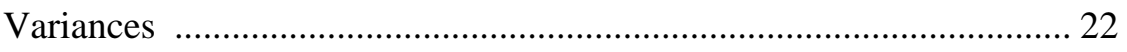

Upcoming Major Activities .............................................................. 22 
W BS 1.4 BEAM TRAN SPO RT SYSTEMS

WBS 1.5 INTEGRATED COMPUTER CONTROL

W BS 1.6 O PTICAL COMPONENTS

WBS 1.7 LASER CONTROL

W BS 1.8 TARGET EXPERIMENTAL SYSTEM

W BS 1.9 O PERATIONS SPECIAL EQUIPMENT

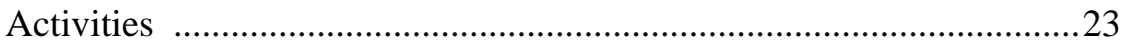

Spatial Filter Vessels/Enclosures ...............................................23

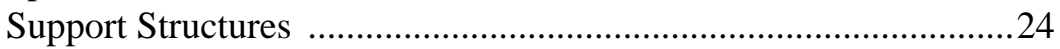

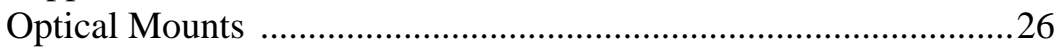

Problems/Impacts/Corrective Actions ..................................................22

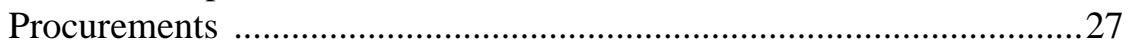

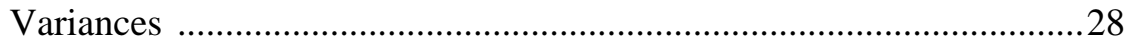

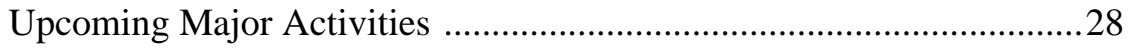

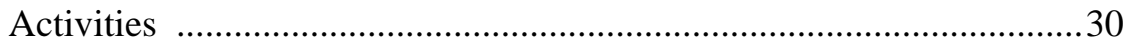

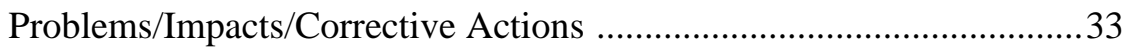

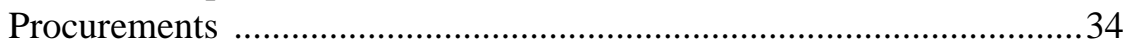

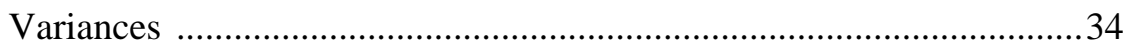

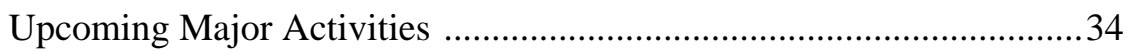

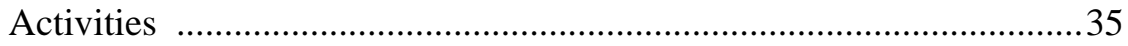

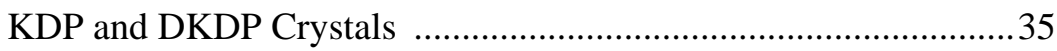

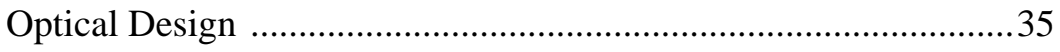

Optical Pulse Generation and Injection System Optics ...................36

Problems/Impacts/Corrective Action ………........................................36

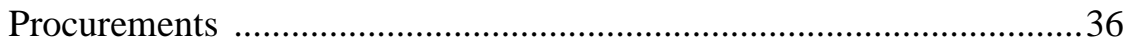

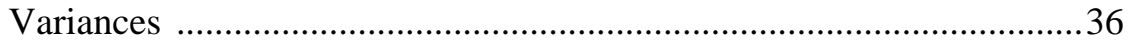

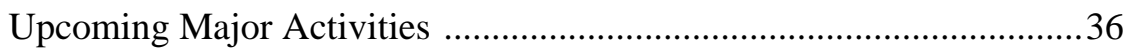

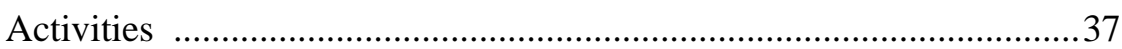

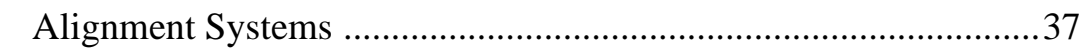

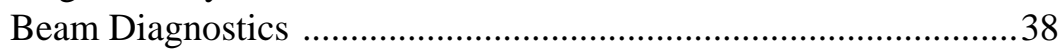

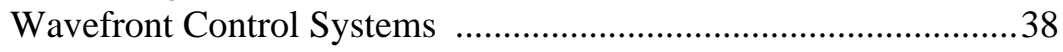

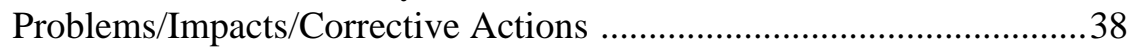

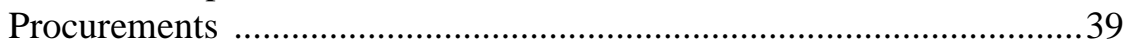

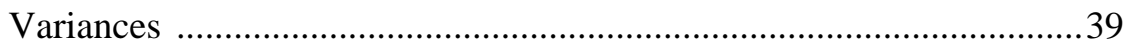

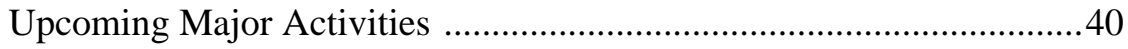

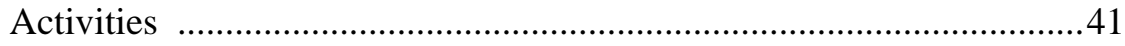

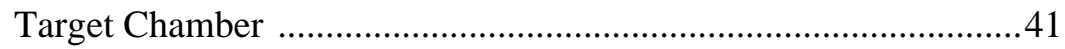

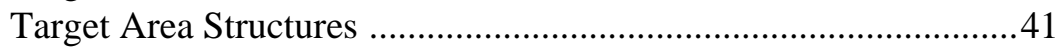

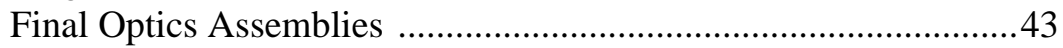

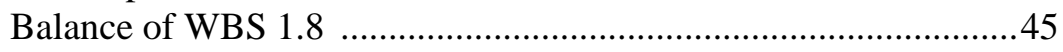

Problems/Impacts/Corrective Actions ..................................................46

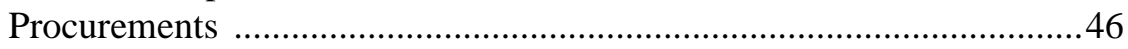

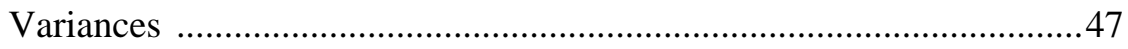

Upcoming Major Activities ............................................................4

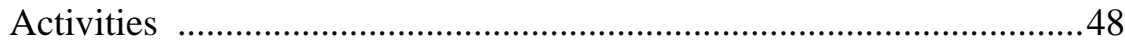

Optical Transport and Material Handling .....................................48

Bottom-Loading (BL) Delivery Systems .....................................48 


\begin{tabular}{|c|c|}
\hline & Top-Loading (TL) Delivery Systems \\
\hline & 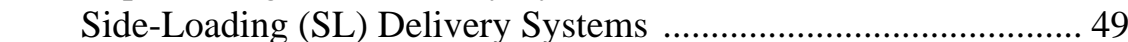 \\
\hline & 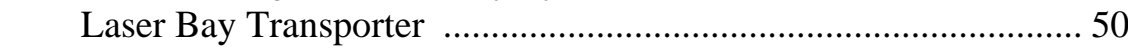 \\
\hline & Switchyard and Target Bay .............................................. 50 \\
\hline & 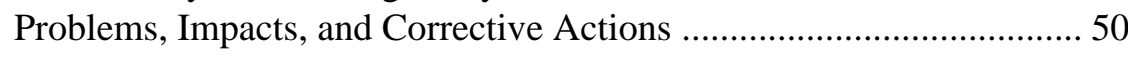 \\
\hline & Procurements \\
\hline & Variances \\
\hline & 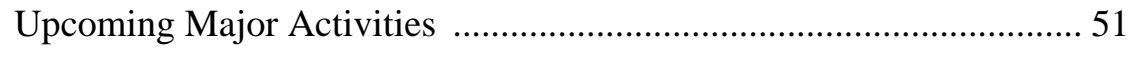 \\
\hline $\begin{array}{r}\text { W BS } 1.10 \text { START-UP } \\
\text { ACTIVITIES }\end{array}$ & 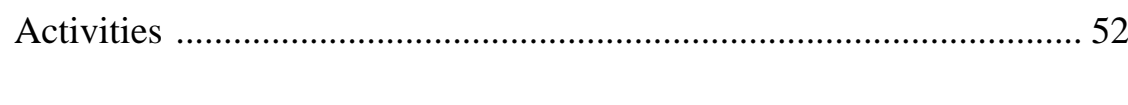 \\
\hline W BS 1.11 ES\&H AND & Activities ............. \\
\hline SUPPORTING R\&D & Assurances ............ \\
\hline & 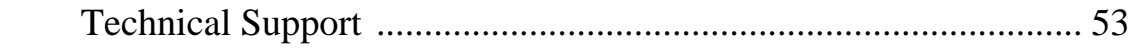 \\
\hline & 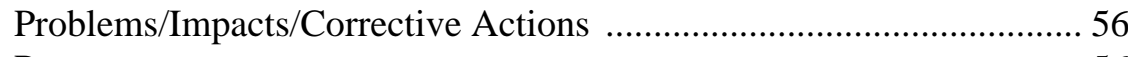 \\
\hline & Procurements \\
\hline & Variances \\
\hline & 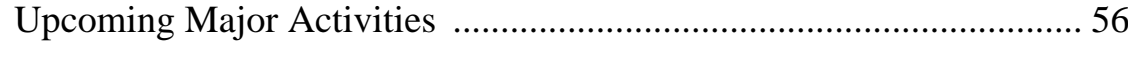 \\
\hline
\end{tabular}

Attachment 1: $\quad$ Status of DOE/NNSA Performance Measurement Milestones .............. 58 SCHEDUle Status

Attachment 2: $\quad$ Project Plan-to- Actual Cost and Cost Plus Commitments 61

\section{Fin AN CIAL STATUS}




\section{NATIONAL IGNITION FACIUTY QUARTERLY STATUS REPORT SUMMARY MARCH 2000}

\begin{tabular}{|c|c|c|c|c|}
\hline Project Name: & National Ignition Facility & Building No. & \multicolumn{2}{|c|}{581,681 at LLNL } \\
\hline $\begin{array}{l}\text { NNSA Line Item } \\
\text { No.: }\end{array}$ & $96 \mathrm{D}-111$ & Project Manager: & E. I. Moses & $\begin{array}{l}925-423-9624 \\
925-423-2612 \text { (fax) }\end{array}$ \\
\hline $\begin{array}{l}\text { Budget \& } \\
\text { Reporting No.: }\end{array}$ & $\begin{array}{l}39 \text { DP } 02 \text { (PACE) } \\
\text { DP } 0213 \text { (OPC) }\end{array}$ & System Engineer: & M. L. Spaeth & $\begin{array}{l}925-424-4940 \\
925-422-4667 \text { (fax) }\end{array}$ \\
\hline Funding Source: & $\begin{array}{l}\text { Weapons Stockpile } \\
\text { Stewardship - ICF }\end{array}$ & Program Sponsor: & C. J. Keane & $301-903-4323$ \\
\hline $\begin{array}{l}\text { Original } \\
\text { Funding Year: }\end{array}$ & '96 (first quarter) & Construction Manager: & V. S. Roberts & $\begin{array}{l}925-424-3662 \\
925-423-7588 \text { (fax) }\end{array}$ \\
\hline $\begin{array}{l}\text { Project } \\
\text { Summary } \\
\text { Description: }\end{array}$ & \multicolumn{4}{|c|}{$\begin{array}{l}\text { The Project provides for the design, procurement, construction, assembly, installation, and acceptance testing of the } \\
\text { National Ignition Facility (NIF), an experimental inertial confinement fusion facility intended to achieve controlled } \\
\text { thermonuclear fusion in the laboratory by imploding a small capsule containing a mixture of the hydrogen isotopes } \\
\text { deuterium and tritium. The NIF will be constructed at the Lawrence Livermore National Laboratory (LLNL), } \\
\text { Livermore, California as determined by the Record of Decision made on December 19, 1996, as a part of the } \\
\text { Stockpile Stewardship and Management Programmatic Environmental Impact Statement. }\end{array}$} \\
\hline $\begin{array}{l}\text { Project } \\
\text { Justification: }\end{array}$ & \multicolumn{4}{|c|}{$\begin{array}{l}\text { The mission of the National Inertial Confinement Fusion (ICF) program is to achieve controlled thermonuclear fusion } \\
\text { in the laboratory. This program supports the National Nuclear Security Administration (NNSA) mandate of } \\
\text { maintaining nuclear weapons science expertise required for stewardship of the stockpile, testing of nuclear weapons } \\
\text { effects, and the development of fusion power by providing a database for inertial fusion ignition. This mission was } \\
\text { identified in the NIF Justification of Mission Need, which was endorsed by the Secretary of Energy. Identification of } \\
\text { target ignition as the next important step in ICF development for both defense and nondefense applications is } \\
\text { consistent with the earlier (1990) recommendation of NNSA's Fusion Policy Advisory Committee, and the National } \\
\text { Academy of Sciences Inertial Fusion Review Group. In 1995, the NNSA's Inertial Confinement Fusion Advisory } \\
\text { Committee affirmed the program's readiness for ignition experiments. A review by the JASONs in } 1996 \text { affirmed the } \\
\text { value of the NIF for stockpile stewardship. }\end{array}$} \\
\hline $\begin{array}{l}\text { Interfaces with } \\
\text { Other Projects }\end{array}$ & \multicolumn{4}{|c|}{$\begin{array}{l}\text { The NIF is a key element of the Stockpile Stewardship Program. It will provide scientific data for secondaries and } \\
\text { will complement hydrodynamic tests and material testing for primaries. The NIF will provide data to calibrate ASCI } \\
\text { models. Position papers on NIF's role in Stockpile Stewardship are being prepared. }\end{array}$} \\
\hline $\begin{array}{l}\text { Risk } \\
\text { Management: }\end{array}$ & \multicolumn{4}{|c|}{$\begin{array}{l}\text { The System Engineering group has been organized and chartered to identify and manage risk. Working Groups within } \\
\text { this organization include Beampath, Flange to Flange (cleanliness), Alignment, Contamination Control, Laser and } \\
\text { Target Area Building (LTAB) lighting, Test Plans, Activation, and Requirements Update. }\end{array}$} \\
\hline $\begin{array}{l}\text { Execution \& } \\
\text { Acquisition } \\
\text { Strategy: }\end{array}$ & \multicolumn{4}{|c|}{$\begin{array}{l}\text { The model successfully employed to execute the Conventional Facility will be adapted for the Beampath } \\
\text { Infrastructure Systems. This model relies on the services of an Architect/Engineer (A/E) for design and an Integration } \\
\text { Management and Installation (IMI) Contractor to assist in managing the complex interfaces during installation and } \\
\text { the commissioning of construction contracts. } \\
\text { The Acquisition Strategy for laser equipment will focus on the use of integrating contractors to the maximum extent } \\
\text { possible to achieve the performance specifications and incorporate technology advances. }\end{array}$} \\
\hline
\end{tabular}




\section{Project Manager's Second Quarter 2000 Progress Report}

Summary Status

\begin{tabular}{|l|l|l|l|}
\hline \multicolumn{1}{|c|}{ Category } & Last Period & This Period & $\begin{array}{c}\text { Projected Next } \\
\text { Period }\end{array}$ \\
\hline Cost & Major concern & Major concern & Major concern \\
\hline Schedule & Major concern & Major concern & Major concern \\
\hline Technical & Satisfactory & Satisfactory & Satisfactory \\
\hline Overall Project & Major concern & Major concern & Major concern \\
\hline
\end{tabular}

N IF PRojeCt

MANAGER'S

ASSESSMENT

OVerall Project ASSESSMENT
Major concern due to schedule and cost.

Safety: In January, an incident occurred at the NIF site when a worker was struck by a heating, ventilation, and air conditioning (HVAC) duct during installation. The worker received serious back injuries, but will be able to return to work in several months. An Occurrence Report was filed with the Department of Energy (DOE), and Incident Analysis and Site Management Review Teams investigated the direct and root causes of the accident and made recommendations to the Project Manager. One major recommendation was to obtain the services of a major industrial firm with an excellent safety record to review the accident and make recommendations. DuPont was contracted and spent a week at the site. Their recommendations and final report are scheduled for the end of April.

Two additional safety incidents occurred in March. One of these incidents, occurring in the CSP-6/10 package, prompted a stand down of work of all contracts associated with the Subcontractor (CSP-04, CSP- 
05, and CSP-6/10) to refocus on safety communications and procedures.

Technical Status: The general status of the technologies underlying the NIF Project remains satisfactory. The issues currently being addressed are (1) cleanliness for installation, assembly, and activation of the laser system by Systems Engineering working groups; (2) laser glass, where a second pilot run at both commercial suppliers is expected to confirm the mitigation steps identified in the first pilot run; and (3) operational costs associated with Final Optics Assembly (FOA) optics components, where methods are being developed to mitigate $3 \omega$ damage and to resolve beam rotation issues.

Schedule: The project completion schedule remains a major concern for the quarter. The Beampath Infrastructure System (BIS) design and contract for the Integration Management and Installation Contractor are on the critical schedule path. The procurement package has been reviewed with DOE Procurement and NNSA Project organizations. The DOE HQ approval is scheduled for mid-April 2000.

The construction status of the Conventional Facilities at the end of March 2000 is $86 \%$ complete.

Cost: The NIF Project Total Project Cost (TPC) is $\$ 1.2 \mathrm{~B}$. The Project has obligated $76 \%$ of the TPC funds. The remaining contingency is $\$ 17.3 \mathrm{M}$. Because of schedule delays and projected increases in the design, construction management, assembly, and installation of the system infrastructure, cost growth of the TPC is anticipated and will remain a major concern until the budget rebaseline process is completed. The cost roll up for Option 1 was completed in March 2000 in anticipation of review with the Level 1 and 2 Baseline Change Control Boards (BCCBs) and in May 2000 with the Level 0 BCCB, Energy Systems Acquisition Advisory Board.

Second Q uarter Rebaseline Activities
The NIF Project performed the following key actions in the second quarter to rebaseline the Project before June 1, 2000: (1) implemented and statused the NNSA approved Rebaseline Plan; (2) defined the first deployment option, Option 1, in terms of method of accomplishment, bottom-up schedule, and cost estimate; (3) implemented and statused weekly the Transition Period Implementation Plan; (4) implemented contract activities to bring in industry to design, fabricate, and assemble the BIS in the form of engineering and a major Integration Management and Installation sole source contract; (5) continued the major external reviews of the Project; (6) completed intermediate and final reviews of the cost and schedule rebaseline leading to a Level 1 and 2 
BCCB meeting; and (7) made significant technical progress in laser glass production, laser first-article procurements, and FOA resolution.

Project Rebaseline Planning: The Rebaseline Plan lays out the integrated activities to achieve new procurement strategies to involve industrial partners in the beampath infrastructure and lays out the use of contractors to design, manufacture, and assemble laser systems using enforceable bid documents, as is currently done in the Conventional Facilities. The Rebaseline Plan was approved by the NNSA and implemented this quarter. The only activity not on schedule is the development of the second option due to the delay of DOE/NNSA guidance.

Management Organization: The organization to effectively implement the rebaseline of the NIF was announced in the first quarter. The management approach has been reviewed with several external panels and with the DOE/NNSA at the Level 1 and 2 BCCB meetings.

Schedule Rebaseline: Inputs to the bottom-up rebaseline schedule (covering 24,000 activities) for the first of two completion options have been completed and transmitted to the DOE. This schedule was presented to the Level 1 and 2 BCCBs at a joint March review.

Procurement Strategy: LLNL proposed, and the independent Beampath Structure Advisory Committee concurred, that the BIS Integration Management and Installation contract be given to an industrial firm. DOE HQ has been briefed, and approval to proceed is expected in mid-April.

Independent Reviews: (1) University of California (UC) President's Office Project Management Panel review of NIF status, management approach, and method of accomplishment was completed; (2) General Accounting Office (GAO) review of the NIF continued with individual interviews; (3) Secretary of Energy Advisory Board (SEAB) Task Group of independent industry and scientific experts to advise on NIF procurement and engineering strategies reviewed their interim report in a public conference call; (4) the NIF Council conducted Performance Review and Technology Review group meetings; (5) Science and Technology Advisor to Senator Domenci reviewed NIF status; and (5) the UC ES\&H Panel reviewed recent accidents.

Second Q uarter Activities Highlights
Site and Conventional Facilities: Significant progress on the Target and Laser Buildings accounted for the increase in construction completion. Due to a safety stand down that started on March 15, 2000, all NDBI work was halted until a satisfactory corrective action plan was developed. 
Laser/Optics Systems: In the master oscillator system, first-article chassis have been constructed, tested, and assembled in an integrated fashion. Tests of the fiber oscillator, double-pass amplifier, electrooptic gate, and the first fiber amplifier chassis are now being conducted.

Beam Transport System: The BIS Integration Management and Installation Services subcontractor solicitation package and approach were presented to DOE Programmatic and Procurement organizations with approval to proceed scheduled for mid-April (critical path action).

Integrated Computer Control: The test group completed testing of the Flashlight software release on schedule in January 2000 and documented the results in a test summary report. The Flashlight release was the third release of control system software and the first deployment of software for the Front-End Integrated System Test.

Optics: Most of the optical design of the FOA using a wedged lens was completed in March. The remaining tasks included detailed ghost analysis and coordination with FOA mechanical engineers to assure that the design solution does not limit access and availability.

Laser Control: To date, about 360 Xinetics actuators for the deformable mirrors (DMs) have been received and tested. They are of high quality; all but nine have passed all incoming inspection tests (98\%).

Target Experimental System: During the past quarter, significant progress has occurred on the FOA with respect to engineering, ultraviolet (UV) optics damage, and optics production.

Operations Special Equipment:The integrated tests of the bottomloading universal delivery system have completed many successful fully automated sequences consisting of docking, cover removal, and plasma electrode Pockels cell (PEPC) line-replaceable unit (LRU) insertion.

$E S \& H$ and Supporting $R \& D$ : To date, Schott has produced about 225 meter-sized glass slabs meeting all of the stringent NIF specifications in their Pilot II campaign. In addition, the glass has been produced at a rate 20 times faster than could be achieved using existing one-slab-ata-time discontinuous melting technology.

Third Q uarter

The major activities scheduled to occur in the third quarter are to (1) Scheduled Activities make presentations to the SEAB Task Force after preparing responses to the recommendations from their Interim Report, (2) complete the cost and schedule rebaseline status reviews with DOE/NNSA HQ and present to the Level 1 and 2 BCCB meeting followed by the Level 0 
BCCB (ESAAB), (3) present the BIS procurement and obtain the DOE HQ Procurement organization approval to proceed, (4) award the contract for the Integration Management and Installation Contractor for the Beampath Infrastructure System, (5) complete Optics Assembly Building (OAB) facility turnover to Operations, (6) complete the PEPC automated insertion demonstration, (7) start the Hoya Pilot II glass production pilot run, (8) deliver the first laser slab from Schott, and (9) receive spatial filter tubes and end vessels from the vendor. 


\section{WBS 1.1 Project Office}

\section{ACTIVITIES}

Project 0 ffice The major Project Office activities were to: (1) implement the rebaseline plan by preparing the rebaseline schedule and cost estimates based on the options; (2) participate in external reviews by the UC, SEAB, and GAO; (3) present options to the Level 1 and 2 BCCBs; and (4) provide weekly, monthly, and quarterly status reports.

In the rebaseline activity, Option I was selected by the DOE/NNSA as the first option to implement. The first major action was to develop the procurement methodology strategy for the Beampath Infrastructure Systems (see WBS 1.4) and to prepare the rebaseline schedule and cost estimate for that option. The other options selected by the DOE/ NNSA in their March 9 letter $^{1}$ will be developed from that bottom-up estimate. The rebaseline schedule was developed and submitted to the NNSA in March 2000. The schedule formed the basis for the Option 1 bottom-up cost estimate (based on 24,000 activities), which was completed later that month.

Several external reviews occurred in the second quarter: (1) UC President's Office Project Management Panel review occurred, (2) GAO review of the NIF continued with individual interviews; (3) SEAB Task Group of independent industry and scientific experts to advise on NIF procurement and engineering strategies reviewed their interim report in a public conference call; (4) the NIF Council conducted Performance Review and Technology Review group meetings; and (5) the UC ES\&H Panel reviewed recent construction site accidents.

Assurances An accident occurred at the NIF site in January when a worker was struck by a HVAC duct during installation. The worker received serious back injuries but will be able to return to work in several months. An Occurrence Report was filed with the DOE, and Incident Analysis and Site Management Review Teams investigated the direct and root causes of the accident and made recommendations. One major recommendation was to obtain the services of a major industrial firm with an excellent safety record to review the accident and make recommendations. DuPont was contracted through the ICF/NIF Operations Manager and spent a week at the site. During this time, two accidents were

1. Letter T. Giaconda to C. B. Tarter, "Options for National Ignition Facility," March 9, 2000. 
System Integration

Information Systems

System Performance, $M$ ission, and Risk

A nalysis experienced by NDBI and its subcontractors (see WBS 1.2). This led to a safety stand down while major corrective actions were performed.

A significant portion of the effort in System Engineering this quarter was toward rebaselining the cost, schedule, and scope of the NIF Project. The project scope and proposed items that needed to be included as part of the baseline plan because of their importance to successfully completing the NIF were reviewed. System Engineering also worked with the Functional System Description (FSD) Managers to help them understand the expections for their role in completing the engineering and commissioning NIF Steps. The Change Control Board (CCB) Level 4 evaluated the scope change proposals and making decisions regarding those to be baselined.

A new web-based Engineering Change Order (ECO) form was rolledout for the NIF project. This form has several advantages-it walks the person through all mandatory fields, thereby increasing the quality and completeness of the document, it has a provision to be corrected after approval, and it provides additional information on the disposition of material.

As an alternative to Structural Dynamics Research Corporation's (SDRC's) Metaphase product to replace Sherpa, an alternative product is being investigated (see Problems/Impacts/Corrective Actions).

The NIF Problem Identification and Correction System is the software system that supports the implementation of NIF Project Procedures 1.8, Action Tracking, and 3.2, Nonconformance Reporting. The Problem Reporting components of the system have progressed through several of development and test iterations. Final prerelease testing is planned to be complete at the end of April by a small set of 20 users. As confidence grows in the correct operation of the system, additional users will be added, and the beta designation will be upgraded to production release.

A plan was outlined (Performance Bundle Plan) for the performance optimization of a NIF Beamline (power and energy) after the initial commissioning is complete. The resources and schedule for accomplishing this plan were developed and included in the new baseline.

The status and goals of the NIF modeling efforts were presented to the NIF Council for their review and comment.

The effort to revalidate the NIF laser performance baseline began in earnest this quarter. It took on two tacks, controlling the configuration 
of the analysis software and input parameters and examining in detail the performance of the laser. The NIF laser performance analysis began with the Injection Laser System (ILS). The impact of ILS optics quality on contrast ratio and focal spot size of the main laser was modeled.

The next effort is to identify ILS optics and optics locations that are particularly large contributors to degradation in laser quality. This information will be used to provide or modify optics specifications to the ILS procurement review.

FSD Integration Early in this quarter the FSD Integration Group refined an FSD for the NIF. The FSD represents all of the NIF in a functional hierarchy. This hierarchy allows the elements at all levels to form operational units that can completely be described, starting with requirements through test plans. The Project is using this structure to organize the budgets and work so that each FSD organization can be responsible from requirement definition and design through to testing.

The FSD Group has also worked quite extensively to ensure that the requirements and technical information that form the basis of the Beampath Infrastructure design are correct. The information contained in the draft system definition documents was incorporated into the Process and Instrumentation Drawings (P\&IDs) that are being delivered to Parsons.

Another significant verification activity has been to coordinate and develop simple computer-aided design (CAD) model representations of the Special Equipment LRUs, including the interface points. These representations are used for defining how the utilities (interface control) will be attached. In addition, extensive effort has continued to pin down the requirements and operational modes of the beampath utilities.

The FSD organization has started to shift its attention from the utility reverification effort to the line-replaceable equipment requirement development and updating. This effort has initially focused on the laser transport in the switchyard and the FOA, primarily due to the attention being paid to the redesign of these areas and the need for timely updated information.

System Alignment The NIF Alignment 3-mm Survey Shoot was completed in February and March. The objective was to obtain a snapshot of the survey monuments used to place beampath infrastructure. There are over 900 monuments in the laser bays, switchyards, and target bays. The goal was to obtain a calculated uncertainty of $<3 \mathrm{~mm} 3 \sigma$ (gives a $97 \%$ like- 
lihood that the monument in is within the $3-\mathrm{mm}$ radius. The network has closed to well within the advertised $3 \mathrm{~mm} 3 \sigma$ error levels.

To further increase the accuracy of the location of the survey monuments, the building needs to be thermally stable. To verify this, air and surface temperature monitors have been installed in the LTAB.

To provide and verify coordinates needed for placement of vessels and structures in the CSP packages, a tool is being developed that operates on the 3-D CAD models. This tool automatically extracts and verifies coordinates from the mechanical design models.

A Contamination Control (CC) Advisory Board was established to interface with FSD Managers to establish CC Policy. The board also identified scope that needed to be added to the NIF baseline to ensure that the cleanliness requirements were met.

A Cleaning Methodology Decision Tree was developed that describes the logical decisions necessary to prepare a Statement of Work (SOW). Precision cleaning is considerably more complex than conventional cleaning following mechanical fabrication. The decision tree addresses issues such as material selection, achieving visible cleanliness, achieving precision cleanliness, passivation of stainless-steel components, and special packaging instructions.

Methodologies and tools for cleaning the Beamline in-situ are being developed. In conjunction with many of the LRU transport and handling design engineers, a design concept for a cleaning kit that includes tools to open and enter the beamline in a clean fashion was developed. A cleaning tool that has recently been identified is a sticky roller. These rollers are being tested for effectiveness in removing particles as well as residual nonvolatile residue (NVR). Another cleaning method involves a cleaning and protecting film from an industrial partner.

Fast and effective cleaning verification tools continue to be sought. The acquisition of the Optically Stimulated Electron Emission instrument that NASA Langley has developed for measuring NVR on structural surfaces is actively being pursued.

The possibility that initial substrate contamination or subsurface (polishing) defects are the prime initiator of slab damage is being investigated This study is looking at initial contamination on samples of polished laser amplifier glass (slab glass) prior to exposure to flashlamp light using atomic force microscopy. The glass is then exposed to various levels of flashlamp illumination and reexamined 
for atomic-level changes in the surface. So far, one set was exposed to 100 shots, and a 1000 shot exposure is under way.

Confirguration There was significant activity within the CCBs in support of the $M$ anagement, Change rebaselining activity. The CCB4 initiated twice-weekly standing meetControl Actions ings to review Engineering Change Requests (ECRs) and Contingency Transfer Requests (CTRs).

The following tables list the formal actions completed by the Level 4 and Level 3 Change Control Boards during this quarter.

Level 4 Change Control Board Actions: 


\begin{tabular}{|c|c|c|c|}
\hline ECR & Title & Resolution & $\begin{array}{l}\text { Cost } \\
(\$ K)\end{array}$ \\
\hline$\overline{750}$ & $\begin{array}{l}\text { LM4-LM8 Mirror System-OC } \\
\text { Rev }\end{array}$ & Approved & 0 \\
\hline 1316 & $\begin{array}{l}\text { PAMMA Utilities under } \\
\text { CSP-9 }\end{array}$ & Approved & 25.0 \\
\hline 1345 & $\begin{array}{l}\text { Simplify Format of NIF } \\
\text { Planning System (NPS) Codes } \\
\text { for FSD Elements }\end{array}$ & Approved & 0 \\
\hline 1346 & $\begin{array}{l}\text { Change WBS in 2.9.x and } \\
\text { 3.1.x }\end{array}$ & Approved & 0 \\
\hline 1354 & $\begin{array}{l}\text { Misc Updates to FSD, from } \\
\text { Rev A to Rev B }\end{array}$ & Approved & 0 \\
\hline 1356 & ECR for ISDF Fabrication & Approved & 69.3 \\
\hline 11357 & ISDF Fabrication & Approved & 94.9 \\
\hline 1408 & $\begin{array}{l}\text { Spatial Filter Vessel Kinematic } \\
\text { Locator } \\
\text { Adjustment Cam }\end{array}$ & Approved & 50 \\
\hline 1410 & Add title to WBS 2.8.3.5 & Approved & 0 \\
\hline 1437 & $\begin{array}{l}\text { Production design Changes for } \\
\text { FOA Vacuum ISOL }\end{array}$ & Approved & 100 \\
\hline 1457 & $\begin{array}{l}\text { Modify } 3 \omega \text { Calorimeter Chamber } \\
\text { by Shortening }\end{array}$ & Approved & 0 \\
\hline 1474 & $\begin{array}{l}\text { Argon System (U400) Baseline } \\
\text { P\&IDs }\end{array}$ & Approved & 170 \\
\hline 1484 & $\begin{array}{l}\text { Adopt TCC Coordinate System } \\
\text { For CSP-19 }\end{array}$ & Approved & 0 \\
\hline 1485 & Delete SY Jib Cranes & Approved & 0 \\
\hline 1491 & REVISE WBS 2.2 & Approved & 0 \\
\hline 1507 & $\begin{array}{l}\text { New WBS Elements For } \\
\text { Information Sys 1.1.4.2 }\end{array}$ & Approved & 0 \\
\hline 1515 & $\begin{array}{l}\text { LM1 Electrical Interface Cover } \\
\text { Mod Rev C }\end{array}$ & Approved & 5.7 \\
\hline 1535 & $\begin{array}{l}\text { Target Bay Beamtube Opening } \\
\text { and Embed Survey }\end{array}$ & Approved & 54 \\
\hline 1552 & Compressed Air Baseline PID & Approved & 0 \\
\hline 1554 & $\begin{array}{l}1 \omega \text { Diagnostic Beam Path } \\
\text { Change }\end{array}$ & Approved & 130 \\
\hline 1556 & $\begin{array}{l}\text { Target Area Vacuum Baseline } \\
\text { PID }\end{array}$ & Approved & 0 \\
\hline 1589 & Water System Baseline PID & Approved & 0 \\
\hline
\end{tabular}




\begin{tabular}{|c|c|c|c|}
\hline CTR & Title & Resolution & $\begin{array}{l}\text { Cost } \\
\text { (\$K) }\end{array}$ \\
\hline 335 & Modify TRW Support & Approved & 185 \\
\hline 337 & $\begin{array}{l}\text { Funding for Claim Settlement } \\
\text { with CSP-5 }\end{array}$ & Approved & 400 \\
\hline 343 & $\begin{array}{l}\text { Funding for Field Pool for CSP- } \\
6 / 10\end{array}$ & Approved & 250 \\
\hline 344 & $\begin{array}{l}\text { Cavity Mirror and Periscope } \\
\text { Mounts }\end{array}$ & Approved & 311 \\
\hline 345 & $\begin{array}{l}\text { Reconciliation of Funding } \\
\text { Required to Implement ECR } \\
1282 \text { and Perform Additional } \\
\text { PAMMA Cleanroom Work }\end{array}$ & Approved & 88 \\
\hline 346 & $\begin{array}{l}\text { Independent Assessment of TAB } \\
\text { Concrete Cracking }\end{array}$ & Approved & 125 \\
\hline 347 & $\begin{array}{l}\text { Implement Independent } \\
\text { Schedule Review }\end{array}$ & Disapproved & N/A \\
\hline 348 & $\begin{array}{l}\text { Reconciliation of Funding } \\
\text { Required to Implement BTR } 74 \\
\text { PAMMA Cleanroom } \\
\text { Construction and MOR Floor }\end{array}$ & Disapproved & N/A \\
\hline 349 & $\begin{array}{l}\text { Funding for Field Pool for CSP- } \\
6 / 10\end{array}$ & Approved & 450 \\
\hline 350 & CSP-17 Award and Field Pool & Approved & 302 \\
\hline 351 & $\begin{array}{l}\text { Change of Utilities and } \\
\text { Modification of Mezzanine Steel } \\
\text { framing to Capacitor Bay under } \\
\text { CSP9 }\end{array}$ & Approved & 145 \\
\hline 353 & $\begin{array}{l}\text { PABTS Breadboard Procurement } \\
\text { Split }\end{array}$ & Approved & 375 \\
\hline
\end{tabular}

(Note: Approved items in the table above with cost impact greater than $\$ 100 \mathrm{~K}$ were reviewed and endorsed by CCB4 and then approved by the Project Manager.) 
Level 3 Baseline Change Control Board Actions:

\begin{tabular}{|l|l|l|l|l|}
\hline BCP & \multicolumn{1}{|c|}{ Title } & Resolution & Date & $\begin{array}{l}\text { Cost } \\
(\mathbf{\$ k})\end{array}$ \\
\hline 001 & $\begin{array}{l}\text { Unconverted Light Management } \\
\text { Using Color Separation Grating }\end{array}$ & Withdrawn & $1 / 4 / 00$ & N/A \\
\hline 003 & FOA 3-Omega Calorimeter & Approved & $1 / 4 / 00$ & 0 \\
\hline 004 & $\begin{array}{l}\text { SY Gate Valve Beam Block } \\
\text { Capability }\end{array}$ & Approved & $1 / 4 / 00$ & 567.5 \\
\hline 006 & $\begin{array}{l}\text { Change to Air Atmosphere in } \\
\text { Amplifier Beam Enclosures }\end{array}$ & Approved & $1 / 4 / 00$ & 609 \\
\hline 011 & $\begin{array}{l}\text { Clad Internal Surfaces of LM1 } \\
\text { and Periscope }\end{array}$ & Approved & $2 / 3 / 00$ & 2600 \\
\hline
\end{tabular}

The current contingency log is attached.

PROBLEMS/ IMPACTS/ CORRECTIVE Actions
Construction site accidents led to several corrective actions: (1) convene Incident Analysis Team for most serious accident, (2) convene Site Safety Management Review Team, (3) hire DuPont as an industrial safety consultant, (4) conduct a safety stand down of the contractor and subcontractors of concern until safety procedures and training were satisfactory (see WBS 1.2).

SDRC announced that they have purchased Sherpa, the NIF's product data management (PDM) tool. Their plan is to phase out Sherpa and transfer Sherpa customers to SDRC's PDM tool, Metaphase. There appears to be several major issues that would effect the NIF's transition to Metaphase. First, Macintosh computers are not very well supported; the latest version of their document management function is highly integrated into MS-Word, but only for Wintel platforms. Likewise, it is not clear that legacy memos generated on Macintosh platforms could be accessed and read. Second, how Metaphase is priced is significantly different than how Sherpa was priced. Sherpa provided for concurrent user licenses; Metaphase does not. Even with the 70\% discounts SDRC is offering, it may cost NIF $\$ 300 \mathrm{~K}$ to $\$ 400 \mathrm{~K}$ to purchase enough seats to meet the 600 person user base. Third, the main transition tool for legacy data is a new product that was announced but will not be available until July 2000. Finally, given the significant dif- 
ferences in the products, the NIF would require three to four manyears of consulting help to make a transition in a six to nine month period. In addition to the disruption of a new product, the direct cost is likely to be about $\$ 2 \mathrm{M}$.

Procurements DuPont contract was placed through the ICF/NIF Operations Manager.

VARIANCES The rebaseline process has not been completed and, therefore, there are currently no variance statements for FY00 cost or schedule.

UPCOMING MAJOR In the third quarter, the following will be accomplished:

ACTIVITIES

- Incorporate the DuPont recommendations into the Construction Safety Program.

- Resolve all issues related to the Safety Standdown for NDBI

- Issue the Integration Management and Installation contract.

- Complete the cost estimate and schedule for two selected deployment options.

- Prepare the rebaseline Project Data Sheets for each selected Option.

- Present the rebaseline cost and schedule for two options to the Level 1 and 2 BCCB.

- Provide the data for the submittal of the rebaseline cost and schedule to the Level 0 BCCB.

- The NIF 300-mm Global (survey) Network will be released in April. 


\section{WBS 1.2 Site AND Conventional FaCiuties}

ACTIVITIES Conventional Facilities work reached 86\% completion in March.

Sitework for the month of March included the placement of the remainder of both the communication and electrical duct banks and the backfilling of the vaults.

Progress in the Laser Building included the erection of masonry for the Visitors Center structure adjacent to Laser Bay 1. In Laser Bay 1, the taping of drywall continued. The temporary platform at the west end was completed, and the remaining high work was begun. Finishing of the pedestals in Laser Bay 1 continued with the water blasting, conditioning/priming, and final coats of paint. This work is about $80 \%$ complete. Structural framing for the rails of elevator 1 continued in March. In Laser Bay 2, Pentagon (the precision cleaning subcontractor) mobilized and began cleaning the return air plenums, starting at the west end. As an area was completed, it was sealed up with insulation and sheet rock to maintain the cleanliness. The underfloor return air ducts were also cleaned, and the return air dampers installed.

In the Laser Building Core Area, installation of ceramic tile continued in the restrooms and installation of the raised floor and T-bar ceiling grid was performed in the Control Room, Strategy, and Computer Rooms, including installation of seismic duct supports, underfloor sprinkler lines, conduit and wire, and light fixtures.

The installation of ductwork continued in the class 100 Preamplifier Module Maintenance Area (PAMMA) clean room. The installation of the metal pan ceiling was completed. Painting continued on the capacitor bay ceiling steel. Roll-up doors and stud framing and some sheet rock began in the OAB corridor, along with work on the HVAC system in this area.

Pipefitting and electrical work continued on the Mezzanine levels. Work continued on the air-handling units for Laser Bay 2 and PAMMA areas.

The major work in the Target Building involved the installation of the Switchyard 1 labyrinth wall segment from elevation 68.75 to 85.50 and the pour out of the Target Bay cylinder elevation 69.75 to 84.50 26 ' radius wall segments, 6.5 ' radius wall segments, and radial (spoke) walls. 
The Target Building also showed progress on the -21.75 level with the installation of mechanical and fire sprinkler piping and electrical conduit; on the 17.5 elevation with the installation of pipe supports, fire sprinkler piping, and electrical conduit; and on the 50.5 elevation with the commencement of installation of piping and electrical structural supports. During this period, the HVAC chase frames were installed at the various levels throughout the structure. In addition, the installation of structural steel pipe bracing was completed, with the exception of level 69.75, which is being performed at this time. The shoring and forming for the Target Bay roof pour continued. This pour is presently scheduled for April 21, 2000.

Work in the Diagnostics Building included continuation of metal stud framing and drywall, continuation of ductwork, and electrical rough-in on elevation -33.75; continuation of metal stud framing, continuation of mechanical ductwork, and toilet room plumbing installation on -3.5 elevation; continuation of mechanical and sprinkler piping on 17.5 elevation; framing of the toilet room ceiling, continuation of electrical rough-in, piping risers, and commencement of pipe support installation on the 29.5 elevation; continuation of wood nailers, weldout of the upper duct run on elevation 50.5; and continuation of liner panel siding on the elevator shaft.

All mechanical work associated with Switchyard 2 platform at elevation 70 resumed on March 13, 2000, following the accident investigation. During the first half of the month, electrical conduit and fire protection piping installation continued on the north and west walls below elevation 70 .

Due to a safety stand down that started on March 15, 2000, all CSP 6/ 10 work halted until March 30, 2000, when Nielsen Dillingham Builders, Inc. was given approval to restart their work.

Production work in the $\mathrm{OAB}$, slowed by the safety stand down, continued with the performance of final punchlist repairs, including valve tagging, utility line labeling, and acceptance of the EVA and fire alarm systems. The Special Equipment group continued moving in materials and clean room equipment. Due to the stand down, final completion of the OAB is projected for April 2000.

Pro blems/ Impacts/ Corrective Actions
Safety Awareness: In January, an incident occurred at the NIF site when a worker was struck by a heating, ventilation, and air conditioning (HVAC) duct during installation. The worker received serious back injuries, but will be able to return to work in several months. An 
Occurrence Report was filed with the Department of Energy (DOE), and Incident Analysis and Site Management Review Teams investigated the direct and root causes of the accident and made recommendations to the Project Manager. One major recommendation was to obtain the services of a major industrial firm with an excellent safety record to review the accident and make recommendations. DuPont was contracted and spent a week at the site. Their recommendations and final report are scheduled for the end of April.

Two additional safety incidents occurred in March. One of these incidents, occurring in the CSP-6/10 package, prompted a stand down of work of all contracts associated with the Subcontractor (CSP-04, CSP05, and CSP-6/10) to refocus on safety communications and procedures. Additional corporate resources from Jacobs Facilities were brought in to assist in improving the safety on the project. An executive safety meeting was conducted including corporate executives and safety officers from project Subcontractors on March 23.

Congestion on the west site eased in March as most trenches were backfilled for the time being. However, the underground installation of sanitary sewer and electrical duct bank will resume in April in the Switchyard 2 area that will require close coordination between the CSP-9 and CSP-6/10 subcontractors.

The progress in the installation of Switchyard 1 steel structure under Infrastructure is slowed by the field changes that could cause certain delay to the installation of Switchyard 1 precast roof girders and associated activities with the placement of roof slab, rigid insulation, and roofing under CSP-6/10.

VARIANCES The rebaseline process has not been completed, and therefore, there are currently no variance statements for FY00 cost or schedule.

UPCOMING MAJOR ACTIVITIES
- The Final Acceptance of OAB (Cleaned \& Commissioned), CF555221, is delayed due to the safety stand down and is being negotiated with NDBI.

- The placement of Target Bay roof slab is also delayed due to the safety stand down and is being negotiated with NDBI.

- Diagnostic Building start-up of HVAC equipment is being negotiated with NDBI. 


\section{WBS 1.3 LASER SYSTEMS}

\author{
ACTIVITIES \\ O ptical Pulse \\ Generation System
}

In the master oscillator system, first-article chassis have been constructed, tested, and assembled in an integrated fashion. Tests of the fiber oscillator, double-pass amplifier, electro-optic gate, and the first fiber amplifier chassis are now being conducted on a regular basis in the off-line, integrated system test facility. These chassis are meeting their performance specifications, with the exception of the double-pass amplifier, which has exhibited an instability. This is understood and is to be corrected in the production unit that is planned for deployment in May.

Highland Technology continues to work on the first-article amplitude modulator chassis that they are constructing; this chassis is designed to produce the required temporal pulse shapes on the NIF laser beams. Preshipment tests indicate that the rise and fall time, amplitude dynamic range, and impulse width specifications are being achieved. The timing jitter is yet to be measured. Acceptance testing of the first unit is currently in progress at LLNL, with delivery of the next three units expected in April.

Analysis of the modulation in the spectral transmission of the isolators used in the master oscillator chassis showed that the source of modulation was filters and waveplates producing etaloning effects that in turn lead to significant FM-to-AM conversion. Modifications are being made to these components by the supplier that are expected to eliminate most of this modulation.

The prototype Pre-Amplifier Module (PAM) hardware is being prepared for the upcoming front-end integrated system testing. Electronic and electo-optic modifications are being completed, diagnostics are being assembled, and interlock adjustments are being finalized. Testing with the master oscillator, input sensor package, and computer control system will begin next quarter. The latest version of control software, which will be used for this testing, was developed and released to the independent team for testing. This software includes full capability to operate the PAM control points under manual control and several master oscillator devices using embedded controllers as well as general purpose interface bus instruments.

Fault testing on the new Power Conditioning Unit (PCU) for the PAM was successfully completed at Maxwell, and the unit was delivered to 
A mplifier Assembly

Amplifier Power Conditioning System

(PCS)

Pro blems/ IMPACTS/ CORRECTIVE ACtions
LLNL. The documentation and drawing package is being reviewed for completeness, and a procurement package is being prepared.

There was a great deal of progress towards preparing the B381 amplifier bus assembly area for clean assembly of the first amplifier bundle. The NIF survey group surveyed the monument system. The rails, which are duplicates of the rails that will support the amplifiers in the LTAB, were installed and aligned to the required accuracy for assembly of the FAU buses. The first production frame assembly units (FAUs) were installed on the rails, and a shakedown of the procedures for assembling and aligning the buses began. The surrogate slab cassettes that will be used to precisely align the FAUs relative to the support rails were installed in the FAU in preparation for testing the alignment process. The clean room will be recertified in preparation for assembly of the first bundle during the next quarter. The FAU bus transport and handling hardware was tested, including moving a loaded transport container with the Straddle Lifter and using the airbearings to move the transport container in and out of B381.

Design documentation deliverables in support of CSP-14 were completed during the past quarter. Design modifications to enable transportation of a fully loaded PCS module were completed and submitted to LLNL by the vendor. The bank module emulator for testing the PCS control system was completed. The emulator and embedded controller system under test operated properly during initial tests. The first PCS front-end processor (FEP) was tested and represents a complete "vertical slice" of the entire PCS controls architecture. This work represents the backbone from which the rest of the PCS control software will be based. The software requirements for controlling the gas system for the pulsed power switches in the PCS were updated.

The first two electo-optic phase modulators for the master oscillator system were received from JDS Uniphase and forwarded to Rifocs for attachment of fiber connectors. JDS Uniphase continues to experience problems with attaching the special polarizing (PZ) fiber to these devices, with yields under 50\%. Problems occur in the cleaving, where the highly stressed PZ fiber tends to fracture, and in the bonding, where the losses increased significantly during the quality assurance temperature cycle. It was agreed to reduce the range of the temperature cycle to alleviate that part of the problem, but the very low overall yield and the incompatibility with their normal production process has seriously jeopardized future orders of modulators from JDS Uniphase. 
Strategies to develop other suppliers where this specialized work is better aligned to their business is being assessed.

The first deliveries of the breadboards for the Pre-Amplifier Beam Transport System (PABTS) were not received by the end of the month as required in the contract and are projected by the vendor to be at least two months late. It was determined that the most feasible method to receive breadboards as required for CSP-13 was to descope the existing contract and solicit other vendors to pick up the balance. As a result, a new contract for one-half the initial quantity was awarded to another vendor and is proceeding without issue. Present projections are that these units will arrive in time for CSP-13.

Procurements The procurement package for the PAM was prepared, reviewed, and distributed to fourteen potential vendors. Three of the vendors responded within a few weeks that the procurement no longer fits into their business plan and have withdrawn from consideration. Shortly before distributing the Request for Proposal (RFP) for the PAM, it was determined that the PCU would be procured separately from the PAM. Discussions have started to develop that PCU procurement strategy and package.

Bids for the large-aperture Faraday rotators were received and evaluated on a best-value basis. The successful bidder was also the low cost bidder. The low bid was about $25 \%$ higher than the initial estimate. The contract calls for the manufacture of first-article rotators for the PAM and PABTS in FY00 at a cost of $\$ 185 \mathrm{~K}$, with options for production quantities. Overall, this is a $\$ 2.5 \mathrm{M}$ procurement.

Several production FAUs were received from GTC and are being used to evaluate the cleaning and assembly procedures for the amplifier hardware.

Phase III (construction of clean room and facilities) of the AstroPak precision parts cleaning contract was completed. Demonstration of the capability to reach the required particle and NVR cleanliness (Phase IV) began, including cleaning the first-article FAU. The NVR criteria were met, and the particulate criteria were nearly met. Process review is in progress to achieve adequately low particle counts on the FAUs. Phase $\mathrm{V}$ of the contract also began this quarter with awards to provide precision cleaning of kinematic mounts and other amplifier components.

Blastshield frames and glass were received from the vendors on schedule. The first NIF production flashlamps were received from Perkin Elmer three months ahead of schedule, and acceptance tests of these components are in progress. 
Everson Electric attempted casting the first-article FAU top-plate and experienced problems with the mold design. The design was modified, and a second attempt is in progress. This contract is receiving very close scrutiny from amplifier and NIF production personnel since these components are on the critical path for FAU bus assembly.

Testing of the first-article capacitor charging supply was completed, and Maxwell Technologies (now General Atomics) was released to deliver production units. The first of those were received and are currently under test at American Control Engineering.

The first production capacitors were delivered from Maxwell Technologies (also now General Atomics) and will be tested during the next quarter. Many of the components for the PCS module that will be used for reliability and end-to-end electrical testing were ordered.

Drafts of the extensive documentation package for the PCS integration contract were completed, including the Statement of Work and component specifications. Visits to six potential vendors were completed. There appears to be a strong industry pool to provide competition for this important contract.

VARIANCES The rebaseline process has not been completed, and therefore, there are currently no variance statements for FY00 cost or schedule.

\footnotetext{
UPCOMING MAJOR - Expect responses to the first-article PAM RFP from potential venACTIVITIES dors in early May.

- Continue cost estimating, detail budget planning, development of CAPs, and overall project rebaseline planning.

- Complete "dirty" assembly and transport of the FAU bus.

- Commission the FAU assembly clean room.

- Acceptance test the first production capacitors and flashlamps.

- Activate the blastshield assembly and coating equipment in the Optics Processing Development Laboratory (OPDL).
} 


\section{WBS 1.4 BeAM TRANSPORT SYSTEMS}

ACTIVITIES Integrated activities to achieve new procurement strategies to involve industrial partners in the BIS continued. The BIS IMI Services subcontractor solicitation package and approach were presented to DOE Programmatic and Procurement organizations the end of February. The formal submittal of the solicitation package occurred in early March. (This activity is common to WBS 1.8 as well).

Spatial Filter Vessels/ Enclosures
Spatial Filters: Delivery of all four CSF center vessels was completed. Three of four TSFs were received. The fourth vessel was shipped from the vendor at the end of March. Fourteen of 16 spatial filter end vessels have been received. Final deliveries on the end vessels are now expected in April. Circular beam tube assembly delivery was completed with the last of the 240 pieces being received in March. Of the 192 rectangular beam tubes, 139 were on hand at quarter's end with delivery completion expected in April. The vendor has experienced some failures of the vacuum leak test due to pilot holes for ghost mitigation hardware being drilled too deep. This has required repair to a number of tubes.

Fabrication of the spatial filter connector tubes began at SynchroVac in March. They have experienced some difficulties with out-of-roundness on the initial shipment of tube stock from their supplier and are working to resolve this.

The first production unit inspection of the Tower Kinematic Mount Bellows was conducted at the fabricator (Hyspan) in late February. The unit failed due a bellows weld leak. Following corrective actions, the inspection will be repeated in April.

Laser Bay Interstage Enclosures (LBIE): A Procurement Review for the LBIEs was held in February. The RFP for the LBIEs was released on March 22, with the bids due April 14.

The performance of the LRU Interstage Docking Frame fabricator (Major Tool) increased substantially in February, largely due to a project management change on their part. Five units (of 16) had been received by the end of the quarter. Current schedule is for two clusters ( 8 units) to be delivered by May.

The Request for Quote (RFQ) process on the LB/SY/TB bellows assemblies first articles was initiated in February. A great deal of vendor interaction occurred during March before the vendors understood 
that this was not a build-to-print contract. The vendor interaction, fabrication, and testing of these first articles is required to move the remaining bellows designs forward to meet all design and project requirements. Bids are due April 14.

Switchyard (SY) Enclosures: Yuba City Steel Products Co. satisfactorily completed the first-article inspection and testing of the SY straight enclosures in mid-February. As of the end of the quarter, 50 of the 410 pieces had been received.

Ghost Mitigation: An RFQ package for the remaining beam tube 'megaphone-style' ghost mitigation hardware was issued in midMarch. Installation of the spatial filter ghost mitigation towers is being considered for transfer to the CSP-16 Scope of Work from CSP-12, GFE Preparation.

Roving Mirror Diagnostic Assembly (RMDA), Optic Mounts, and Gate Valve: Initial roving mirror optic mount stability analysis results indicate that the current design may not meet optical rotational stability criteria. Model refinement is under way. In addition, these analyses are not final since the LRU (part of the Roving Mirror Assembly [RMA] system) design and properties are still immature and not modeled in detail. Detail drawings of the gate valve are expected to begin in early April. ECR 1119 requires incorporation of a beam block function into the gate valve along with remote operation capability. A plan to prototype the gate valve drive system for contamination control and performance was developed along with a qualified bidders list for the prototype.

Subassembly and Preparations of Government-Furnished Equipment $(G F E)$ : During February and March, precision cleaning and clean assembly was completed on all four CSF center vessels and seven SF end vessels. Twelve round beam tube bundles were precision cleaned in February, bringing the total cleaned to 43 (out of 240). CSP-12 preinstallation work continued on SF end vessels in preparation for precision cleaning. Work began on assembly and cleaning of the Transport Spatial Filter Center (TSFC) vessels. The first TSFC assembly was complete and undergoing precision cleaning at the end of March.

Support Structures Laser Bay Structures: Concrete placement and painting is complete for all Laser Bay $1 \& 2$ concrete pedestals. The contractor and ATT Metrology surveyed embedded plate locations and found all standard, nonpenetration plates to be acceptable. However, many plates with concrete penetrations at LB2 TSF center vessel concrete pedestals were found to be out of tolerance. The thirteen worst cases of out-of- 
tolerance are to be repaired by core drilling out the steel sleeve. This does not effect the construction schedule.

An ECR to clad the interior flame-sprayed surfaces of the periscope and LM1 support structures with stainless-steel sheet was presented to the Level 4 and Level 3 CCBs in mid-January. The aluminum surface is quite porous, and high-pressure washing of these surfaces continues to dislodge aluminum particles even after repeated washings. Following their approval, detailed design was begun. A formal design review was held on February 16 with no major action items generated. Vendor pre-bid qualification was conducted in parallel with Procurement. Tentative schedules and installation sequences were developed with the CSP-13 design staff to minimize schedule impacts on the installation. The RFB was issued for the contract March 22. Six vendors attended a Bidders conference at LLNL.

CSP-12 inspection of the periscope support structure PEPC frame assembly LRU openings found them to be undersized based on the current PEPC LRU design. Original openings, before cladding rework, do not provide adequate clearance between the LRU and structure. Addition of cladding, without enlarging the openings, would reduce clearances to the point of interference. This affects all 24 LRU openings in the four PEPC frames. An ECR was approved in early March. The frames were shipped to the original vendor, Martinez \& Turek, who completed machining two of them by the end of March.

Process Equipment: The periscope bottom enclosure plate contractor submitted all documentation required to start fabrication. Frames have been cut and webs welded in place for the first article. The frames distorted and needed to be straightened. The first two articles will be stress relieved in April, and first-article machining will be in midApril. This fabrication is one month behind schedule, but does not affect the construction schedule.

Hogan Manufacturing completed delivery on the ILS modifications to the preamplifier support structure (PASS) in February, on schedule.

All four units of the LM1 support structure, fabricated at Olympic Tool, have been delivered. Units 1, 2, and 3 have been accepted. Unit 4 was shipped prior to acceptance and contained many minor out-of-tolerance features. Because the nonconformances are minor, the shipping back to Olympic Tool would exceed the cost of repair, and dealing with Olympic is difficult, the structures will be repaired at LLNL. These repairs will be made prior to the structures being sent out for stainless-steel cladding. This does not effect the construction schedule. 
Switchyard Structures: The main structure for SY2 has been installed. SY1 fabrication at Coast-AGRA and erection on site are continuing. Shop drawings and RFIs continue to be received from Coast-AGRA and are being processed. These RFIs continue to be incorporated into the SY1 \& 2 Pro-E models that are forwarded to Parsons for use in correctly locating the utilities and equipment for the CSPs. Over 700 shop drawings were reviewed and incorporated into the models during the quarter.

Progress continued on design completion and procurement of the structure-mounted hardware, which is the interface between the structural frames/beam enclosures in the laser bays and the switchyards, target area, and optical mount LRUs.

The first production article of the LM1 Electrical Interface Panel, delivered as a precision-cleaned assembly, was received from Gregory Associates; it is being evaluated for form-fit-and-function.

The procurement package for the LM2 and LM3 kinematic mounts for CSP-16 was completed, and the request for quotation (RFQ) was released in March. (This had been delayed somewhat due to minor issues.) The bids are scheduled to close in April, with an award date in May.

The release of the LM2 and LM3 structure-mounted electrical interface panel required for CSP-16 is delayed until April (due to the late release of the LM2 and LM3 kinematic mounts previously mentioned). The scheduled delivery date for the first cluster of assemblies is $8 / 4 / 00$; the required date for CSP-16 is $9 / 24 / 00$. These interface panels are the connector interface between the motor controllers and the LRU stepper motors, and they are the cleanliness barrier between the beam enclosures and the laser bay atmosphere.

The LRU kinematic mount installation specification was written and submitted as part of the CSP-19 100\% review package. The installation drawings, which are also part of CSP-19, are not finished; revisions are needed prior to release. A meeting was held with Engineering Services regarding CAD support for this task. Personnel have now been assigned, and weekly status meetings are being conducted. This will be completed by the end of April.

The LM7 LRU assembly models for the upper mirror bay were simplified, and the number of unique structure housing sizes was reduced from 11 to 4 . Also, the LRU kinematic mount locations for LM7 were standardized. This is part of the target bay quad frame model redesign effort for the Wedged-Lens-Beam-Path-Redesign (see WBS 1.8). 
PROBLEMS/ IMPACTS/ Corrective Actions

Procurements
The SF end vessel fabricator (Ranor) slipped their schedule by two to three weeks in February due to poor welder performance and low staffing. The 14th vessel delivery slipped from February to midMarch. The final two vessels slipped until mid-to-late April. Conversations with the Ranor management are ongoing to prevent further schedule delays. Ranor has experienced some failures of the vacuum leak test on the last of rectangular beam tube designs due to pilot holes for ghost mitigation hardware being drilled too deeply. This has required repair to a number of tubes.

RMA interface changes continue to impact the RMDA mount design. There is a continuing concern that the evolving RMDA system design has the potential to result in interface changes due to immature LRU and delivery system design. This issue is being worked in conjunction with other CSP-19 issues. As a result, design and analysis of the RMDA mount structure continues to be delayed.

The first spatial filter end vessel showed signs of free-iron contamination after gross cleaning. The concern was that the evolution of loose rust on the interior beamline surfaces could migrate and damage optics over the life of the vessel. Consultation with LLNL and off-site corrosion experts indicated that surface contamination of stainless steel during fabrication is a frequent occurrence in shops that work with both mild steel and stainless steel. The consultants recommend that stainless-steel parts produced under these conditions have a surface acid etch, similar to that described in ASTM A380 performed prior to precision cleaning. Identification of beamline components and LRUs effected by this problem is under way to support an ECR for funding to perform the required surface treatment. The ECR is expected to be presented to the CCB in April. This was delayed due to work on the Periscope/LM1 cladding ECR.

A $\$ 109 \mathrm{~K}$ procurement was placed with Hyspan for fabrication of SF kinematic mount bellows assemblies in January.

Release for Bid packages were issued for the following items during this quarter:

- Ghost mitigation hardware for beam tubes with an estimated value of $\$ 250 \mathrm{~K}$.

- Laser Bay interstage enclosures with an estimated value of $\$ 1100 \mathrm{~K}$. 
- Periscope and LM1 support structure stainless-steel cladding with an estimated value of $\$ 2200 \mathrm{~K}$.

Optical mount procurements for structure-mounted hardware needed for CSPs are tracking consistent with or ahead of the CSP need dates.

The upper and lower kinematic interface assembly kits for laser mirror-1 (LM-1) for the first two clusters have been received from Liberty Machine. The balance of this order will be completed in April. The first cluster delivery of LM1 electrical interface panels is scheduled for April. Fabrication of the balance of this ordersremains on schedule.

Fabrication continues for the LM1 utility panels and the pneumatic mount actuators for LM1, LM2, and LM3 (being fabricated by Electrol Manufacturing Co.). Initial parts for the lower kinematic mount pneumatic actuator assembly were received and are being evaluated for surface contamination and function. These parts are being used to validate the cleaning processes and Quality Assurance (QA) used by Electrol. First-article assemblies of the mount actuator assembly and the LM1 utility panel are on schedule to be delivered in April. The delivery of the precision-cleaned pneumatic cylinders has been completed. First cluster delivery for the utility panel and lower mount assemblies for LM1 is scheduled for April. Fabrication of the balance of this order remains on schedule with completion planned for July, which is ahead of schedule for installation, by CSP-16.

VARIANCES The rebaseline process has not been completed, and therefore, there are currently no variance statements for FY00 cost or schedule.

UPCOMING MAJOR ACTIVITIES
- Continue work for completion of Title II GFE and CSP designs and place orders for most of the remaining beampath systems GFE under this WBS.

- Continue deliveries and construction of vessels, structures, and beam tubes.

- Do GFE preparation activities to complete the SF end and center vessel assembly and cleaning.

- Install SF tower support table kinematic actuators to support construction.

- Award contracts for the RFB packages issued in March.

- Release for Bid the following items in the next quarter: 
- TSF extension/injection tubes with an estimated value of \$300K.

- Laser Bay and Switchyard p-gaskets with an estimated value of $\$ 425 \mathrm{~K}$.

- Laser Bay interstage enclosure rupture panels with an estimated value of $\$ 350 \mathrm{~K}$.

- Switchyard enclosure elbows with an estimated value of $\$ 400 \mathrm{~K}$.

- Roving mirror kinematic structures with an estimated value of $\$ 400 \mathrm{~K}$.

- Laser Bay and Switchyard enclosure bellows with an estimated value of $\$ 2750 \mathrm{~K}$.

- Plan to receive DOE approval to request proposal for the BIS Integration Management and Installation Services (IMI) Services Subcontract in April.

- Plan for Jacobs submittal of IMI Services proposal in May, with negotiations and preparations to award contract through June, for an award in July.

- Complete LM1 kinematic mounts and hardware contract for CSP12 from Liberty Manufacturing. Receive 24 assemblies (two clusters worth) of LM1 electrical interface panels from Gregory Associates and first clusters' worth of LM1 utility panels and LM1 pneumatic actuator mounts from Electrol Manufacturing.

- Award contract for LM2 and LM3 kinematic mount fabrication and release RFP for LM2 and LM3 electrical panels and spatial filter end vessel kinematic mount gas covers.

- Continue transport mirror mount LRU redesign. 


\section{WBS 1.5 INTEg RATED COMPUTER CONTROL}

ACTIVITES Software Rebaseline Size Estimate: Approximately 1265 "effective" KSLOC (thousand source lines of code) are estimated for the complete control system. For labor-estimating purposes, the effective number includes source code written by NIF staff and $30 \%$ of additional code that is auto-generated by computer-assisted tools. To date, three formal releases of control system software amounting to 241 effective KSLOC have been placed under configuration control and put through formal testing. About $800 \mathrm{KSLOC}$ are yet to be written by NIF programmers. Approximately $75 \%$ of the code is Ada95, 20\% is Java (user interfaces), and $5 \%$ is $\mathrm{C}$ code (device drivers). This estimate was constructed by measuring the KSLOC for software components already delivered and extrapolating to account for the remaining components (e.g., there are approximately 1300 software components to be built including 250 user interfaces).

Software Rebaseline Labor Estimate: The Project rebaseline plan estimates 376 person-years of go-forward work earmarked for software requirements, coding and debugging, formal testing, documentation, commissioning, and management. This estimate was developed from a bottoms-up roll-up of the many detailed tasks. The amount of labor already expended on software requirements, design, and coding over the prior three years of the Project is approximately 75 person-years.

SAIC was commissioned to perform an independent software labor estimate of the NIF control system. Results from a COCOMO II analysis predicted that 416 person-years would be needed to deliver the remaining code. A code size smaller by one standard deviation (761 KLOC) would take 306 person-years and a code size larger by one standard deviation (1287 KLOC) would require 529 person-years. The COCOMO II analysis used the post-architecture model, which is consistent with the established software architecture and successful resolution of key risks. Within the software industry, COCOMO estimates are reported to be within $30 \%$, about $70 \%$ of the time. This analysis roughly confirms the NIF rebaseline estimate.

Controls Testing: The test group completed testing of the Flashlight release (FEIST 1.0) in January 2000 and documented the results in a test summary report (NIF-0043959). A total of 84 test incidents were documented, including 55 software defects $(65 \%)$ and 13 requirements issues (15\%). The remaining test incidents were primarily attributed to the test hardware and procedures. The last two formal 
tests (Flashlight and Penlight) have resulted in a defect rate of about 1 defect per KSLOC. Plans have been developed and tests initiated for the following release, FEIST 1.5. The evaluation of an automated test tool suite for future regression testing was completed in February 2000, and feedback was prepared for the tool vendors. In March 2000, the test team also completed testing for an upgrade to the software defect tracking system and initiated an effort to normalize and perform quality control for schedule activities associated with controls development and testing across the project.

Supervisory Software: Development was completed for the FEIST 1.5 release in February 2000 and continues towards the FEIST 2 Milestone, scheduled to be completed in April 2000 (see Front-End System Test status below).

The system manager framework was enhanced to condense the startup of all programs that constitute a release into a single script; in the previous release there were 60 individual scripts. A graphical user interface (GUI) was developed to start, stop, and view the status of all processes running on the control system.

A standardized Java package hierarchy for the GUI framework was established, and a web-based Java documentation tree that allows easy navigation of the Java source code was generated.

Front-End Processor (FEP) Software: Development was completed for the FEIST 1.5 release and continues towards the FEIST 2 Milestone (see Front-End Integrated System Test status below). The Power Conditioning FEP was demonstrated with a Java GUI running test hardware and also interfaced to a bank module emulator developed by Sandia National Laboratories. The Wavefront Hartmann Sensor and Deformable Mirror FEPs were successfully demonstrated in closedloop control for a single beam in the wavefront lab and will be deployed in April 2000. An interim release of the Special Charge-Coupled Device (CCD) Camera FEP using the FEP framework and Javabased GUIs will also deployed in April. Development of the PEPC Plasma and Switch Pulser and Target Diagnostics FEPs are underway for interim releases in September 2000.

Optics Damage Inspection: Support for a secondary Optics Inspection system was added to the rebaseline plan, including manpower to develop software to automate data collection and analysis of ultrasonic transducer signals or video images.

Front-End Integrated System Test (FEIST): The FEIST 1.5 release was completed in February 2000 with the deployment of an integrated set of 
FEPs, supervisors and framework servers into the Integrated Computer Control System (ICCS) test bed. This release added functionality to the Flashlight/FEIST 1.0 release that controls PAM devices from broadview graphic user interfaces. This is the first release in which all operating data were stored in the Oracle database under control of framework servers. Previous releases used a mixture of database with flat files and handcrafted scripts. The FEIST 1.5 software release configuration was composed of 38 main programs, built with 152 software components.

Software development by the Supervisory and FEP teams continued to the FEIST 2 major release milestone. For FEIST 2, the Supervisory team will deliver shot capability for the PAM and the Input Sensor Package (ISP) and provide upgrades to the Message Logger, System Manager, and GUI frameworks. Shot capability will be provided by the Shot Director; Shot Setup Server; and the PAM, Laser Diagnostics, and Beam Control Shot Supervisor programs. The framework upgrades used to build Supervisory and FEP programs have been completed and deployed. Coding for Supervisory Applications for FEIST 2 is nearing completion towards an April 2000 deployment.

For FEIST 2, the FEP team made upgrades to eight FEPs included new GUI control panels for Timing, Master Oscillator, Preamplifier as well as several new devices, exception handling, and bug fixes. Motor range limit checking and stops were added to the alignment controller and new firmware was developed for the laser energy photodiode controller. Shot capture capability has been demonstrated between the Timing and Video FEPs, and a Java-based viewer are under development for the Video FEP.

Software Configuration Management: The configuration management function is responsible for delivering a complete and consistent set of control system products into both the alignment laboratory, and into the ICCS test bed, where the independent test team will validate the software. A quality control checklist that guides the post-development activities needed to deploy a software product into the computer system for test has been developed. Completion of the checklist assures that all computer software configuration items interoperate from the same database, all use the same framework services, and all are built without error diagnostics from the compiler. Each configuration item is self-identifying so that an audit trail connects each with the source code that built it, and all sources are frozen into the baseline release configuration.

The Software Change Control Board (SCCB) drafted a procedure for managing the embedded controllers that will be deployed in the facility and side labs. Embedded controller software, some developed by 
NIF personnel and some purchased from a variety of sources, is constructed using tools and computers separate from the development environment. The new procedure will assure that the SCCB identifies and controls all the resources needed to preserve the embedded controllers' functionality as technology evolves during the NIF's lifetime.

Integrated Safety System: Interconnect wiring diagrams for the safety interlock system have been completed ( 1000 sheets). Checking of the drawings is under way, with about $85 \%$ of the drawings having been checked.

Target Area Vacuum System: Work was begun to update the target area vacuum system control interconnect drawings ( 200 sheets). The vacuum system working group is continuing to document the process interlocks for the system, which is currently about $70 \%$ complete, and expected to complete in late April 2000.

Beamline Infrastructure Controls: Work continued with Jacobs Engineering to complete the control abstracts for the tempered water, argon, amplifier cooling, and spatial filter vacuum control systems. Work was also completed with Jacobs Engineering adding the control loops to the utility system piping and instrumentation diagrams.

Industrial Controls Contract: Work started to task Jacobs Engineering with the implementation of the control systems for the spatial filter vacuum system, synthetic air cooling system, argon system, tempered water system, target area vacuum system, and the final optic assembly cooling system.

System Engineering: Updating of software requirement specifications to incorporate the latest information is in progress. The level of detail in these documents is greatly improved, providing 3 to 5 times more definition for code development and test procedures. Approximately $80 \%$ of the FEP specifications have been redrafted or are in progress. Requirements rebaseline for the FEPs is expected to be completed by July 2000. Revision of supervisor software requirement specifications will begin late in the second quarter. Requirements are being linked to the appropriate FSD elements to provide a mechanism for documenting and managing customer requirements and inputs.

PRO BLEMS/ IMPACTS/ Corrective Actions
As a consequence of the rebaseline planning, additional engineering staff requirements starting the second half of FY00 have been revised upward by nine engineers to work on supervisor software, FEP software, optics damage inspection, and industrial controls engineering. 
Concerns raised in February regarding optics damage inspection staffing for image analysis and detection algorithm development have been resolved.

Procurements

VARIANCES The rebaseline process has not been completed, and therefore, there are currently no variance statements for cost or schedule.

Release of the FEIST 2 software by the development team to the test team will slip by two weeks from April 14, 2000 to April 28, 2000 in order to complete integration and quality checks on the release configuration. March 2000.

Timing delay generators: A procurement strategy for delay generators was reached with the vendor, Highland Technology, that calls for production to be divided into four phases over the next four years, with funding for each phase committed in the year of purchase. A contract for the first 21 (of 170) delay generators was awarded March 2000. The initial contract also included nonrecurring engineering charges and the entire lot of critical parts needed for full NIF deployment. Testing continued on-site of the first four delay generators. Two units met specifications, one unit had a minor problem and was returned to the manufacturer, and the other delay generator is being tested.

\footnotetext{
UPCOMING MAJOR - Formal tests of FEIST 1.5 minor release of the preamplifier inteACTIVITIES grated system test software will be completed in April 2000.

- FEIST 2 major release is nearing completion and is scheduled for integration testing and configuration control April 2000.

- Final submission to Parsons of the industrial controls interconnect diagrams ( 1500 sheets) is expected in early May 2000.

- A $100 \%$ design review on the fiducial timing system is scheduled for early May 2000.

- Formal testing of FEIST 2 software is scheduled for completion in early June 2000. After tests are completed, a software quality surveillance will be conducted by a team from the Software Technology Center. The surveillance report is expected July 2000.
} 


\section{WBS 1.6 OPTICAL COMPONENTS}

\begin{abstract}
ACTIVITIES
KDP and DKDP Crystals
\end{abstract}

O ptical Design

Cleveland Crystals, Inc. (CCI) planted enough additional conventional growth deuterated potasium dihydrogen phosphate (DKDP) seeds during $2 \mathrm{QFY} 00$ to bring the total from $50 \%$ to $92 \%$ of those required to produce 100 NIF third-harmonic generation (THG) crystals. Four rapid growth KDP runs were completed at LLNL and vendor locations, which have a potential yield of 33 single-harmonic generation (SHG) crystals. An LLNL boule reached a record $318 \mathrm{~kg}$, with a potential yield of 14 SHG crystals. The total potential yield of visibly inclusion-free KDP crystals are now $9142-\mathrm{cm}$ doublers, $3542-\mathrm{cm}$ triplers, and $9641-\mathrm{cm}$ switch crystals. Under the recently signed DOECEA (Commissiariat a L'Energie Atomique) collaboration agreement, a portion of these crystals will be provided to the CEA for use on the Laser Integration Laboratory. The plan to increase the conversion crystals from 41- to 42-cm square for improved ghost mitigation causes a reduction in projected yield of $13 \%$.

A low-temperature DKDP rapid-growth run was completed, demonstrating the feasibility of connecting two tanks together with continuous filtration to provide a supplemental growth solution. Although the crystal did not reach a size large enough to yield a NIF crystal, samples from the boule will be used to test whether this approach can achieve the high damage threshold in production equipment that was earlier achieved in small tanks.

Most of the optical design of the FOA using a wedged lens was completed in March. The remaining tasks included detailed ghost analysis and coordination with FOA mechanical engineers to assure that the design solution does not limit access and availability.

FOA configuration changes in February have delayed the start of the detailed ghost modeling into early May due to schedule conflicts at the external engineering firm tasked with this analysis. LLNL personnel are beginning to work with the ghost analysis to speed the process.

The Switchyard/Target Area Configuration drawing, updated with the new mirror placements required for the wedged lens scenario, was completed and placed under configuration management $(\mathrm{CM})$ in late April. 
The PAM and PABTS Vacuum Relay Telescope design documentation was completed in February. Work has now begun on final documentation of the PABTS configuration, including timing and detailed component drawings. The optical model of all 16 front-end beamlines is complete. A special release of the optical modeling code, CODE V, has been issued by Optical Research Associates, which allows this model to be extended to include the main laser and subsequent optics. The construction of the integrated model for beamline 137 has begun.

0 ptical Pulse G eneration and Injection System 0 ptics

Pro blems/ IMPACTS/ CORRECTIVE ACTION

Procurements

VARIANCES The rebaseline process has not been completed, and therefore, there are currently no variance statements for FY00 cost or schedule.

UPCOMING MAJOR ACTIVITIES

- The integrated main laser model will be completed in April, with documentation completed in early May.

- The production plan for NIF small optics will be completed in April. 


\section{WBS 1.7 LASER CONTROL}

ACTIVITIES NIF rebaseline planning activities have been a predominant activity during this time period. A complete accounting of all costs associated with systems when broken down by the FSD was completed.

Release of design drawings under $\mathrm{CM}$ continues to be a concern although all lead engineers have met all near-term deliverables for all CSP-related design reviews and procurement packages. Weekly review of status, staffing, and priorities are performed to ensure the highest priority drawings are completed on a schedule consistent with the needs of the project. The design drawing status for WBS 1.7 is 3207 drawings required, 1970 drawings are released under CM (61\% completion). In addition, a large number of CSP installation drawings have been created but not yet placed under CM. The areas with the largest number of drawings remaining are the Precision Diagnostics System (PDS) and the Roving Mirror Diagnostic Assembly (RMDA).

A lignment Systems

The procurement from Armstrong Technologies of the kinematic mounts for the CSF and TSF spatial filter towers (total of 216) preceded on schedule, with about $50 \%$ received at the end of the quarter. The designs for the TSF alignment and the CSF platform assemblies were completed and are in CM. Requisitions for the components to build an engineering prototype of these platform assemblies are in progress, and the design of the TSF diagnostic platform, the tower structure, and the tower test station continued. The purchase order for the first article injection telescope, one component of the TSF diagnostic platform, was placed with Zygo Corp.

Two tower carts, for loading and unloading towers from the test stand, have been fully assembled and mounted on the Tower Test Stand to evaluate functionality. Testing of a fully loaded cart is the next step. Installation of a raised floor in front of the test stand in B391, simulating conditions in the $\mathrm{OAB}$, was completed.

The design of the Input Sensor Package was completed and put under $\mathrm{CM}$. The engineering prototype of the package was modified to support testing of the integrated controls for the front-end laser system (FEIST). The design of the relay optics and the lower injection systems made significant progress, especially in the area of the required enclosures. 
Beam Diagnostics

W a vefront Control

Systems

Pro blems/ ImPACTS/ Corrective Actions
All PDS design resources have been directed toward creating and completing installation drawings needed for the CSP-19 100\% design review. Several internal package design reviews were conducted for PDS. Space for the assembly of PDS/LODI CSP-19 GFE and table build-up and refurbishment was approved. The Nova switchyard will be used for this activity, which will start in August 2000.

The latest energy diagnostic calorimeter amplifier was tested with all three of the different calorimeters, and the operation and nominal sensitivities were verified with electrical stimuli.

FEIST 2.0 Software for power diagnostics was installed; it will be released next month. Changes included revisions to the power diagnostics maintenance GUI. This included closing all of the outstanding software change requests from the FEIST 1.5 software release.

An LLNL-developed code, MPCOAT ver. 1.03, was delivered to the Laboratory for Laser Energetics (LLE) for analyzing interferometer measurements of finished and coated DM faceplates. The code was used to evaluate the first DM faceplate coated in pilot production. This analysis determined that the coated optic did not meet the gradient and PSD specifications. Nonuniformity and edge effects of the coating are the likely cause. Corrective actions are being implemented, and a second unit is scheduled to be coated in May.

A preliminary DM shipping container design was released for comment. Updates to the DM assembly procedure and to the QA traveler cards (for DMs and actuators) were released. The new Phase Shift interferometer head was received for the LLE DM interferometer. Parts were received and assembled for a preclean area to be installed at the entrance to the LLNL DM interferometer.

The wavefront control software was upgraded to the Flashlight 0.5 frameworks release, and Flashlight 0.5 development views were created for both of the wavefront FEPs.

Fourteen blocks of Xinetics actuators have been received to date. Nine blocks (about 360 actuators) have been tested. They are of high quality-all but nine have passed incoming inspection tests (98\%).

Design changes to address the beam rotation problem affect details of the optical layout in the PDS. The integrated optics module (IOM) changes cause one mirror and the IOM frame to be mounted differently. This is a relatively minor impact compared to those in other areas, but is noted nonetheless. Once the detailed optical path through 
the final optics is determined, then the detailed path through the last mirror in the PDS can be established and the hardware designs finalized; some GFE required for CSP-19 is affected. The corrective action in place is to participate in the beam rotation engineering effort and to submit a change order to the CSP-19 construction contract. The changes are expected to be minor and not worth delaying CSP-19.

\section{Procurements}

About $50 \%$ of the tower kinematic mounts $(\$ 216 \mathrm{~K})$ have been received from Armstrong Technologies and have been working well.

Orders for two of the upper injection system units were placed with Zygo. Updated drawings were delivered for their review, and a kickoff meeting is planned for late April.

Deliveries and anticipated deliveries of alignment control FEPs are on schedule with no issues $(\$ 2.2 \mathrm{M}$ of orders). These orders are split among four vendors: Power 10, VMIC, OMS, and Dawn. All of the input boards (136 units), output boards (136 units), motor controllers (1072 units), and power supplies (106 units) have been received. Production is underway on the VME crates (24 of the 106 units have been completed).

All procurements for pilot DMs have been placed. All DM production contracts except for the remaining actuators will be let by LLE or by WBS 1.6.3 (optics). All pilot procurements for wavefront controllers have been placed, except for interface cards (a minor procurement).

To date, about 360 Xinetics actuators for the DMs have been received and tested. They are of high quality; all but nine have passed all incoming inspection tests (98\%). Issues with the discrepant parts are being worked, and some are being returned to Xinetics for appraisal. Production is on schedule.

A requisition to modify contract B503973 to acquire the additional fiber needed for the $3 \omega$ power diagnostic in the target area was written and approved. The new fiber will take an additional two years to fabricate. In June 1999, an export control request was submitted to loan to Vavilov a fiber "launch optic" assembly. It, as yet, has not been approved. (It is being reviewed at DOD-DTRA.)

VARIANCES The rebaseline process has not been completed, and therefore, there are currently no variance statements for FY00 cost or schedule. 
UPCOMING MAJOR - Continue cost estimating, detail budget planning, development of ACTIVImES CAPs, and overall project rebaseline planning.

- Complete PDS and RMDA designs needed for the 100\% CSP-19 Review (scheduled for April).

- Continue testing associated with FEIST involving the prototype input sensor. 


\section{WBS 1.8 TARGET EXPERIMENTAL SYSTEM}

\begin{abstract}
ACTIVITIES
Target Chamber
\end{abstract}

Target A rea Structures
During this quarter, the target chamber gunite application was completed. The 16-in. borated concrete shell awaits painting. Painting of the chamber will take place in mid-April, followed by mapping and alignment. Final chamber alignment will be done after the target bay roof is on the building to account for the dead load weight.

The post-gunite leak-up rate test to verify the vacuum integrity of the chamber was completed. The rate of rise was the same as before guniting, indicating that no leak path was formed during the gunite process.

The remaining items on the chamber contract are the final mapping, alignment, and installation of spacer shims, expected to be complete in July ( a one-month delay).

The jacking ring has been put in place and aligned. There is a concern that the location of the target bay center will not be know with sufficient precision at the time of chamber alignment. This may necessitate a final adjustment to the chamber next year. The jacking ring will be left in place until then.

Target Area Government Furnished Equipment (GFE) Components: Cost and schedule impacts of the wedge lens engineering change were incorporated in January, with RFB for the target area beampath GFE to begin in June and continue through September. In addition, final beampath GFE design input for CSP-15A was scheduled for delivery to Parsons in July. Schedule analysis showed both these efforts to be on the critical path for target bay beneficial occupancy. The design group worked with the procurement organization to develop procurement strategies that could shorten the fabrication schedule.

During the quarter, the target area beam path optical model has been completed and is being used to modify the mirror frame structures in the target area. Several mirror frames have been completely remodeled, and detail drawings are in the checking process. The detailed location listing of the kinematic mounts relative to the target chamber coordinate system has not been completed, and it is required in order to be $100 \%$ complete on any given mirror frame. As of the end of March, two mirror frames, representing 4 of the 48 frames, are ready to be entered into SHERPA (when the kinematic data is provided). An additional eight frames are expected to be ready for a procurement package by the 
end of April. It is hoped that incremental release of the mirror frames will save several months in the overall procurement time. The horizontal beam tubes have been completed, and the procurement specification is being reviewed. The plan is to release these for bid in late April or early May. There has been progress on the retractable and removable beam tubes and on the guillotines required for the mirror LRUs.

The target area engineers and designers prepared and presented a briefing for the Jacobs constructability engineers at LLNL and at Parsons. This briefing covered the design, assembly, and installation of the beampath GFE in the target area.

Target Area Beampath and Utilities: The target area engineers and designers provided Parsons with the design information for the horizontal and vertical beam tubes that have been modified for the beam rotation fix. It was previously planned that this information would be given to Parsons as part of the July 26 deliverables package, but, by providing the preliminary data, Parsons should be able to complete the beam path assembly drawings for the CSP-15A design package early.

Information was provided to the Parsons structural designers to prepare support structures for the horizontal beam tubes and beam tube inserts that line the concrete holes between the switchyard and the target bay.

Target Chamber Service System (TCSS): The RFQ package for a "Design and Build" of the utility lift portion of the TCSS was issued to six companies in January. Four bids were received in early March. A technical review and "Best Value" selection are expected to be complete and the contract awarded in April.

The $100 \%$ design review package was issued by PaR Systems, Inc (the boom lift vendor) in February. The package has been distributed for discipline review at LLNL, and a formal Engineering Design Review is scheduled for early April.

Target Area Handling: A simplified model of the upper mirror room was completed during the quarter. Studies with this model on installation and removal of the Target Bay laser mirrors and IOMs resulted in a new concept that may eliminate the need for Davit cranes at level 50' 6". This concept uses commercially available articulated jib hoists for the IOMs and the inner mirror frames at the ceiling and intermediate levels. Work has begun on a similar model of the lower mirror room.

Work updating requirements for several systems within the target area continues with Parsons. During the quarter updated requirements were given on the Level 29' 6" access door, the Plenum Plug, and the Rotunda hoist system (subsequently placed on hold during March). Following a 
meeting on the conceptual design for the Plenum plug, a revised concept was incorporated. Criteria for the Davit cranes and monorails are being reviewed in light of the jib hoist concept. Level 40' hoist system criteria were modified to lengthen the rails for IOM removal.

Numerous Target Area handling deliverables were transmitted to Parsons including: (1) procurement package drawings and specification for the utility lift system, (2) utility requirements and facility piping requirements for the TCSS, (3) LLNL 3D model of the TCSS, (4) clarification of requirements and design details for the Plenum plug and its associated removal mechanism, and (5) the list of GFE for the calorimeter spool assembly installation (January 27).

Final 0 ptics Assemblies

During the past quarter, significant progress has occurred on the FOA with respect to engineering, UV optics damage, and optics production.

In the UV damage area, an extensive study of UV damage growth has been completed, and for each of $\mathrm{SiO}_{2}$ and DKDP, clearly identified a threshold for growth and growth-rate coefficient. For both materials, growth rate is found to be exponential but with lower threshold $(5.2 \mathrm{~J} /$ $\left.\mathrm{cm}^{2}\right)$ and slower-growth rate for $\mathrm{SiO}_{2}$ and high threshold $\left(7 \mathrm{~J} / \mathrm{cm}^{2}\right)$ and faster-growth rate for DKDP. The growth-rate coefficients are being related to material mechanical properties, and hence, other materials with expected resistance to damage growth will be evaluated as well. With a good set of damage growth data in hand, a first set of data on damage mitigation is now being done. Initial results in which damage initiated spots were etched with HF acid to a depth of ten microns showed remarkable improvement. Whereas, three of three nonetched control spots showed immediate damage growth upon illumination at $8 \mathrm{~J} / \mathrm{cm}^{2}$, five of five acid-etched spots resisted growth for 1000 shots when illuminated at fluences up to $8 \mathrm{~J} / \mathrm{cm}^{2}$. A detailed campaign on damage mitigation that will include $\mathrm{SiO}_{2}$, acid etching, plasma etching, and laser annealing is beginning. Mitigation work on DKDP will focus on water etching.

With respect to the production of frequency conversion optics, measurements show that the bulk optical damage threshold is lower for DKDP cut as a tripler than for the material cut perpendicular to the pyramid axis. Even so, the best conventional and rapid-growth triplercut material has scattering losses from bulk damage that are within the NIF operating requirements. Two specific defects on the surface of finished DKDP that were located with laser-induced luminescence have been correlated with the subsequent laser-induced damage. This confirms an earlier global correlation. If all or most of the defects that lower the surface damage threshold can be located by luminescence, 
they can be characterized structurally and chemically, and steps can be taken in the finishing and handling of the slabs to eliminate them.

A 41-cm z-cut KDP crystal was run successfully through the baseline NIF crystal cleaning, 1-week thermal anneal, and coating processes using the NIF equipment. Surface dehydration of KDP crystals confirmed by both FT-IR and XPS surface analytical techniques on crystals held for one to four weeks at $160^{\circ} \mathrm{C}$ suggests that a longer anneal should provide more robust protection against etch pits.

Tripler-etch pit mitigation efforts continue to focus on development of robust HMDS-treated sol synthesis and on diluent solvent selection to simultaneously meet NIF coating thickness uniformity and repeatability specifications. Evaluation of a matrix of polar-nonpolar and highlow evaporation rate solvents demonstrated that decane can eliminate dewetting and nonuniformity issues observed with other solvents. A model incorporating the geometry and process parameters of the NIF spin coater agrees well with experimental data for average coating thickness as a function of sol concentration, solvent, and spin conditions. Development will continue until the NIF coating specifications can be met with HMDS-treated sol.

The efforts on FOA engineering have focused on both completing the "conventional" hardware and advancing the design upgrades to more effectively handle the UV fluence.

First-article vacuum isolation valve testing continued throughout the quarter. The final long-duration cycle test was initiated at the end of March. It is expected the valve will be shipped to LLNL at the completion of this test.

A great deal of work has gone into rewriting the design requirements for the FOA. The new requirements capture the direction specified by the NIF council and incorporate the latest knowledge of UV damage and the expected optics exchange rates.

Progress was made on the top-level conceptual design upgrade of the FOA. At this time, the concept consists the vacuum isolation valve, calorimeter chamber, disposable debris shield spool, and four integrated optics modules. The primarily concern has been with personnel access to the optics within the FOA and the space required for FOA maintenance.

A commitment has been made to a disposable debris shield that will be deployed in front of the main shield as an inexpensive optic that can be routinely changed. Preliminary concepts for the disposable debris shield system and an exchange mechanism for the focus lens and crystals have been developed. The concepts are being taken to a level ready for conceptual design review. 
Balance of W BS 1.8 The design of the first-wall panels, WBS 1.8.1.2, has been completed. Detailed design of the first-wall flashing is almost complete. The installation of the panels is being validated using the Pro-E modeling software to insure proper spacing of the panels. The first-wall panel model assembly is being verified, and any discrepancies or overlaps are being fixed. The first wall drawings are complete except for the overall assembly drawing and the installation fixture. Work was done with the target chamber service system personnel concerning the access port interface. First-wall protection for the access port was designed as was the protection for the plenum cover. The Title II 100\% design review was successfully presented. The Subsystem Design Requirement (SSDR) was updated to remove all TBD entries. A prototype flashing assembly was built, and several recommendations to improve the design were made and have been included in the design. The cost and schedule for the first-wall panels have been updated.

The fabrication of the first target positioner boom was behind schedule. After the fabrication was completed, acceptance tests were performed on the boom. The boom passed its free-free vibration test but failed its static deflection test at the vendor, $\mathrm{R}^{3} / \mathrm{COI}$. It was determined that the mounting fixture and the measurements system were the cause of the test failures. As such, LLNL has agreed that the boom passed the acceptance test.

The performance testing of the prototype Diagnostic Instrument Manipulator (DIM) was finished. Since the prototype DIM is only half-length, a complete test of all DIM performance requirements was not possible. Tests included positioning accuracy, repeatability, and temperature stability. The mechanical detail drawings for the DIM are nearly complete. The electrical design is coming along well, and detail drawings are being made. Some changes are being made to the design as the overall design is reviewed. The Title II 100\% design review for the DIM was successfully presented in March. Comments have been received and are being addressed, and the SSDR was updated.

The construction of the classified control room is progressing. In the classified control room the raised floor, sprinklers, air handlers, and ceiling T-rails with overhead lights have been installed, and the room is painted. The home run conduits and cable pull can that were 
Problems/ IMPACTS/ CORRECTIVE ACTIONS installed in this room near the ceiling below the 28 - $\mathrm{ft}$ level have not been spayed with fire proofing spray as agreed for security. This has been deferred to CSP-14 when the laser bay utility pipes will be installed through the classified control room.

A new draft defining the design of a NIF diagnostic controller has been finished and is being reviewed. The software for the diagnostic front-end controller has been started with the goal of having a first version by August. The software for the diagnostic controller has also been started.

Beam rotation issues continue to impact schedule and design completion costs. A baseline plan change covering the cost for completion of the beam tube and structures redesign was incorporated in early March. Retention of the knowledgeable ProSource designers, who have been relocated off-site, may be a potential problem in the future. During part of the quarter, the Target Area Structure and Enclosures group was below the level of designer manpower needed to complete the redesign by August during part of the quarter. Additional designers have been assigned.

The egress problem from the diagnostic mezzanines at the 7'10"' level has a solution that has very little impact to the project. By reclassifying these spaces from mezzanines to rooms, because they are closed in and isolated from the switchyards, the occupancy can be raised from three people for a mezzanine to ten people based on 100-sq. ft. per person in a room. The longest distance in the room to a two-hour rated horizontal exit has to be less than 100 feet. This condition can be fixed by changing the west wall of the mezzanine to a two-hour rated wall and adding a two-hour wall across the vestibule from the mezzanine to the west switchyard wall. This new wall will enclose these vestibules and isolate them from the switchyards to create a two-hour rated space to exit through to the diagnostics building. The east exit with the ladder down to the switchyard steel can remain as is with no changes, and it is classified as an auxiliary exit.

Procurements

The delivery date for the target positioner boom has been delayed to April 10. Procurement requisitions for the support structures, gimbal parts, and vacuum vessels have been signed off and sent out during March. Procurement actions for the tilt and roll mechanism and for a prototype of the ball screw support mechanism have been initiated. 
VARIANCES The rebaseline process has not been completed, and therefore, there are currently no variance statements for FY00 cost or schedule.

UPCOMING MAJOR ACTIVITIES
- Paint, map, and align the Target Chamber.

- Redesign the Target Building GFE beam tubes and mirror frames as required for the beam rotation solution.

- Release for Bid the mirror frame packages for 4 of 24 designs in April.

- Complete the RFB of all mirror frames by mid-July.

- Work with Procurement for initial procurements and continue to develop means to reduce schedule impacts of beam rotation redesign on fabrication and delivery of other Target Area beampath hardware.

- Award TCSS utility lift design/fabrication contract.

- Review vendor's (PaR) boom lift 100\% design package and authorize start of fabrication.

- Continue work with Parsons on Target Bay beampath and handling design issues for CSP15A and 15B design packages.

- Continue the design work for completion of Title II designs for the target positioner, the first-wall panels, the DIM, and the target diagnostic data acquisition system.

- Start procurement of parts for the first-article DIM.

- Finish the rebaselining activities.

- Develop the software for the diagnostic FEP and controller.

- Start the assembly of the first target positioner in the basement of B391 along with the fabrication of the second boom assembly.

- Begin a major activity to evaluate mitigation of fused silica UV optical damage by use of acid etching, plasma etching, and laser $\left(\mathrm{CO}_{2}\right.$ and $\left.\mathrm{UV}\right)$ annealing. A campaign to understand the remaining contributors to initiation of damage at $10 \mathrm{~J} / \mathrm{cm}^{2}$ has begun in order to reduce initiators by two orders of magnitude and mitigate growth such that initiated damage can be held in check for at least 1000 shots at full NIF fluence.

- Work through a conceptual design of a disposable debris shield cassette in FOA engineering that will allow rapid and cost-effective exchange of shields on a regular basis. 


\section{WBS 1.9 Operations SPECIAL EquIPMENT}

\author{
ACTIVITIES \\ O ptical Transport and \\ Material Handling
}

Bottom-Loading (BL) Delivery Systems
Overall Assessment: The primary focus for $2 \mathrm{Q} 00$ has been on design/ drawing completion of the delivery systems and the testing of the firstarticle systems. The integrated tests of the BL universal delivery system have completed many successful fully automated sequences consisting of docking, cover removal, and PEPC LRU insertion. The first fabrications and hardware for the flashlamp and amplifier slab delivery systems are being assembled and tested. Testing has been completed on the flashlamp cover seal and cover removal mechanism. The assembly of the amplifier slab cover removal mechanism has started. The contract for the second and third transporters was awarded, and fabrication of those transporters has begun by the vendor.

Universal: The spatial filter insertion system (SFIS) is complete. The SFIS test stand is assembled and installed. Wiring has been completed for the test stand, and modifications made to control the system using the computer on board the canister. The SFIS lifting fixture load test and safety note are complete and approved. The mock LRU has been assembled to use during the test program.

The airflow system fabrication is complete. The second universal canister weldment will be used to install and test the airflow system. The canister was previously used for purge testing and, therefore, is already sealed up. Prior to testing, necessary modifications will be to bring it up to the same configuration as the first weldment.

Many successful PEPC insertion sequences have been performed. These include docking the canister with the transporter, removing the beamline cover, installing the PEPC test LRU, replacing the beamline cover, and undocking the canister and then repeating to remove the PEPC LRU. The repeatability of the canister docking has been demonstrated utilizing an improved docking ball. Demonstrations of the integrated system for the PEPC group, NIF management, and several others are planned for early April.

Universal Beamline Covers: Fabrication is continuing on the covers. The perimeter seals contract has been awarded, and the first delivery is scheduled for April. An RFQ for vacuum baking and precision cleaning of the seals has been issued. LLNL capabilities and costs for performing this work are being evaluated as well. 
Flashlamp: The horizontal translation mechanisms are completed and en route from THK. The carriage system fabrication is complete, and assembly will be completed in April. The cover remover prototype repeatability testing has been successfully completed. The center flashlamp cover was successfully removed and installed multiple times in succession. Leak tests were performed after each insertion to verify functionality. The cover remover system and the LRU enclosures are in fabrication. The top plate fabrication is in process.

Amplifier Slab: Completed assembly of the pneumatics system. Started assembly of the cover remover mechanism. Completed procurement of the canister compliance cylinder assemblies, FAU simulator plate, and the canister support stand. Started procurement of the LRU lifting carriage. Continued detailed design of the upper canister assembly. Started detailed design of the LRU insertion mechanism and the canister structure. Started working on the safety note for the BL canister support stand and the analysis of the canister structure.

Slab Cassette Covers: Received first articles to validate the production design for the slab cassette covers. Fabrication of machined parts for the $1^{\text {st }}$ and $2^{\text {nd }}$ bundles of covers is under way. The contract for cleaning and assembly of the $1^{\text {st }}$ and $2^{\text {nd }}$ bundles is out for quote. The production order for cover seals has been placed. Bakeout and cleaning of the seals is out for quote. The cover production order (bundles 3-24) will be sent out for quote next month. Amplifier docking receivers are in production, and the first bundle (30) has been received.

Top-Loading (TL) Delivery Systems

ading $(S L)$

Delivery Systems
Started refurbishment of the TL canister. Added seismic restraints to the LRU carriage. Replaced rod ends on the LRU carriage and cover translation mechanism. Replaced springs on the pressure relief panel. Added holes to the adapter plate to accommodate the new Laser Bay transporter orientation sensors. Ordered new gaskets to replace the existing ones made from Poron. Procured canister docking pins for use in the OAB and laser bay. Created a plan for integrated testing of the TL canister in the OAB loft. Started working on the safety note for the TL canister support stand. Completion of assembly drawings is on hold.

Thirty-nine out of 72 top loading vacuum covers have been received. Thirty-six covers have been inspected and delivered to infrastructure for cleaning and installation.

Completed the detailed drawings for the SL tug. Started refurbishment of the SL skid. Replaced the control box mounting angles to accommodate increased length of the PAM. Started procurement of the SL 
Laser Bay Transporter

Switchyard and Target

Bay

PROBLEMS, IMPACTS, AND CORRECTIVE ACTIONS tug hitch and counterweights. Developed a new concept for installing input sensors. A forklift will be used to end load the input sensors using a fixture, which attaches to the top. A new concept for transporting the PCUs will use a tug similar to the SL tug to pull the PCUs, which will have wheels. Completion of assembly drawings is on hold. This system will be used as the Controls Test Platform to continue the testing of the system software updates. This delivery system will not be used on the NIF until PAMMA operations, which is scheduled for Feb 01 .

The fabrication of transporters \#2 and \#3 has begun. All long-lead items have been ordered. A meeting was held in Pittsburgh, PA with Alkab Inc. and AGV Products. Alkab, who is machining/welding the frames of the transporter, is AGV Products' subcontractor. Alkab also built the first-article frame. The two transporters will be fabricated concurrently with the first one leading the second by a couple of months. The current schedule shows transporter \#2 delivered to LLNL in mid-December 2000 and transporter \#3 delivered to LLNL in early February 2001. New features that will improve the transporter battery usage, increase hardware accessibility for maintenance, and enhance the transporter safety systems will be incorporated into the new transporters. There will be a design review of these new features scheduled for mid-May 2000. The new transporters are necessary to start the BL delivery systems testing with the $\mathrm{OAB}$ systems. It is not required to test the TL delivery system with the OAB.

The switchyard monorail and vertical specifications and drawings were completed and submitted by March 31, 2000, in support of the CSP-19 infrastructure package. Staffing is in progress to begin design effort the first of April on completing the LM4 and LM5 transport fixtures and the roving mirror transport canister.

The Transport and Handling group is running out of space for building new canisters in the B432 test facility. Space allocation drawings for the best utilization of the facility are being updated. Discussions are ongoing with other groups using the facility to determine the availability of any unused space.

Delivery of the flashlamp canister weldment has slipped into April due to a fabrication error discovered during final inspection. Special threaded inserts had to be made to correct for a bolt patter misalignment. The corrective action will not affect the design functionality. 
Procurements No major procurements were made this quarter.

VARIANCES The rebaseline process has not been completed, and therefore, there are currently no variance statements for FY00 cost or schedule.

UPCOMING MAJOR - New "crabbing" motors will be installed in the first-article transACTIVITIES porter in April.

- The universal BL canister will be used for demonstrations to senior NIF management to demonstrate docking, cover removal, and PEPC installation/removal activities. The demos will also use the Laser Bay Transporter.

- A video will be made of the PEPC LRU and PAM LRU installation operations to be used for training.

- The universal BL canister will be used to demonstrate a full stack up of all hardware required to install a Periscope LRU.

- A demonstration of a SF Lens LRU insertion/removal full sequence will be performed using the Laser Bay transporter and universal BL canister this summer.

- During the next few months, the flashlamp and amplifier slab delivery systems will continue to be assembled and tested as fabrications and hardware are received. 


\section{WBS 1.10 START-UP ACTIVITIES}

Activities Scope, schedule, and budget for this area are being reviewed, and plans will be discussed when the rebaselining exercise is completed. 


\title{
WBS 1.11 ES\&H AND SUPPORTING R\&D
}

\author{
ACTIVITIES \\ Assurances The ES\&H review of the ES\&H impacts of using synthetic air for the \\ NIF beam tubes and cooling systems was completed and reviewed \\ with DOE OAK. Agreement was reached to prepare a Guidance \\ Request Response. \\ Technical Support \\ To date, Schott has produced about 225 meter-sized glass slabs meet- \\ ing all the demanding NIF specifications in their Pilot II campaign. In \\ addition, the glass has been produced at a rate 20 times faster than \\ could be achieved using existing one-slab-at-a-time discontinuous \\ melting technology. A problem encountered during the campaign \\ forced a temporary shut down in mid-February. Repairs and modifica- \\ tion of operating parameters are under way, and are expected to be \\ completed in time for restart by late May. It is anticipated that Schott \\ will complete the melting phase of their pilot II campaign by late July. \\ All equipment is in place and ready for Pilot II laser glass production \\ at Hoya Corporation USA. The final contract was completed in March \\ to allow start-up in April. Fine-annealing studies using Pilot I glass \\ have shown promising improvements in glass homogeniety that will \\ be incorporated into Pilot II. Cladding production is expected to con- \\ tinue as planned through the early part of April; cladding yeilds to date \\ exceed $90 \%$. \\ CEA representative Daniel Taroux spent the month of February with \\ the Laser Glass Group at LLNL, primarily to work on the details of \\ planning, coordinating, and integrating CEA-LLNL laser glass pro- \\ duction efforts and contracts with the glass vendors. Plans were com- \\ pleted in March working out the details for cooperation and cost \\ sharing in laser glass production through 2005. \\ A five-year extension to the loan agreement for the use of platinum in \\ laser glass production was signed by the Department of Defense and \\ LLNL. \\ During the second quarter of FY00, LLNL rejected the switch win- \\ dows and target chamber vacuum windows for the NIF first bundle \\ fabricated by Tinsley because they failed to meet NIF specifications \\ for PSD2 (waviness over spatial scales $0.12-2.5 \mathrm{~mm}$ ) and micro- \\ roughness. Corrective actions to change and improve the robustness of \\ the finishing process are ongoing, and a microphase measuring inter-
}


ferometer is being added to the Tinsley NIF Manufacturing Facility to increase in-process visibility of these two critical specifications. The Lapmaster continuous polisher is now meeting the goal of producing windows with less than one wave of transmitted wavefront error and is in use as a process step to correct the PSD2 and micro-roughness problems observed with the windows to date.

All sixteen of the LM2 mirrors to be fabricated during Pilot have now undergone final testing at Kodak. Acceptance to full NIF specifications awaits absolute calibration of normal-incidence reflected wavefront using a "round robin" optic measured by the National Institute of Standards and Technology. Kodak has also demonstrated on an AMPLAB slab the ability to use small-tool polishing to correct long-wavelength wavefront error to within NIF specifications in one iteration when the initial error is less then one wave. In early April, the results from small-tool figuring of the first full-size NIF amplifier are expected. Efforts to finish BK7 glass to a flatness of 5 waves or better on the Speedfam pad polisher have been successful and attention has now moved to demonstrating similar performance on fused silica optics.

Zygo has completed the finishing of 127 NIF optics. A number of the polarizers and amplifier slabs finished by Zygo required preferential figuring at Kodak to overcome raw material inhomogeneity. Three polarizers were completed to full NIF specifications without use of preferential figuring due to the good homogeneity glass provided by OHARA. Sufficient polarizers, LM3, LM7d, and LM8a mirrors have been shipped to meet first-bundle requirements. In addition, Zygo has completed all of the precision diagnostic mirrors for one switchyard.

The LLE has reduced coating nonuniformity by masking to less than $1 \%$. In areas of full refinement, the nonuniformity was reduced to less than $0.1 \%$. Spectra-Physics has resumed coating with their new control system on their coating tank. Work is proceeding with optimizing their cleaning process and training on metrology instruments which have now all been delivered. The acceptance testing of the 18-in. interferometer at Spectra-Physics was successfully completed in February.

CCI presented a preliminary design review for the crystal finishing facility in January, including modifications to the air conditioning design. A final design is expected next quarter. The design is on track to meet the requirement for facility completion by January 2001.

Crystal fabrication process development started at LLNL with the completion of the bandsaw, profiling machine, and horizontal-axis flycutting machine. The semi-finishing machine is expected to be ready 
for process development, and the final finishing machine is expected to resume acceptance testing next quarter.

Moore Tool completed fixing nearly all of the 40 machine noncompliances on the final finishing machine that were compiled by LLNL from last quarter's acceptance tests. Moore recently reported that the French machine passed the surface roughness acceptance test, which gives us reason to expect that LLNL's machine will pass during the next tests. As a backup, upgrades to the flycutter spindle, the spindle bearings, and the flycutter are being evaluated.

The first NIF-scale sol-gel coatings using the new Chemat system were produced. The uniformity of the coating process is now approaching that of the system in the old B392 coating lab used for Beamlet and Nova.

An analysis of the performance characteristics of the baseline twolayer blastshield antireflection coating revealed a minimal benefit from the proposed silicate polymer under the sol. Consequently, the baseline blastshield coating design was changed to a single layer, ammonia-hardened sol. The sol coating is being qualified using the existing 36-flashlamp test station.

The blastshield meniscus coating system was installed and has been tested on full-sized glass panels. The average transmission of an asdeposited coating was $97.8 \%$-nearly equal to the theoretical value of $98.2 \%$. The ammonia curing equipment has been tested and produced densified sol films with the expected shrinkage. The urethane dispensing system (blastshield glass-metal seal) has been set up and tested. The OPDL is expected to be ready to produce blast shield assemblies by mid-April.

The 24-in. Wyko interferometers laser diode lifetime problem appears to be resolved, although it is too early to be certain. A review of the design of the laser diode package revealed sensitivity to optical feedback. This was corrected by incorporating an optical isolator after the laser diode source. Modified diode packages have been incorporated into the interferometers located at Tinsley, Kodak, and LLNL and are functioning very well. This upgrade will be incorporated into the remaining interferometers in April. In addition, a backup design approach has been pursued with Wyko utilizing a HeNe laser source. Training for the Spectra-Physics 18-in. interferometer and acceptance testing for this system is complete.

The second NIF photometer was installed at Spectra-Physics in February. Both of the coating suppliers for NIF large optics now have the 
Pro blems/ Impacts/ Corrective Actions

Procurements

VARIANCES

UPCOMING MAJOR ACTIVITIES new Bauer photometer. This unit has significant capabilities as well as the ability to scan large optics. This unit can measure at three NIF laser wavelengths, at variable polarization, over a range of angles-of-incidence, and on curved surfaces.

The fabrication and assembly contract was awarded to Tinsley as part of the effort to complete the Lens Optical Test System (LOTS). Final metrology cannot begin on lenses until the LOTS is completed and validated. Tinsley has begun reworking windows that failed the PSD II-Waviness and roughness specifications.

Zygo did not complete the first NIF amplifier slab finishing to full NIF wavefront specifications due to small-scale wavefront errors requiring small-tool figuring. Slabs were sent on to Kodak to facilitiate meeting this milestone in early April.

Initial results with a new laser diode package for the Wyko 24-in. interferometers are very promising. Incorporation of an optical isolator may have resolved the diode lifetime issues.

The third (LLNL) photometer is still at Bauer to allow them to resolve operational problems uncovered with the first two units.

The Kodak pilot contract was modified to add ion figuring of 20 polarizer blanks to allow use of glass with marginal homogeneity.

A contract for $\$ 240 \mathrm{~K}$ was awarded at Tinsley for the fabrication and assembly of two LOTSs.

A contract modification for an incremental $\$ 461 \mathrm{~K}$ was made at Tinsley in February to extend the pilot contract through April.

The rebaseline process has not been completed, and therefore, there are currently no variance statements for FY00 cost or schedule.

- The first Pilot II slab will ship from Schott to Zygo in early April.

- Hoya Corporation will begin their Pilot II campaign in April at the conclusion of their edge cladding run. The contract was completed for this work and will be awarded effective April 1. 
- In early April the results from small-tool figuring the first NIF amplifier at Kodak are expected.

- New diodes with optical isolation will be available for the remaining 24-in. Wyko interferometers in April and will be installed at all affected vendor sites.

- Spectra-Physics is scheduled to coat a NIF-size polarizer with the NIF process and begin metrology in April.

- Review of the NIF Final Supplemental Environmental Impact Statement will be complete. 


\section{Attachment 1: Schedule Status}

The schedule status section will provide (1) a summary schedule, (2) a status of the NIF Project Execution Plan milestones, (3) a status of the DOE performance measurement milestones, and (4) the critical path analysis.

At this point, Project schedules are being rebaselined to implement the completion options to be selected by the DOE. A bottom-up schedule for Option 1 with 24,000 individual activities, was submitted to DOE/ NNSA for approval. When the new schedules are prepared, they will be statused in the monthly report.

Summary Schedule

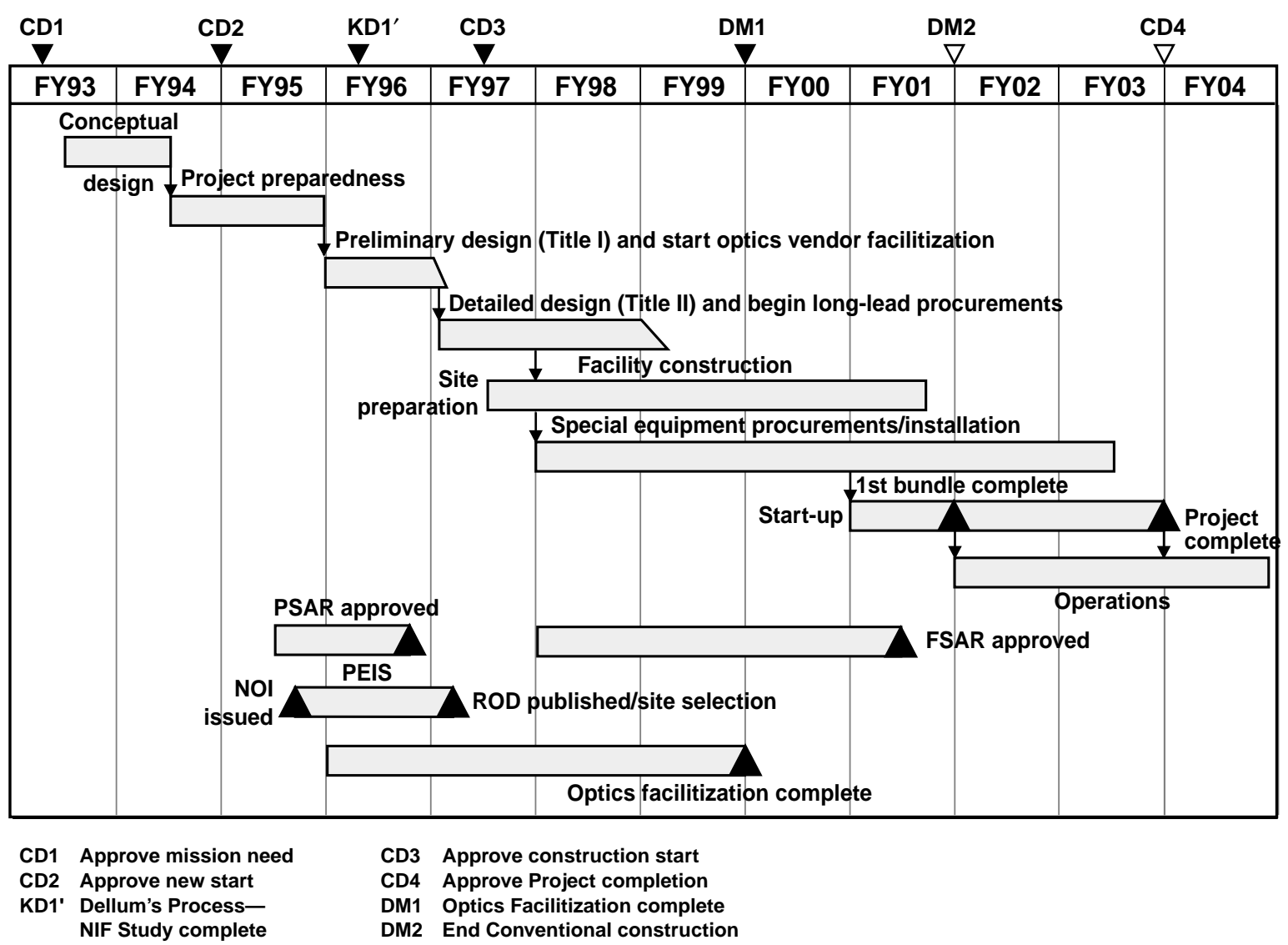

40-00-0195-0269XKpb01

The rebaseline schedule will result in an update to the NIF Project major milestones to reflect the completion options proposed to the DOE. Until the rebaseline schedule is available, the current baseline will be statused. 


\section{Status of NIF Project Execution Plan Milestones}

\begin{tabular}{|c|c|c|c|c|c|c|}
\hline Milestones & $\begin{array}{c}\text { NNSA } \\
\text { Acquisi- } \\
\text { tion } \\
\text { Executive } \\
\text { Level } 0\end{array}$ & $\begin{array}{c}\text { NNSA } \\
\text { Office of } \\
\text { Inertial } \\
\text { Fusion } \\
\text { and the } \\
\text { NIF } \\
\text { Project } \\
\text { Level } 1\end{array}$ & $\begin{array}{c}\text { NIF } \\
\text { NNSA } \\
\text { Field } \\
\text { Office } \\
\\
\begin{array}{c}\text { Level } \\
3\end{array}\end{array}$ & $\begin{array}{c}\text { NIF } \\
\text { Labor- } \\
\text { atory } \\
\text { Project } \\
\text { Office } \\
\text { Level } 3\end{array}$ & $\begin{array}{c}\text { Date } \\
\text { Planned }\end{array}$ & $\begin{array}{c}\text { Date } \\
\text { Actual }\end{array}$ \\
\hline Approval of Mission need (CD1) & $\mathrm{X}$ & & & & Jan 1993 & Jan 1993 \\
\hline CDR Complete & & & & $\mathrm{X}$ & May 1994 & May 1994 \\
\hline Approval of New Start (CD2) & $\mathrm{X}$ & & & & Oct 1994 & Oct 1994 \\
\hline Notice of Intent Issued & & $X$ & & & Jun 1995 & Jun 1995 \\
\hline KD1' Dellums Process Complete & $\mathrm{X}$ & & & & Dec 1995 & Dec 1995 \\
\hline Architect/Engineer Contracted & & & & $\mathrm{X}$ & Dec 1995 & Dec 1995 \\
\hline Title I Initiated & & & & $\mathrm{X}$ & Jan 1996 & Jan 1996 \\
\hline Construction Manager Contracted & & & & $\mathrm{X}$ & May 1996 & May 1996 \\
\hline PSAR NNSA Concurrence & & & $\mathrm{X}$ & & Aug 1996 & Aug 1996 \\
\hline PSAR Approved & & & & $\mathrm{X}$ & Sep 1996 & Sep 1996 \\
\hline NEPA Record of Decision & $\mathrm{X}$ & & & & Sep 1996 & Dec 1996 \\
\hline Approval to Initiate Title II Design & & & $\mathrm{X}$ & & Sep 1996 & Nov 1996 \\
\hline Approval to Initiate Long-Lead Procurement & & & $\mathrm{X}$ & & Sep 1996 & Nov 1996 \\
\hline Approval to Initiate Construction (CD3) & $\mathrm{X}$ & & & & Mar 1997 & Mar 1997 \\
\hline $\begin{array}{l}\text { Issue Pollution Prevention \& Waste } \\
\text { Minimization Plan }\end{array}$ & & & $\mathrm{X}$ & & Sep 1998 & Sep 1998 \\
\hline Optics Facilitization Complete (DM1) & & $\mathrm{X}$ & & & Oct 1999 & Oct 1999 \\
\hline Start Special Equipment Installation & & & & $\mathrm{X}$ & Nov 1998 & Nov 1998 \\
\hline Target Chamber Installed & & & & $\mathrm{X}$ & Oct 2000 & \\
\hline LTAB Superstructure Complete & & & & $\mathrm{X}$ & Dec 2000 & \\
\hline FSAR NNSA Concurrence & & & $\mathrm{X}$ & & Feb 2001 & \\
\hline FSAR Approved & & & & $\mathrm{X}$ & Mar 2001 & \\
\hline LTAB Construction Complete & & & & $\mathrm{X}$ & Jul 2001 & \\
\hline End conventional Construction (DM2) & & $\mathrm{X}$ & & & Sep 2001 & \\
\hline $\begin{array}{l}\text { ORR/ORE Complete-Start Early } \\
\text { Operations }\end{array}$ & & & $\mathrm{X}$ & & Sep 2001 & \\
\hline End of Construction & & & $\mathrm{X}$ & & Apr 2003 & \\
\hline Project Complete (CD4) & $\mathrm{X}$ & & & & Oct 2003 & \\
\hline
\end{tabular}


StATUS OF DOE/ The NNSA-approved NIF Transition Period Implementation Plan conN NSA Perfo Rmance tains a set of performance milestones from October 1, 1999, to June 1, MEASUREMENT 2000. These milestones are statused by NNSA on a weekly basis. The MILESTONES NIF Monthly Status provides the completed milestones at the end of March 2000. 


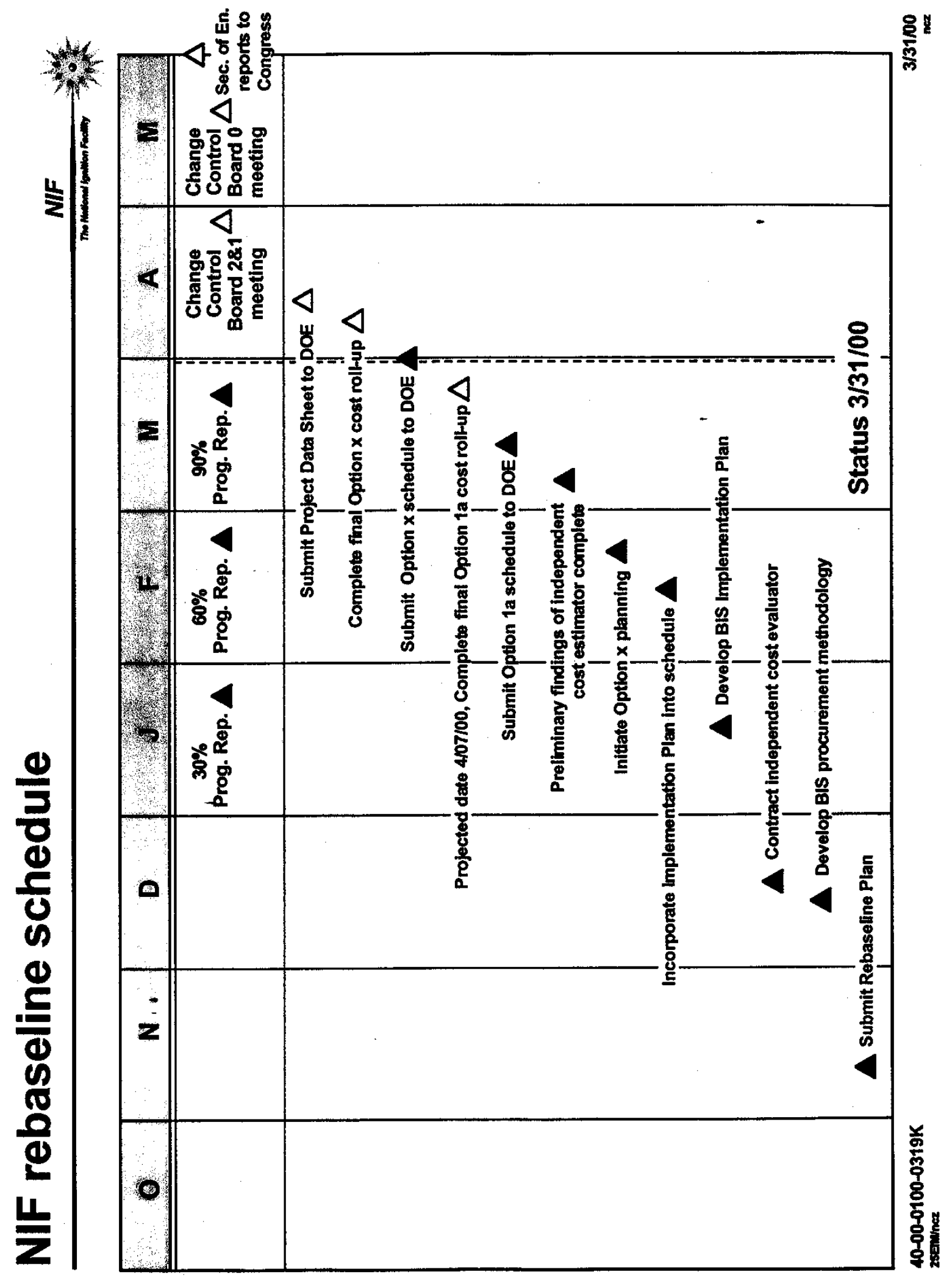




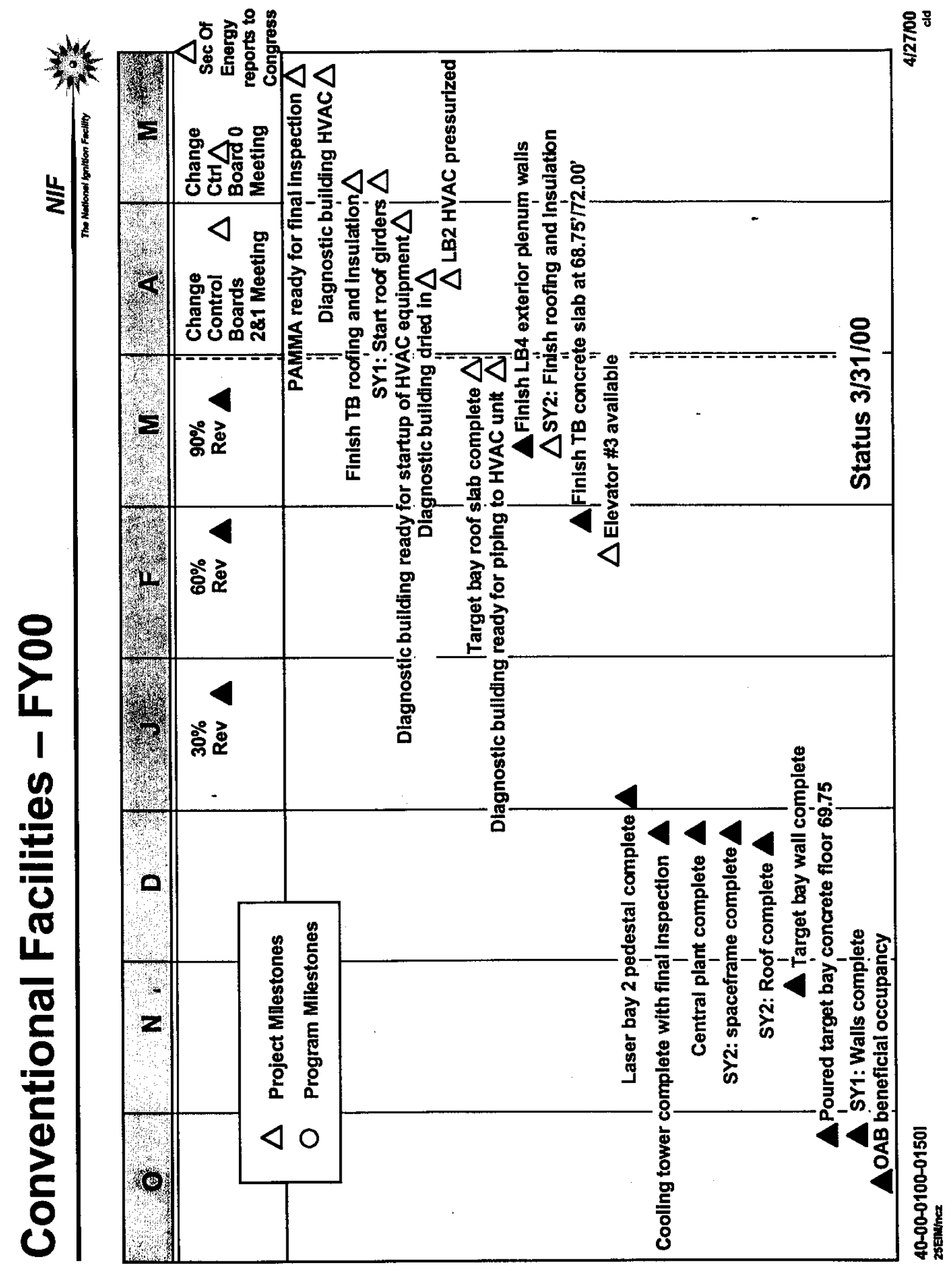




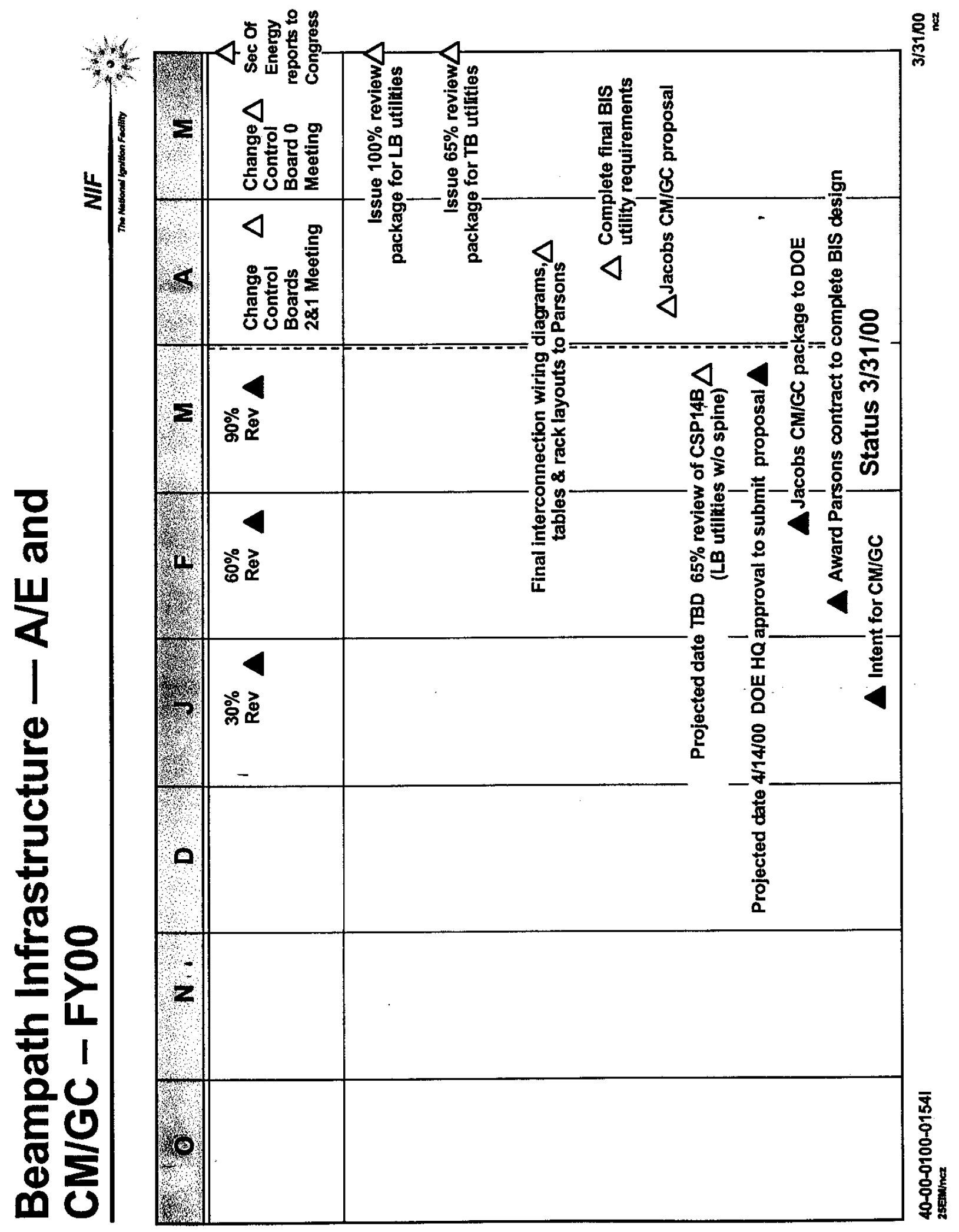




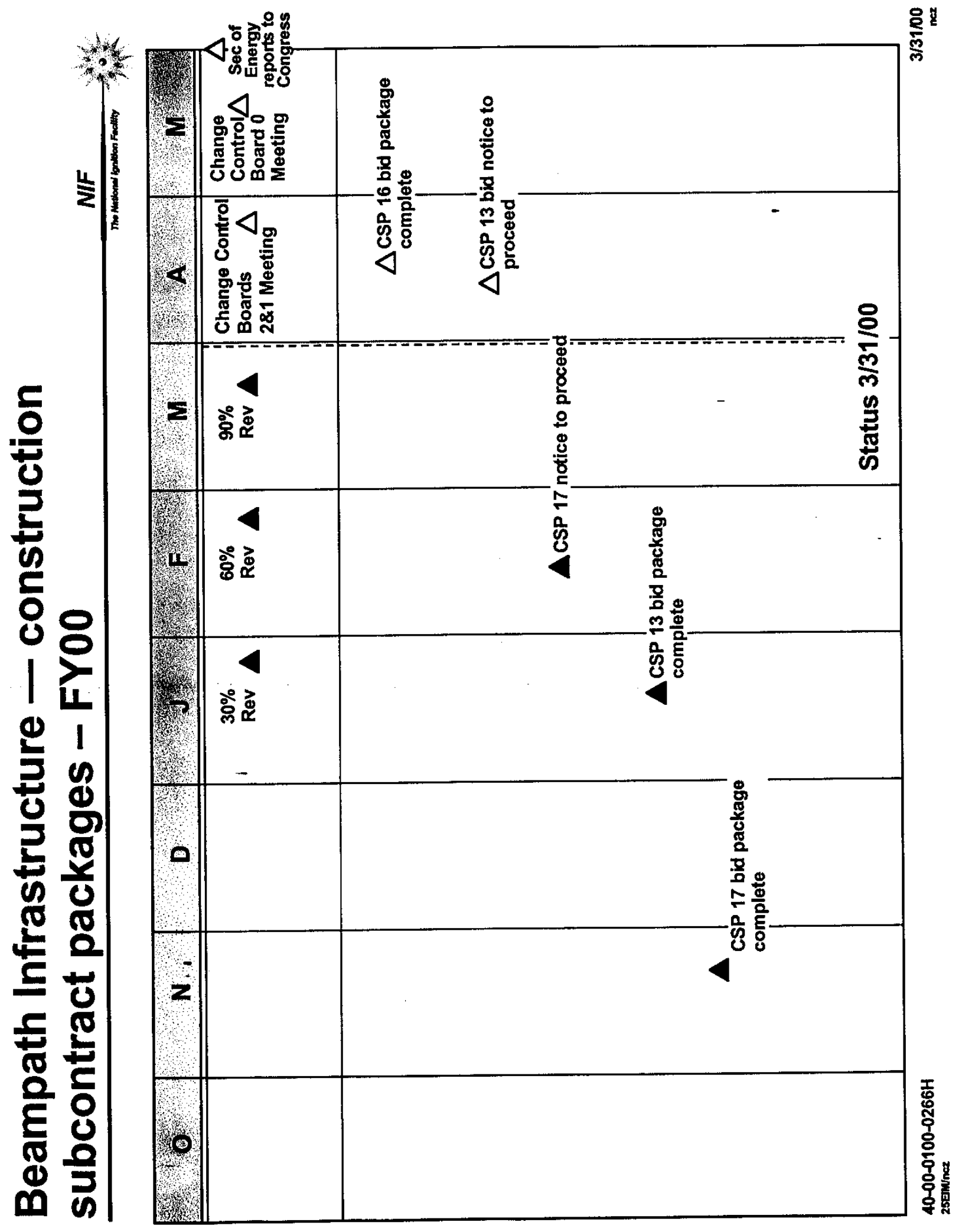




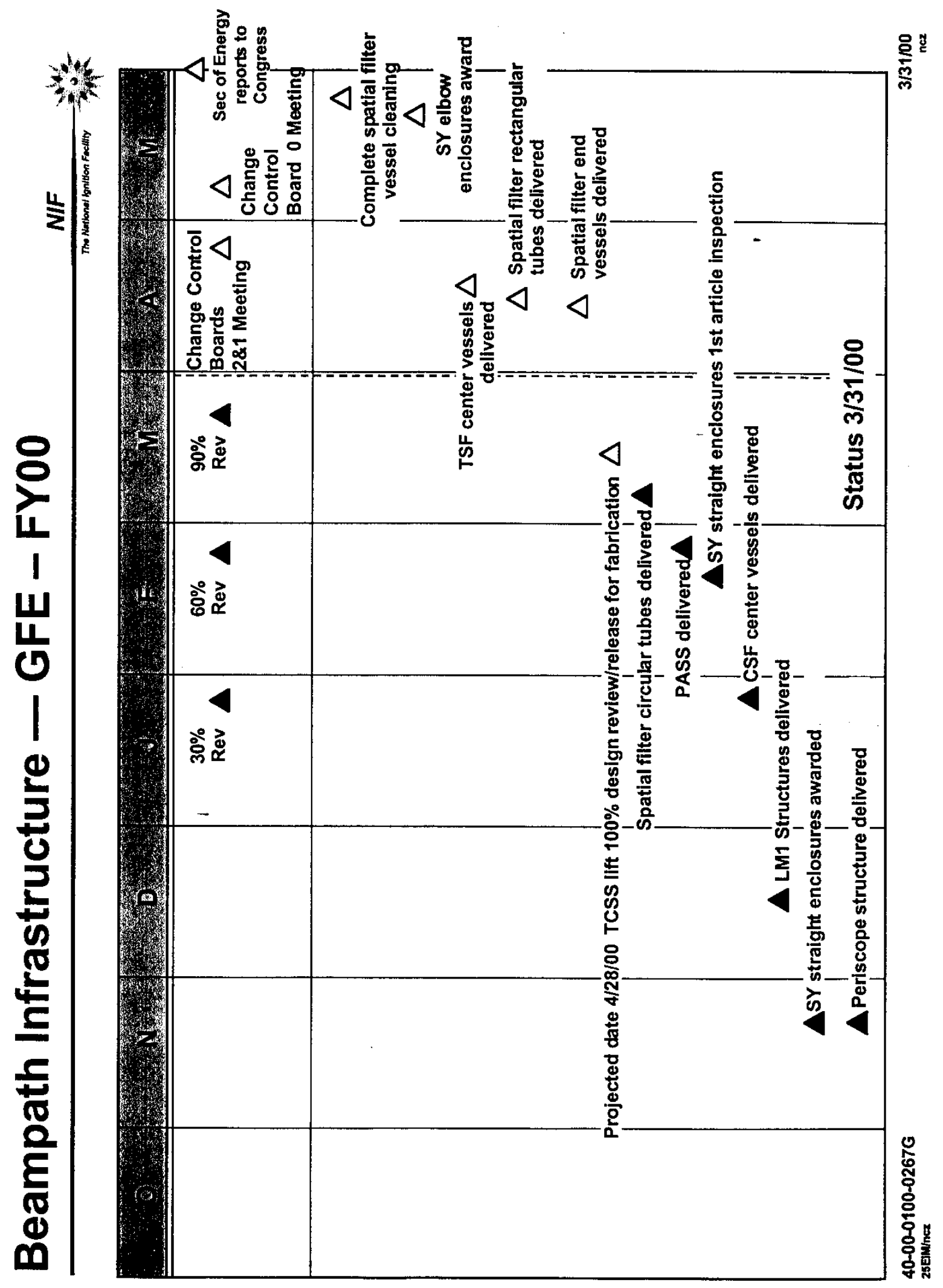




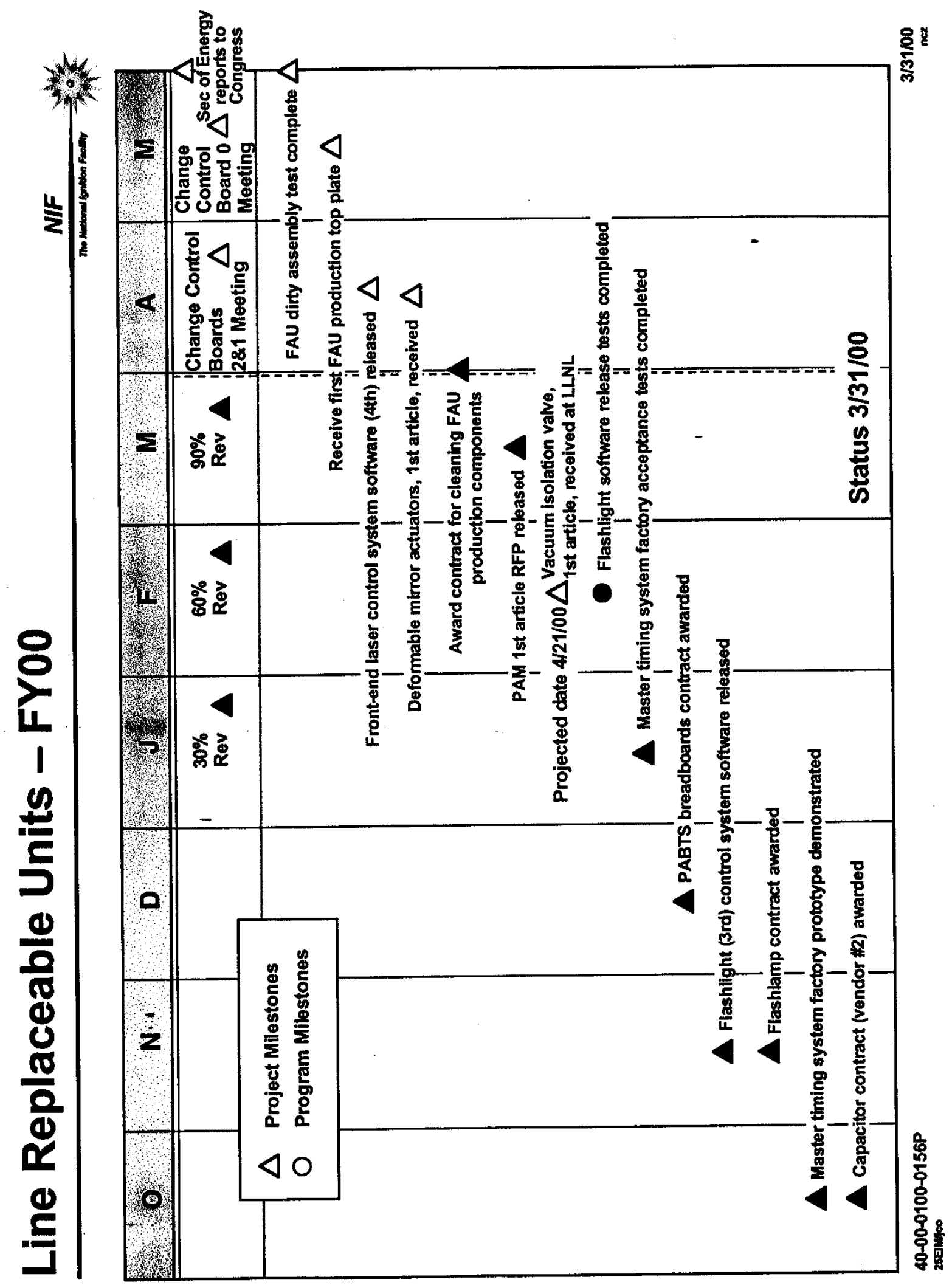




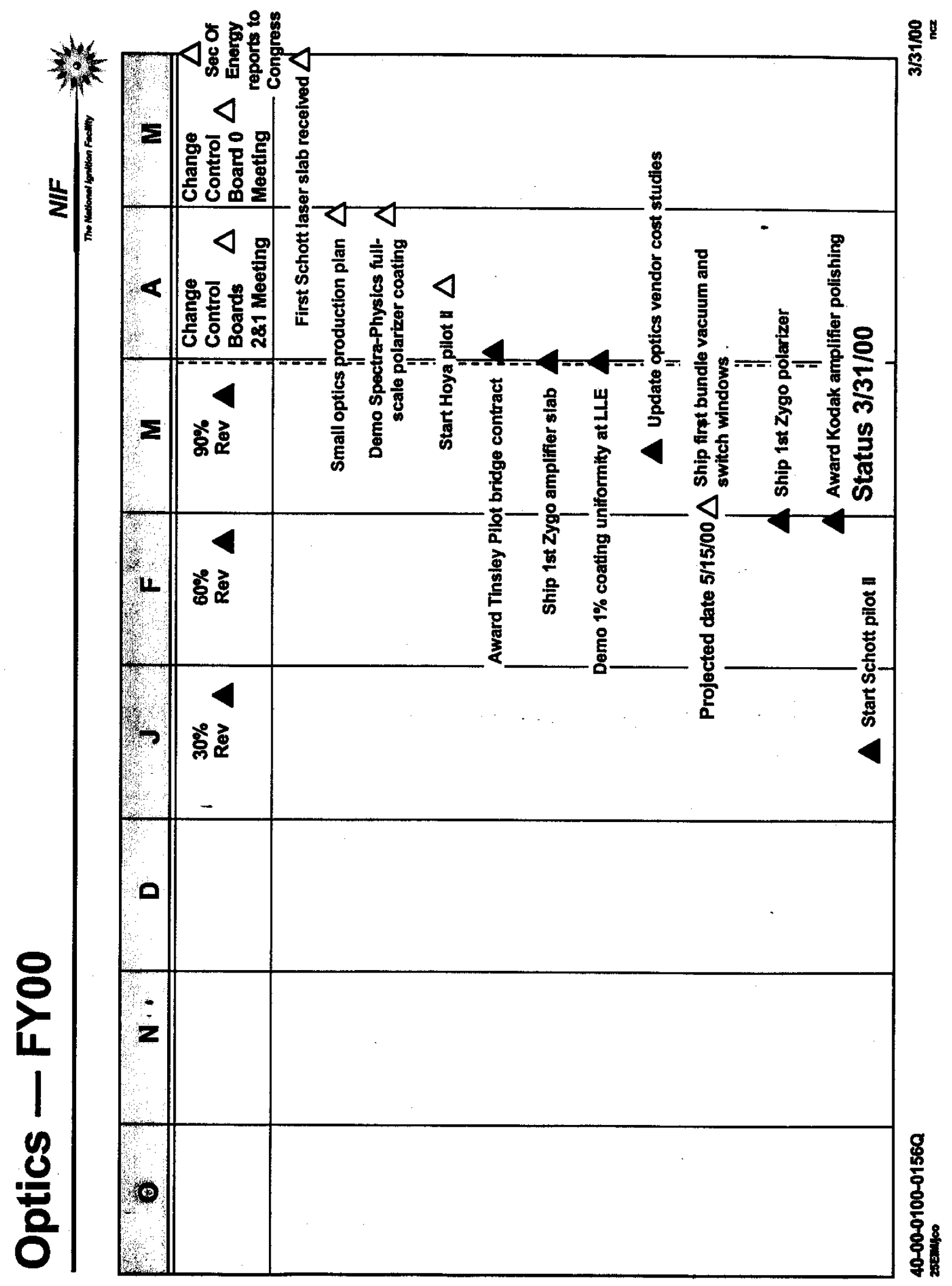




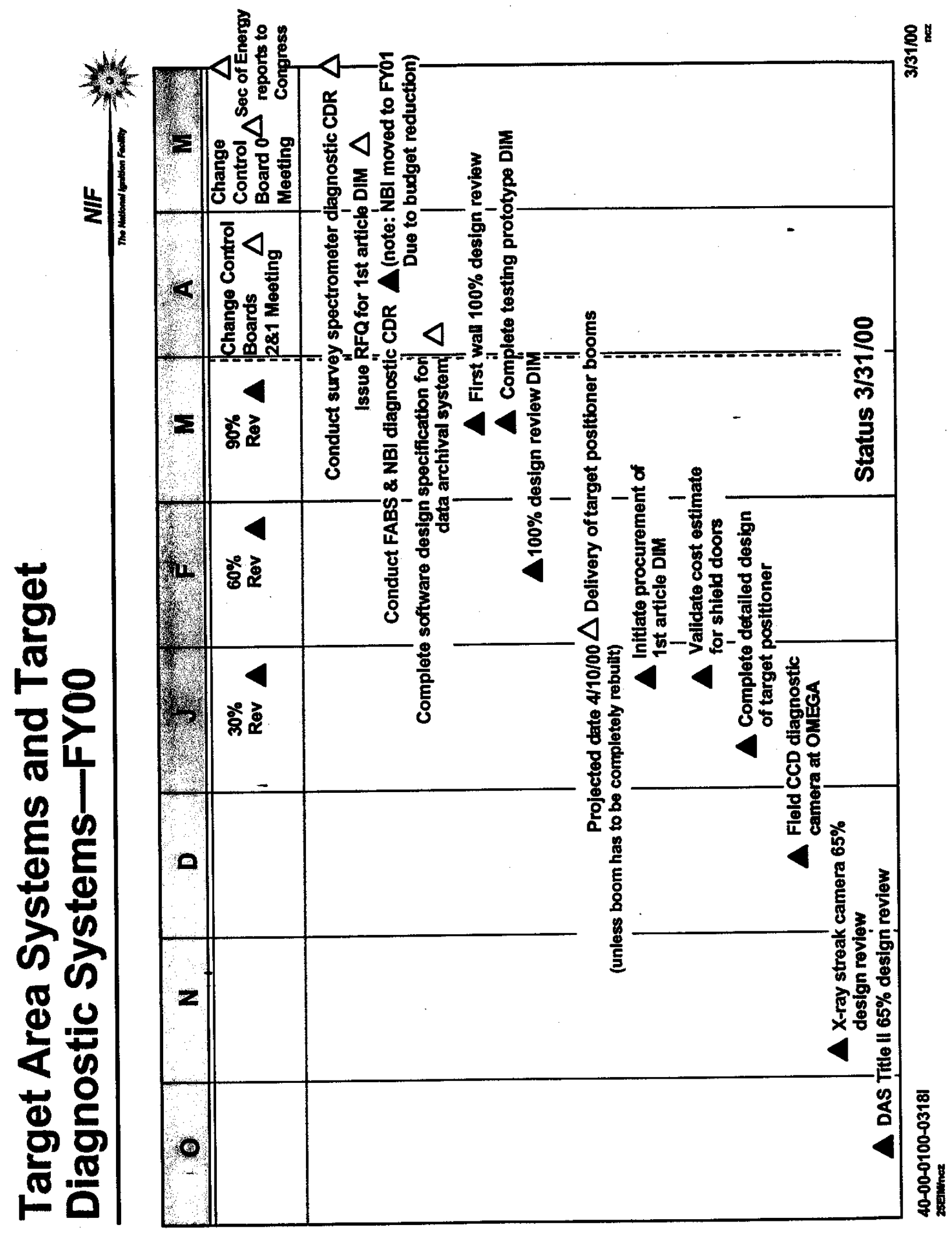




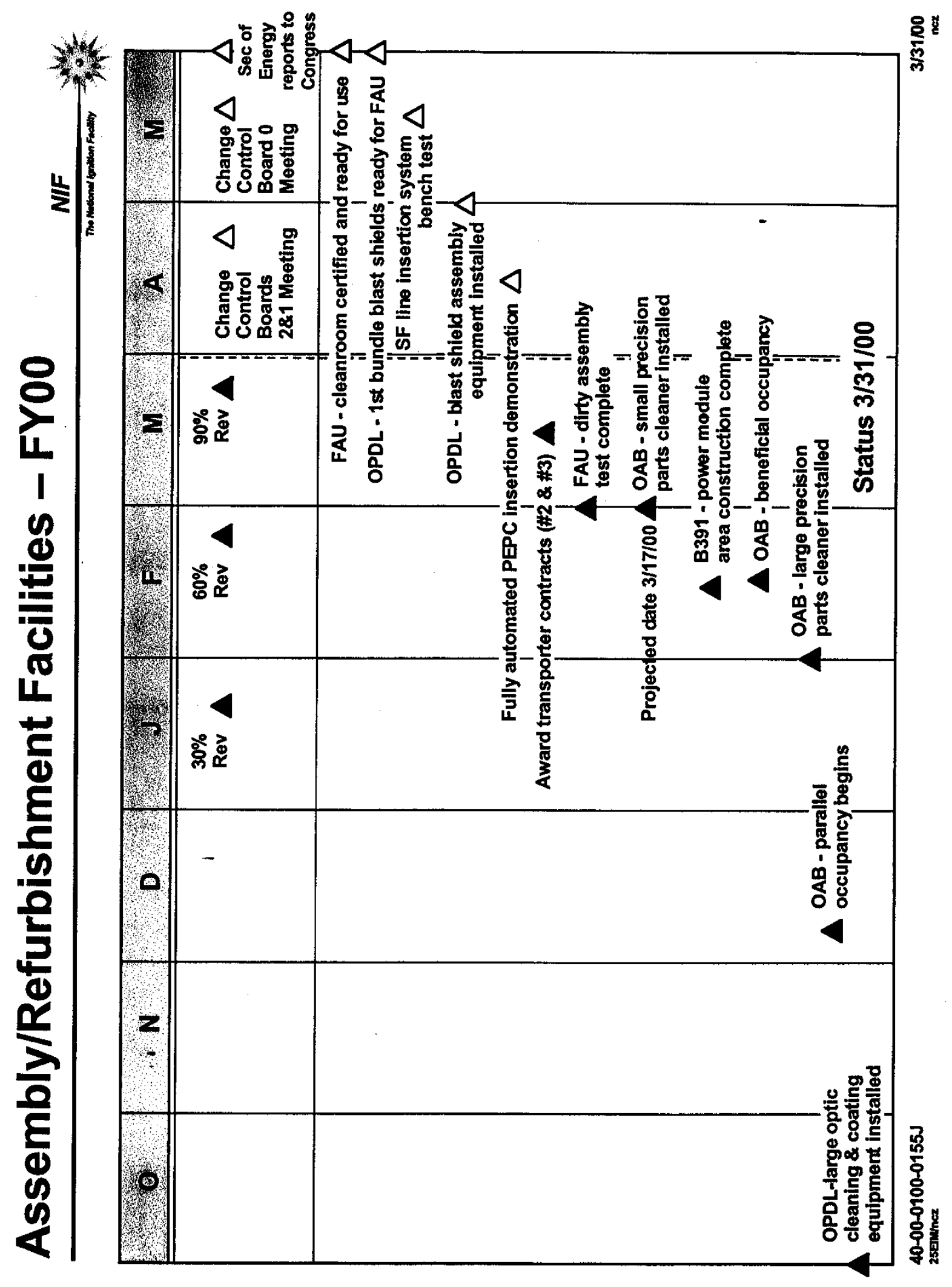




\section{ATtACHMENT 2: FinANCIAL StATUS}

The financial status includes (1) 2Q00 cumulative-to-date Project financial summaries by WBS Level 2 and by participant; (2) FY00 Plan to Actual Cost and Cost plus Commitments monthly for Total Project Cost, Total Estimated Cost, Other Project Cost, and each WBS Level 2 element; (3) the quarterly Contingency Log; and (4) FY00 monthly Manpower Plan to Actual.

Project Plan -toACTUAL COST AND COST Plus Commitments
FY00 NIF Cost and Cost and Commitment plans are presently shown as straight-line estimates of the current year budget allocations. FY00 CAPs are scheduled to be completed when the rebaselining process concludes.

The March 2000 WBS Level 2 variances resulting from actual versus the drafted straight-line budget plans are not individually discussed. TPC, TEC, and OPC Cost and Cost and Commitment variances ranging from $5 \%$ to $50 \%$ of actual below straight-lined plans indicate that overall FY00 costs and commitments are well within the current year funds availability. This conservatism is expected to prevail as long as rebaselining efforts are in progress. 


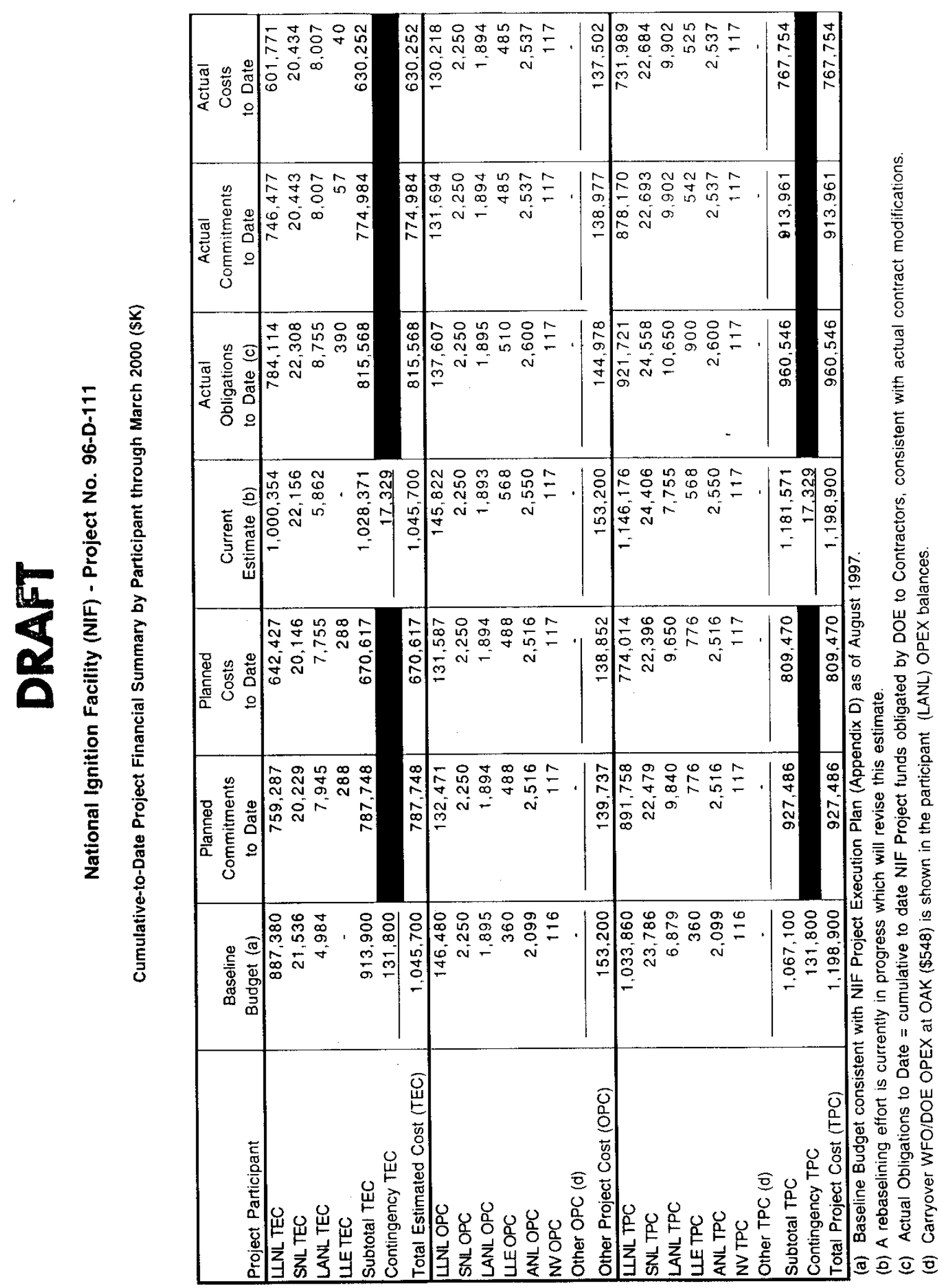




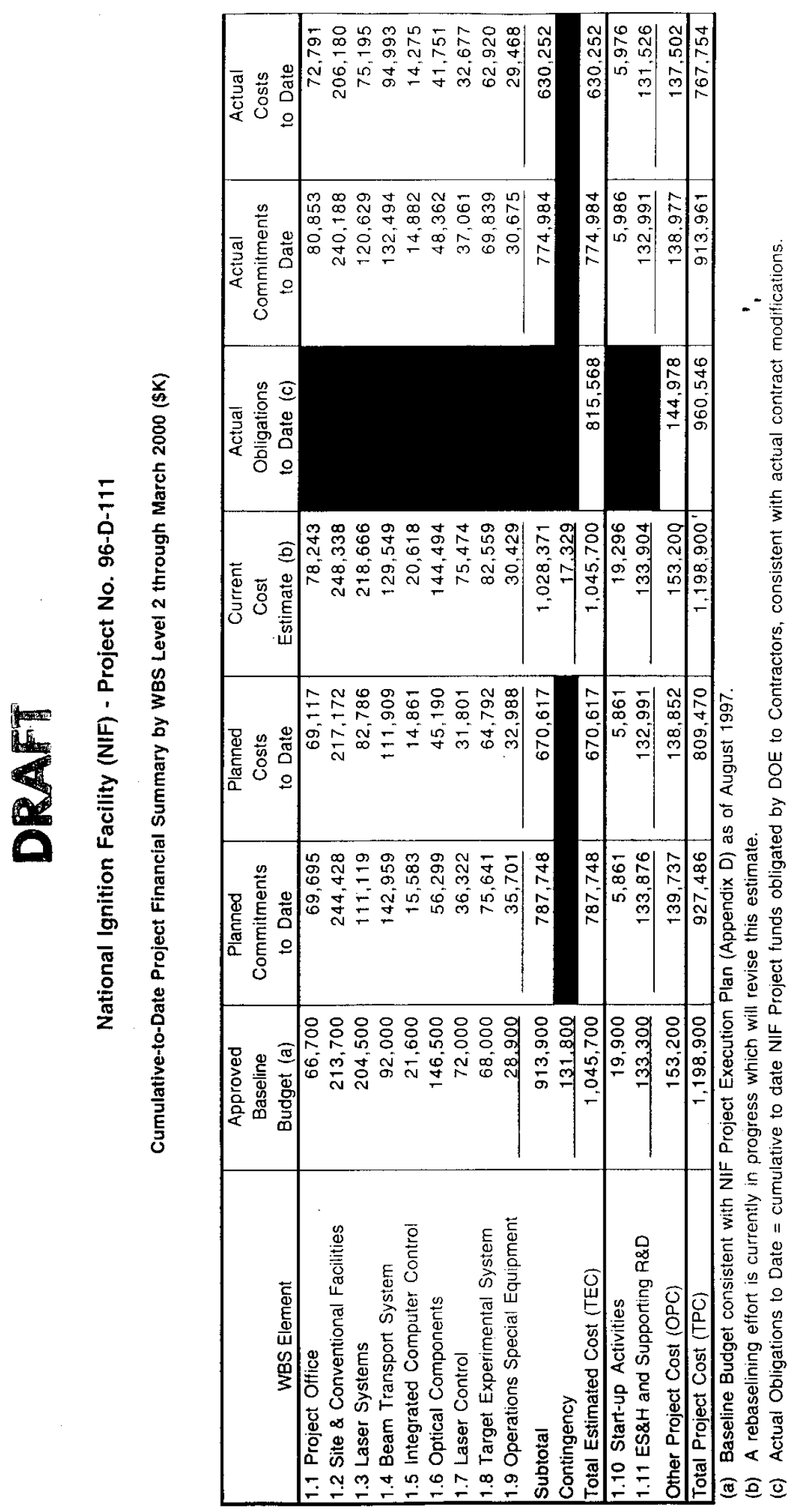




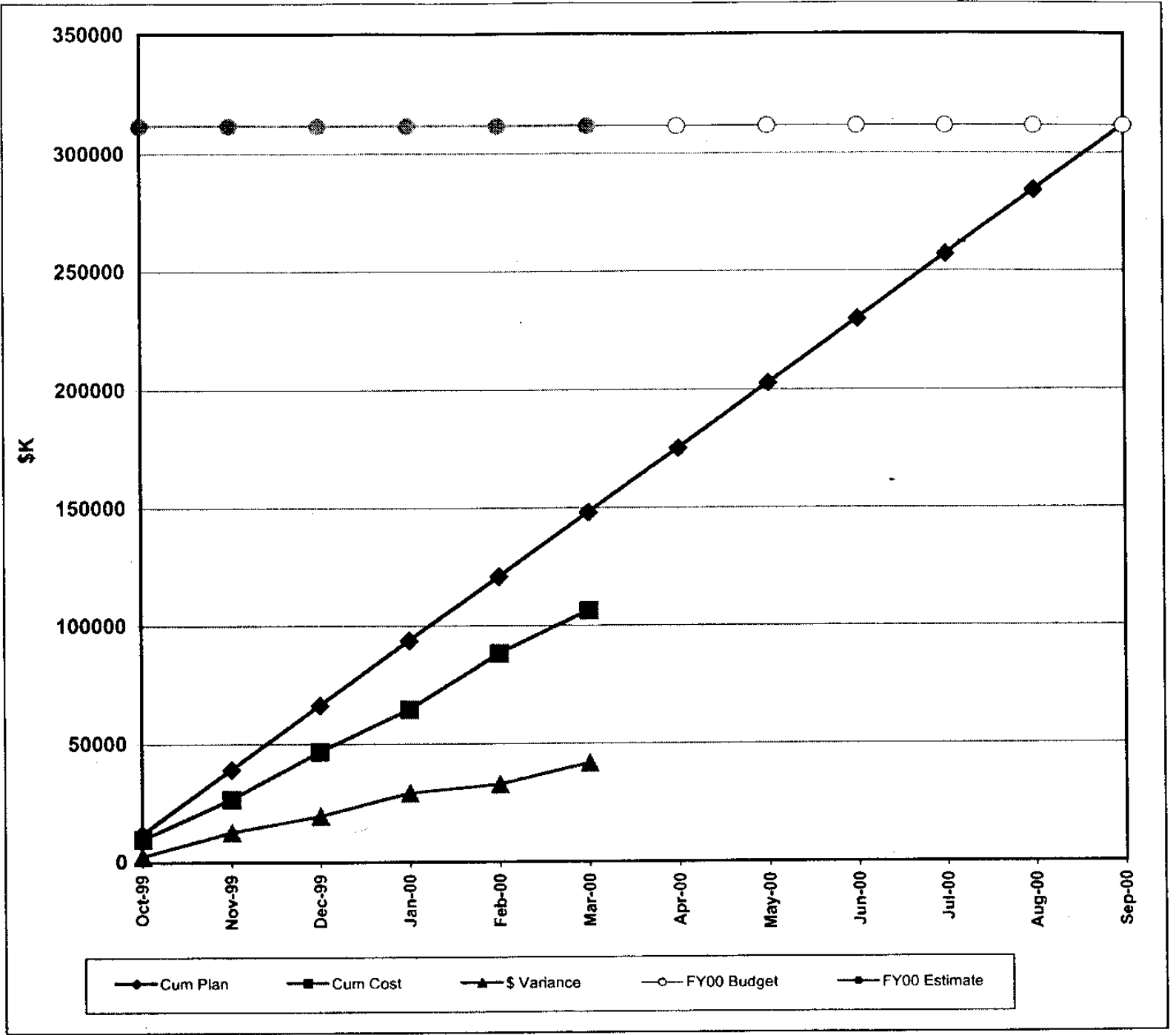

\begin{tabular}{|c|c|c|c|c|c|c|c|c|}
\hline \multirow[b]{2}{*}{ Month } & \multicolumn{2}{|c|}{ Monthly } & \multicolumn{4}{|c|}{ Cumulative } & \multirow{2}{*}{$\begin{array}{l}\text { FY2000 } \\
\text { Budget * }\end{array}$} & \multirow{2}{*}{$\begin{array}{c}\text { FY2000 } \\
\text { Estimate }\end{array}$} \\
\hline & Planned & Actual & Planned & Actual & $\$$ Var & $\%$ Var & & \\
\hline Oct-99 & 12.057 & 9,690 & 12,057 & 9,690 & 2,367 & $20 \%$ & 311,520 & 311,520 \\
\hline Nov -99 & 27.224 & 17,043 & 39,281 & 26,733 & 12,548 & $32 \%$ & 311,520 & 311.520 \\
\hline Dec-99 & 27,224 & 20,136 & 66,505 & 46,870 & 19,635 & $30 \%$ & 311,520 & 311,520 \\
\hline $\operatorname{Jan}-00$ & 27,224 & 17,601 & 93,729 & 64,471 & 29,258 & $31 \%$ & 311,520 & 311,520 \\
\hline$F e b \cdot 00$ & 27.224 & 23,662 & 120,953 & 88.133 & 32.820 & $27 \%$ & 311,520 & 311,520 \\
\hline Mar.0O & 27,224 & 18,329 & 148,176 & 106,461 & 41,715 & $28 \%$ & 311,520 & 311,520 \\
\hline Apr.00 & 27.224 & & 175,400 & & & & 311,520 & \\
\hline May 00 & 27,224 & & 202,624 & & & & 311,520 & \\
\hline Jun .00 & 27.224 & & 229,848 & & & & 311,520 & \\
\hline Jut-OO & 27,224 & & 257,072 & & & & 311.520 & \\
\hline Aug.00 & 27,224 & & 284,296 & & & & 311,520 & \\
\hline Sep-00 & 27,224 & & 311,520 & & & & 311,520 & \\
\hline
\end{tabular}

- Rebaselining in progress will establish Project TPC BAC/EAC. 


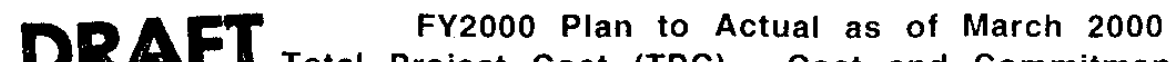
Total Project Cost (TPC) - Cost and Commitments (\$K)

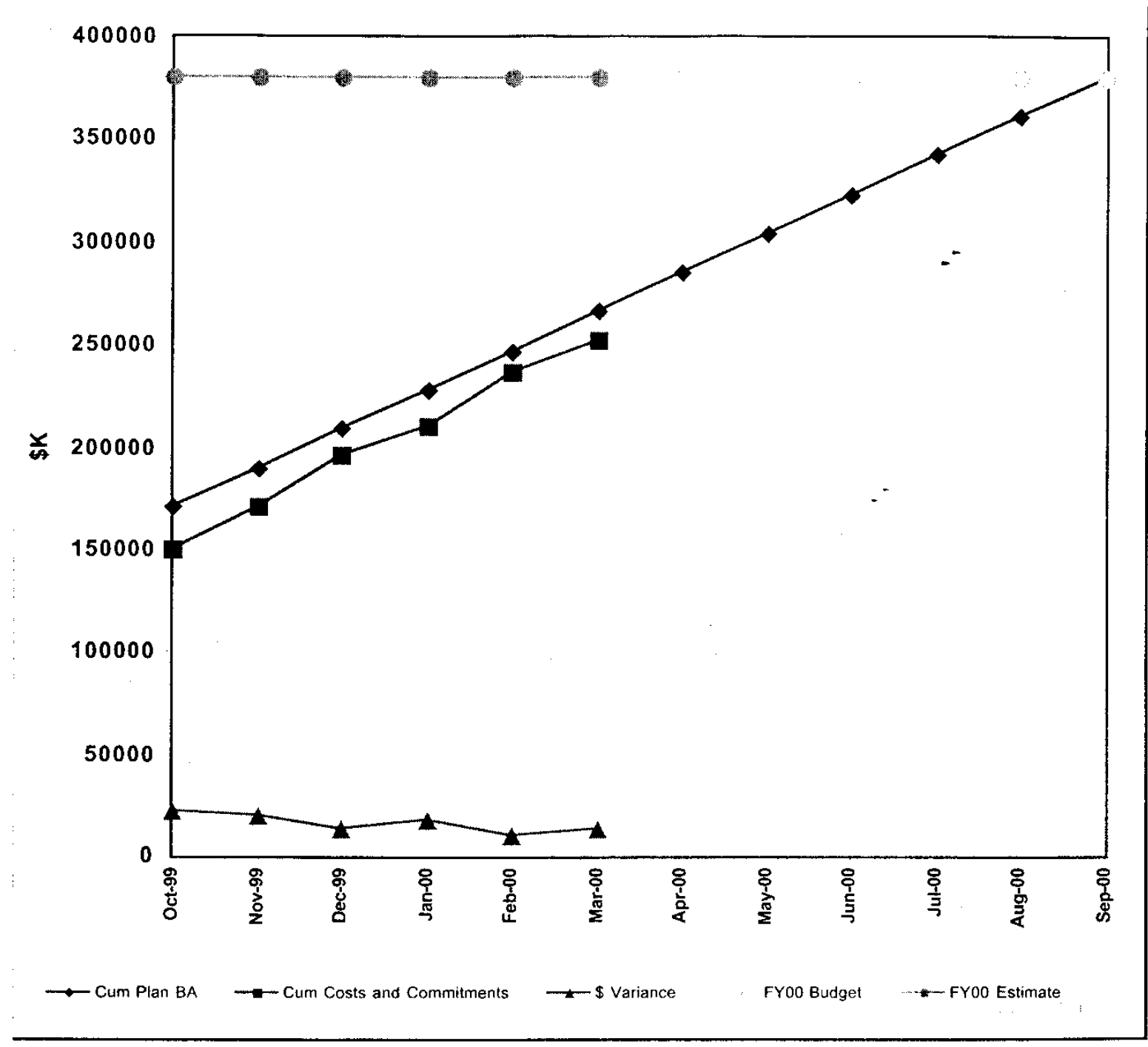

\begin{tabular}{|c|c|c|c|c|c|c|c|c|}
\hline \multirow[b]{2}{*}{ Month } & \multicolumn{2}{|c|}{ Monthly } & \multicolumn{4}{|c|}{ Cumulative } & \multirow{2}{*}{$\begin{array}{l}\text { FY2000 } \\
\text { Budget * }\end{array}$} & \multirow{2}{*}{$\begin{array}{c}\text { FY2000 } \\
\text { Estimate }\end{array}$} \\
\hline & Planned & Actual & Planned & Actual & \$ Var & $\%$ Var & & \\
\hline Oct-99 & 171,009 ** & 149,362 & $171,009 * *$ & 149,362 & 21,647 & $13 \%$ & 380,409 & 380,409 \\
\hline Nov-99 & 19,036 & 21,090 & 190,045 & 170,452 & 19,593 & $10 \%$ & 380,409 & 380,409 \\
\hline Dec-99 & 19,036 & 25,391 & 209.082 & 195.843 & 13,239 & $6 \%$ & 380,409 & 380,409 \\
\hline Jan-OO & 19,036 & 14,699 & 228,118 & 210,542 & 17,577 & $8 \%$ & 380,409 & 380,409 \\
\hline$F e b-00$ & 19,036 & 26,800 & 247,155 & $237,342^{i}$ & 9,813 & $4 \%$ & 380,409 & 380,409 \\
\hline Mar-OO & 19,036 & 15,326 & 266.191 & $252,668 !$ & 13,523 & $5 \%$ & 380,409 & 380,409 \\
\hline Apr-OO & 19,036 & & 285,227 & & & & 380,409 & \\
\hline May-00 & 19,036 & & 304.264 & & & & 380.409 & \\
\hline Jan-00 & 19,036 & & 323,300 & & & & 380.409 & \\
\hline$J u I-O O$ & 19,036 & & 342,337 & & & & 380,409 & \\
\hline Aug-OO & 19,036 & & 361,373 & i & & & 380,409 & \\
\hline Sep.00 & 19,036 & & 380,409 & $!$ & & & 380,409 & \\
\hline
\end{tabular}

- Rebaselining in progress will establish Project TPC BAC/EAC.

* Includes $\$ 126,612 \mathrm{~K}$ of uncosted obligations from FY99. 


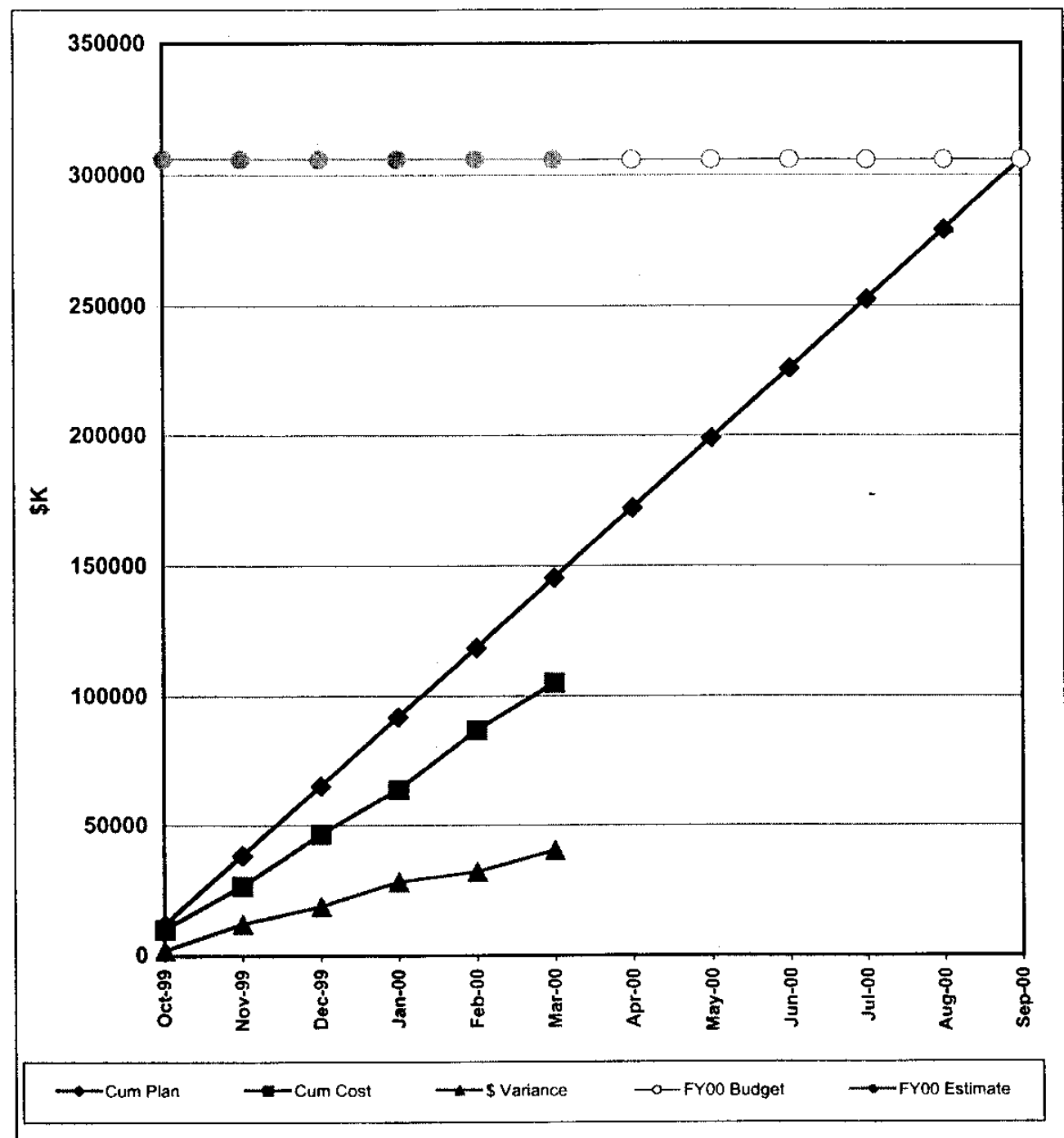

\begin{tabular}{|c|c|c|c|c|c|c|c|c|}
\hline \multirow[b]{2}{*}{ Month } & \multicolumn{2}{|c|}{ Monthly } & \multicolumn{4}{|c|}{ Cumulative } & \multirow{2}{*}{$\begin{array}{l}\text { Fr2000 } \\
\text { Eudgot }\end{array}$} & \multirow{2}{*}{$\begin{array}{l}\text { FY2000 } \\
\text { Estimate }\end{array}$} \\
\hline & Planned & Actual & Planned & Actual & \$ Var & $\%$ Var & & \\
\hline Oct-99 & 11,647 & 9,826 & 11,647 & 9.826 & 1,821 & $16 \%$ & 306,054 & 306,054 \\
\hline Nov-99 & 26,764 & 16,570 & 38.411 & 26,395 & 12,016 & $31 \%$ & 306,054 & 306,054 \\
\hline Dec-99 & 26,764 & 20,132 & 65,176 & 46,528 & 18,648 & $29 \%$ & 306,054 & 306,054 \\
\hline Jan-oo & 26,764 & 17,295 & 91,940 & 63,823 & 28.117 & $31 \%$ & 306,054 & 306,054 \\
\hline Feb-oo & 26,764 & 22,957 & 118.704 & 86.779 & 31.925 & $27 \%$ & 306.054 & 306.054 \\
\hline Mar $=00$ & 26,764 & 18.325 & 145,468 & 105,104 & 40.364 & $28 \%$ & 306,054 & 306,054 \\
\hline$A p r-D O$ & 26,764 & & 172.233 & & & & 306,054 & \\
\hline May-00 & 26,764 & & 198.997 & & & & 306,054 & \\
\hline Jun-00 & 26,764 & & 225.761 & & & & 306,054 & \\
\hline JuI-OO & 26.764 & & 252.526 & & & & 306,054 & \\
\hline Aug.0O & 26,764 & & 279,290 & & & & 306.054 & \\
\hline Sep-00 & 26,764 & & 306,054 & & & & 306,054 & \\
\hline
\end{tabular}

- Rebaselining in progress will establish Project TEC BAC/EAC. 
FY2000 Plan to Actual as of March 2000
Total Estimated Cost (TEC) - Cost and Commitments (\$K)

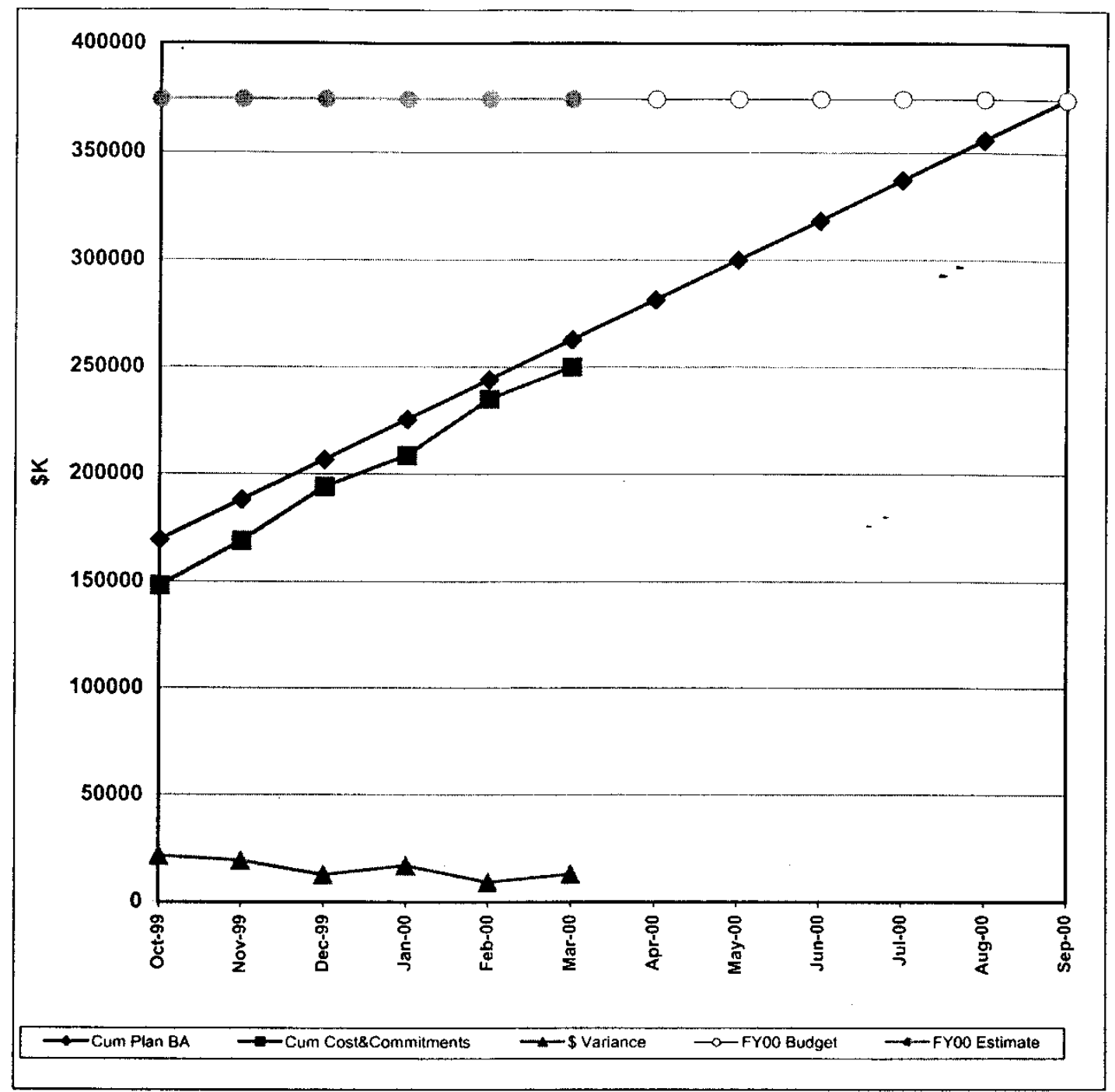

\begin{tabular}{|c|c|c|c|c|c|c|c|c|c|}
\hline \multirow[b]{2}{*}{ Month } & \multicolumn{2}{|c|}{ Monthly } & \multicolumn{5}{|c|}{ Cumulative } & \multirow{2}{*}{$\begin{array}{l}\text { FY2000 } \\
\text { Budget }\end{array}$} & \multirow{2}{*}{$\begin{array}{l}\text { FY2000 } \\
\text { Estimate }\end{array}$} \\
\hline & Planned & Actual & Planned & & Actual & $\$$ Var & $\%$ Var & & \\
\hline Oct -98 & 169,417 & 148,023 & 169,417 & ** & 148,023 & 21,394 & $13 \%$ & 374,416 & 374,416 \\
\hline Nov-98 & 18,636 & 20,837 & 188,053 & & 168,860 & 19,194 & $10 \%$ & 374,416 & 374,416 \\
\hline Dec-98 & 18,636 & 25,315 & 206,690 & & 194,175 & 12,515 & $6 \%$ & 374,416 & 374,416 \\
\hline Jan-99 & 18,636 & 14,429 & 225,326 & & 208,604 & 16,722 & $7 \%$ & 374,416 & 374,416 \\
\hline Feb-99 & 18,636 & 26,251 & 243,962 & & 234,855 & 9,108 & $4 \%$ & 374.416 & 374,416 \\
\hline Mar-99 & 18,636 & 14,981 & 262,599 & & 249,836 & 12,763 & $5 \%$ & 374,416 & 374,416 \\
\hline Apr-99 & 18,636 & & 281,235 & & & & & 374,416 & \\
\hline May-99 & 18,636 & & 299.871 & & & & & 374.416 & \\
\hline Jun-99 & 18,636 & & 318,507 & & & & & 374,416 & \\
\hline Jul-9g & 18,636 & & 337,144 & & & & & 374,416 & \\
\hline Aug-99 & 18,636 & & 355,780 & & & & & 374,416 & \\
\hline Sep-99 & 18,636 & & 374,416 & & & & & 374,416 & \\
\hline
\end{tabular}

- Rebaselining in progress will establish Project TEC BAC/EAC.

-" Includes \$124,820K of uncosted obligations from FY99. 


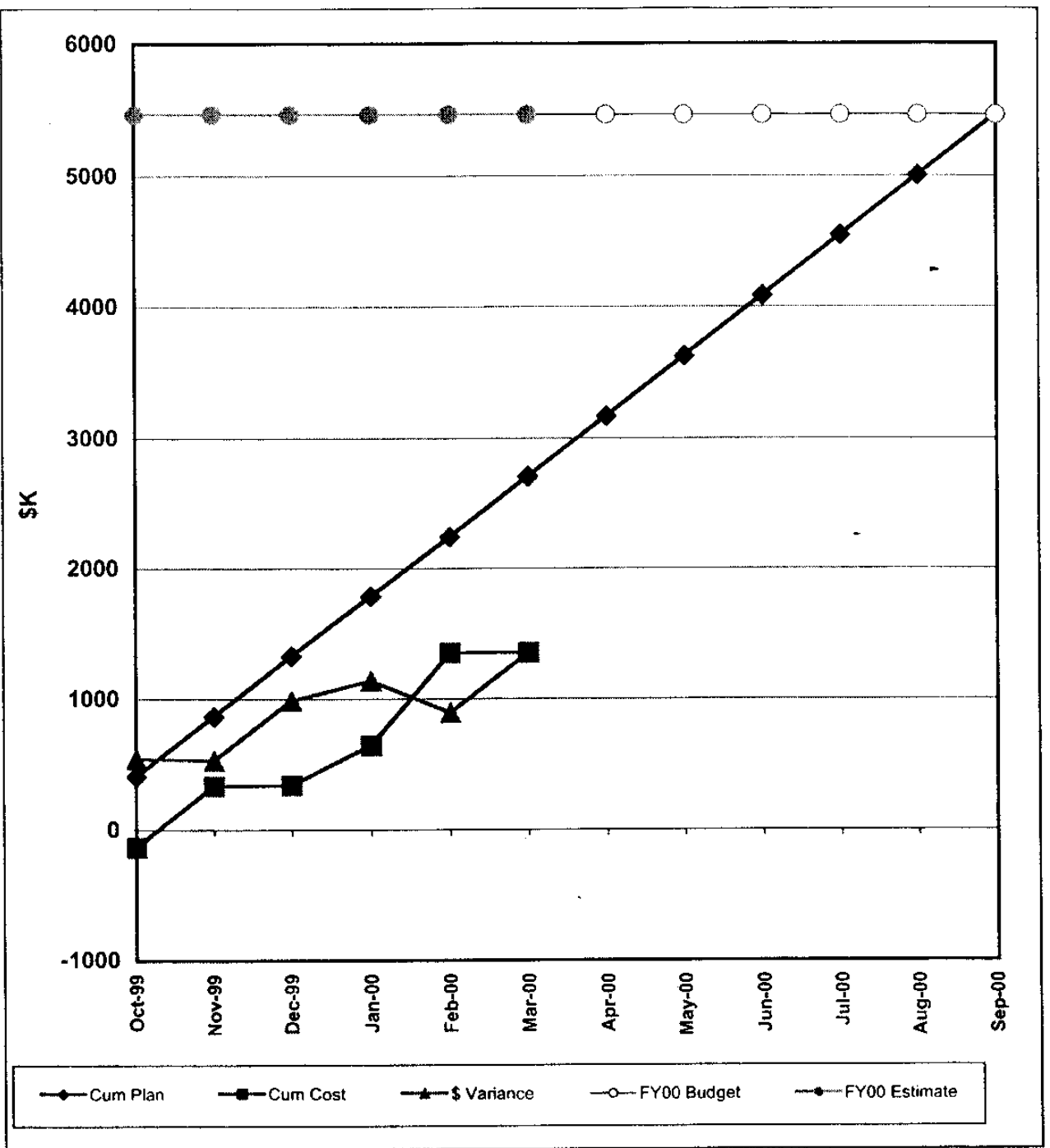

\begin{tabular}{|c|c|c|c|c|c|c|c|c|}
\hline \multirow[b]{2}{*}{ Month } & \multicolumn{2}{|c|}{ Monthly } & \multicolumn{4}{|c|}{ Cumulative } & \multirow{2}{*}{$\begin{array}{c}\text { FY2000 } \\
\text { Budget * }\end{array}$} & \multirow{2}{*}{$\begin{array}{r}\text { FY2000 } \\
\text { Estimate }\end{array}$} \\
\hline & Planned & Actual & Planned & Actual & $\$$ Var & $\%$ Var & & \\
\hline Oct-9g & 410 & -135 & 410 & -135 & 545 & $133 \%$ & 5,466 & 5,466 \\
\hline Nov-99 & 460 & 474 & 870 & 338 & 531 & $61 \%$ & 5,466 & 5,466 \\
\hline$D e c \cdot 99$ & 460 & 4 & 1,329 & 342 & 987 & $74 \%$ & 5,466 & 5,466 \\
\hline Jan-00 & 460 & 306 & 1,789 & 648 & 1,141 & $64 \%$ & 5,466 & 5,466 \\
\hline$F a b-00$ & 460 & 705 & 2,248 & 1,353 & 895 & $40 \%$ & 5,466 & 5,466 \\
\hline Mar-00 & 460 & 4 & 2,708 & 1,357 & 1,351 & $50 \%$ & 5,466 & 5,466 \\
\hline Apr -00 & 460 & & 3,168 & & & & 5,466 & \\
\hline May-0o & 460 & & 3,627 & & & & 5,466 & \\
\hline Jun-00 & 460 & & 4,087 & & & & 5,466 & \\
\hline$J u 1.00$ & 460 & & 4,546 & & & & 5,466 & \\
\hline Aug. 00 & 460 & & 5,006 & & & & 5,466 & \\
\hline Sep-00 & 460 & & 5,466 & & & & 5,466 & \\
\hline
\end{tabular}

- Rebaselining in progress will establish Project OPC BAC/EAC. 
FY2000 Plan to Actual as of March 2000

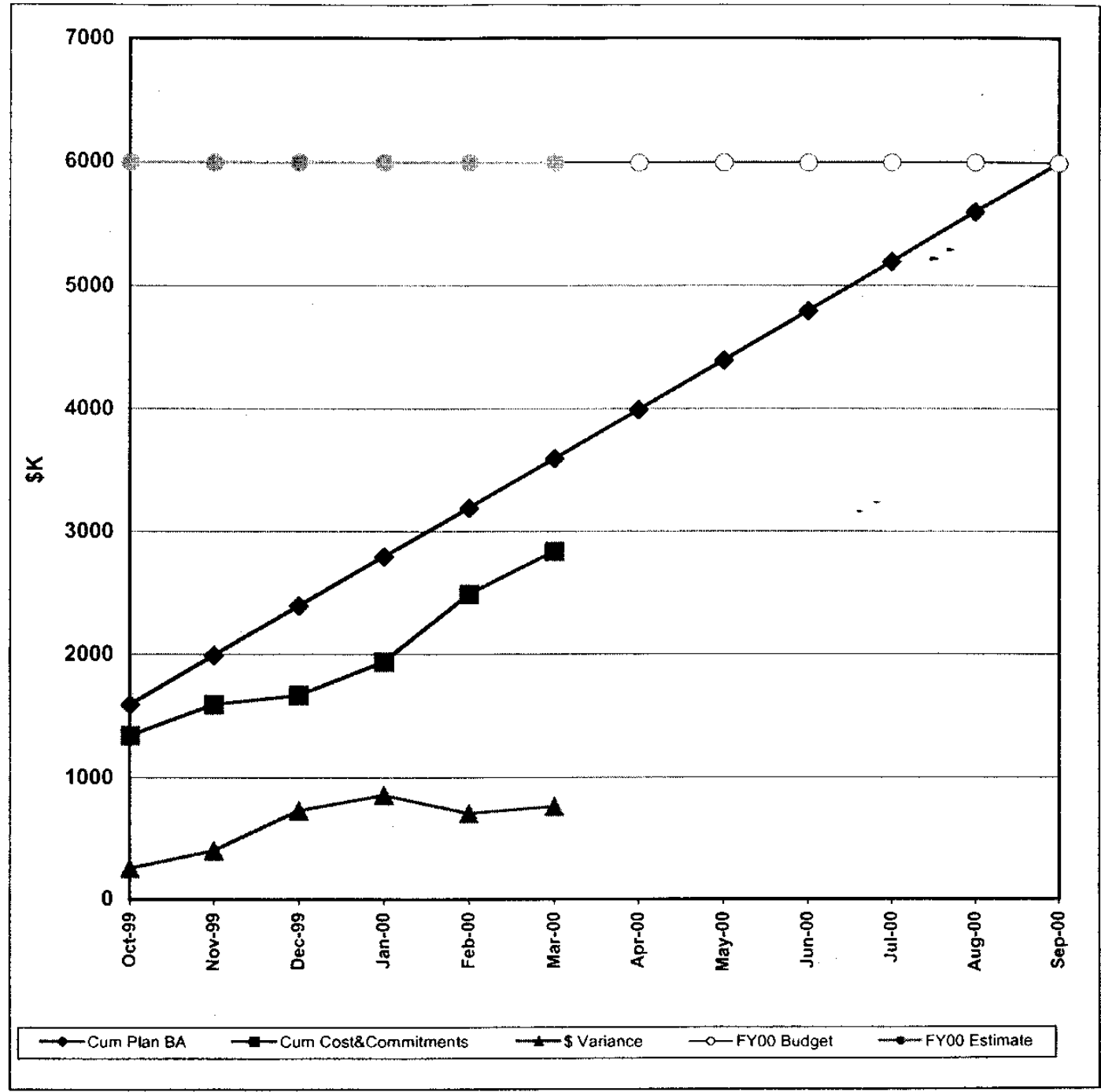

\begin{tabular}{|c|c|c|c|c|c|c|c|c|c|c|}
\hline \multirow[b]{2}{*}{ Month } & \multicolumn{3}{|c|}{ Monthly } & \multicolumn{5}{|c|}{ Cumulative } & \multirow{2}{*}{$\begin{array}{l}\text { FY2000 } \\
\text { Budget }\end{array}$} & \multirow{2}{*}{$\begin{array}{l}\text { FY2000 } \\
\text { Estimate }\end{array}$} \\
\hline & Planned & & Actual & Planned & & Actual & $\$$ Var & $\%$ Var & & \\
\hline Oct-99 & 1,592 & $\star$ & 1.339 & 1,592 & ** & 1,339 & 253 & $16 \%$ & 5,993 & 5,993 \\
\hline Nov-99 & 400 & & 253 & 1,992 & & 1,592 & 400 & $20 \%$ & 5,993 & 5,993 \\
\hline Dec-99 & 400 & & 75 & 2,392 & & 1,668 & 724 & $30 \%$ & 5.993 & 5,993 \\
\hline Jan-0O & 400 & & 270 & 2,792 & & 1,938 & 854 & $31 \%$ & 5.993 & 5,993 \\
\hline $\mathrm{Feb}-00$ & 400 & & 549 & $3,1 \dot{92}$ & & 2,487 & 705 & $22 \%$ & 5,993 & 5,993 \\
\hline Mar-00 & 400 & & 345 & 3,593 & & 2,832 & 760 & $21 \%$ & 5,993 & 5,993 \\
\hline Apr 00 & 400 & & & 3,993 & & & & & 5,993 & \\
\hline May-00 & 400 & & & 4,393 & & & & & 5,993 & \\
\hline Jun-0o & 400 & & & 4,793 & & & & & 5,993 & \\
\hline Jut.00 & 400 & & & 5,193 & & & & & 5,993 & \\
\hline$A \cup g-00$ & 400 & & & 5,593 & & & & & 5,993 & \\
\hline Sep-OO & 400 & & & 5,993 & & & & & 5.993 & \\
\hline
\end{tabular}

- Rebaselining in progress will establish Project OPC BAC/EAC.

* Includes $\$ 1.792 \mathrm{~K}$ of uncosted obligations from FY99. 


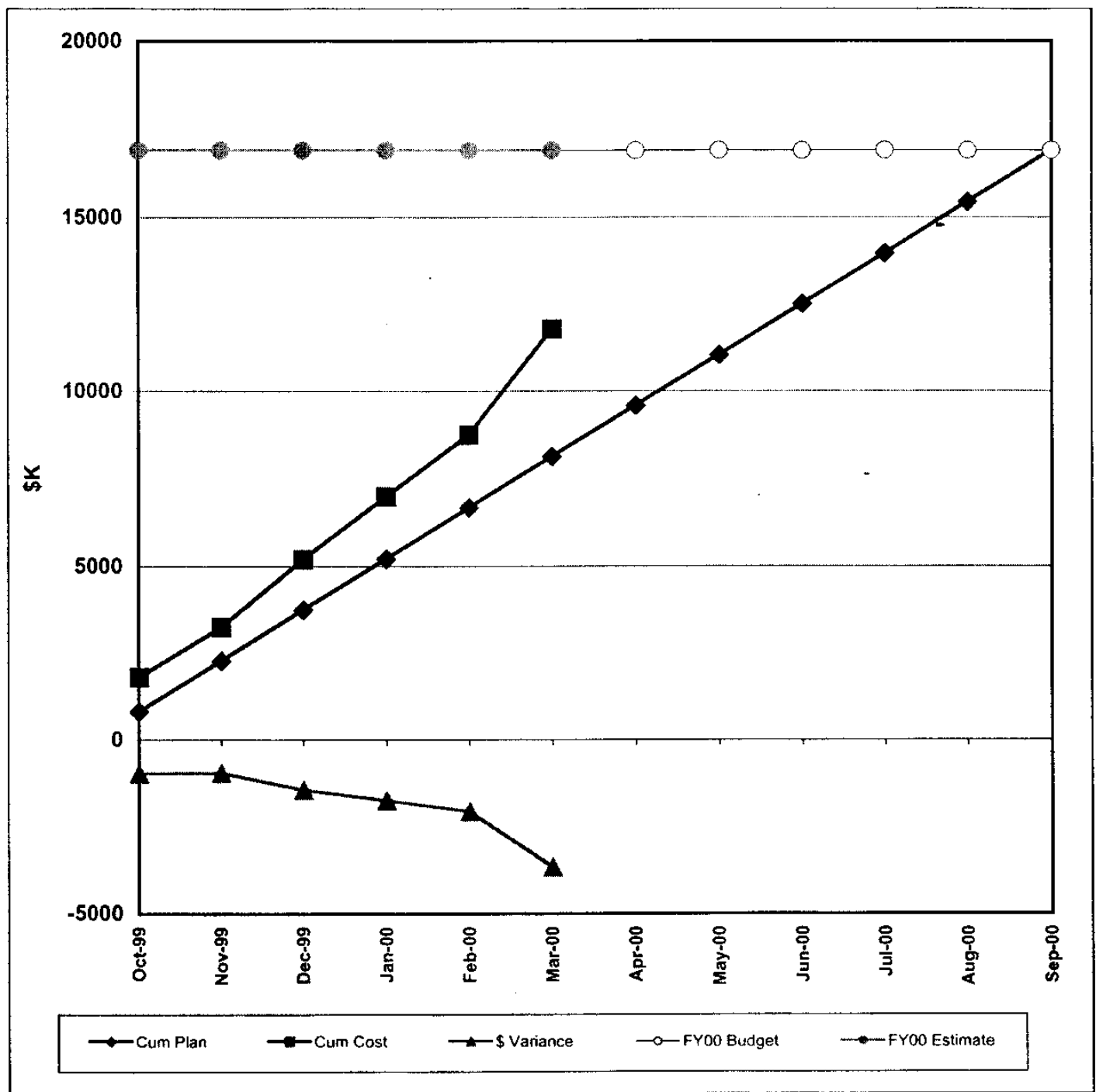

\begin{tabular}{|c|c|c|c|c|c|c|c|c|}
\hline \multirow[b]{2}{*}{ Month } & \multicolumn{2}{|c|}{ Monthly } & \multicolumn{4}{|c|}{ Cumulative } & \multirow{2}{*}{$\begin{array}{l}\text { FY2000 } \\
\text { Budget }\end{array}$} & \multirow{2}{*}{$\begin{array}{c}\text { FY2000 } \\
\text { Estimate }\end{array}$} \\
\hline & Planned & Actual & Planned & Actual & $\$$ Var & $\%$ Var & & \\
\hline Oct-98 & 821 & 1,812 & B21 & 1,812 & .991 & $-121 \%$ & 16,907 & 16,907 \\
\hline Nov-98 & 1,462 & 1,442 & 2,283 & 3,254 & -970 & $-42 \%$ & 16,907 & 16,907 \\
\hline Dec-98 & 1,462 & 1,943 & 3,746 & 5,197 & $-1,451$ & $-39 \%$ & 16,907 & 16,907 \\
\hline $\operatorname{Jan-99}$ & 1,462 & 1.780 & 5,208 & 6,978 & $-1,769$ & $-34 \%$ & 16,907 & 16.907 \\
\hline Feb-99 & 1,462 & 1,772 & 6,671 & 8,749 & $-2,079$ & $.31 \%$ & 16.907 & 16,907 \\
\hline Mar-99 & 1,462 & 3,058 & 8,133 & 11.807 & -3.674 & $-45 \%$ & 16.907 & 16,907 \\
\hline Apr -99 & 1,462 & & 9,595 & & & & 16,907 & \\
\hline May-99 & 1,462 & & 11,058 & & & & 16,907 & \\
\hline Jun-99 & 1,462 & & 12,520 & & & & 16,907 & \\
\hline$J u l-99$ & 1,462 & & 13,983 & & & & 16,907 & \\
\hline Aug.99 & 1,462 & & 15,445 & & & & 16.907 & \\
\hline Sep-99 & 1,462 & & 16,907 & & & & 16,907 & \\
\hline
\end{tabular}


DRAFT

FY2000 Cost and Commitment Plan to Actual as of March 2000

WBS 1.1 - Project Office (\$K)

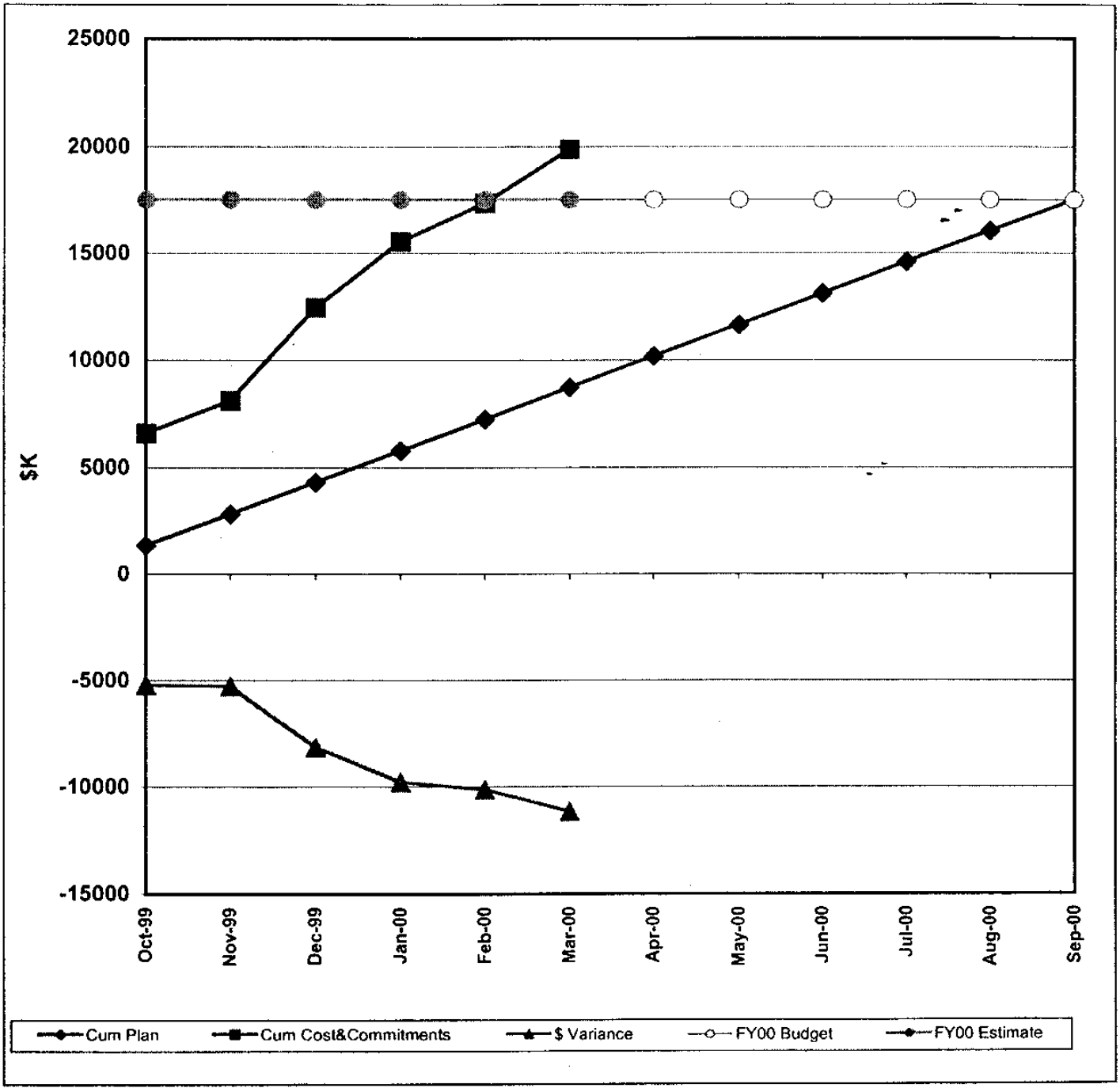

\begin{tabular}{|c|c|c|c|c|c|c|c|c|}
\hline \multirow[b]{2}{*}{ Month } & \multicolumn{2}{|c|}{ Monthly } & \multicolumn{4}{|c|}{ Cumulative } & \multirow{2}{*}{$\begin{array}{l}\text { FY2000: } \\
\text { Budget }\end{array}$} & \multirow{2}{*}{$\begin{array}{l}\text { FY2000 } \\
\text { Estlmate }\end{array}$} \\
\hline & Planned & Actual & Planned & Actual & $\$$ Var & $\%$ Var & & \\
\hline Oct -98 & $1,358^{*}$ & 6,571 & 1,358 & 6,571 & $-5,213$ & $-384 \%$ & 17,537 & 17,537 \\
\hline Nov-98 & 1,471 & 1,531 & 2,829 & 8,103 & $-5,274$ & $-186 \%$ & 17,537 & 17,537 \\
\hline$D e c-98$ & 1,471 & 4,346 & 4,300 & 12,449 & $-8,149$ & $-190 \%$ & 17.537 & 17,537 \\
\hline Jan-99 & 1,471 & 3,092 & 5,770 & 15,541 & $-9,771$ & $-169 \%$ & 17,537 & 17,537 \\
\hline Feb-99 & 1,471 & 1,830 & 7,241 & 17,371 & $-10,130$ & $-140 \%$ & 17.537 & 17,537 \\
\hline Mar-99 & 1,471 & 2,498 & 8,712 & 19,869 & $-11,157$ & $-128 \%$ & 17,537 & 17,537 \\
\hline Apr-99 & 1,471 & & 10,183 & & & & 17,537 & \\
\hline May-99 & 1,471 & & 11,654 & & & & 17,537 & \\
\hline Jun-99 & 1.471 & & 13,124 & & & & 17,537 & \\
\hline$J u l-9 g$ & 1,471 & & 14,595 & & & & 17,537 & \\
\hline Aug-9g & 1,471 & & 16,066 & & & & 17.537 & \\
\hline Sep-99 & 1,471 & & 17,537 & & & & 17,537 & \\
\hline
\end{tabular}

- Includes \$4,263K of uncosted obligations from FY99. 
Facilities Cost (\$K)

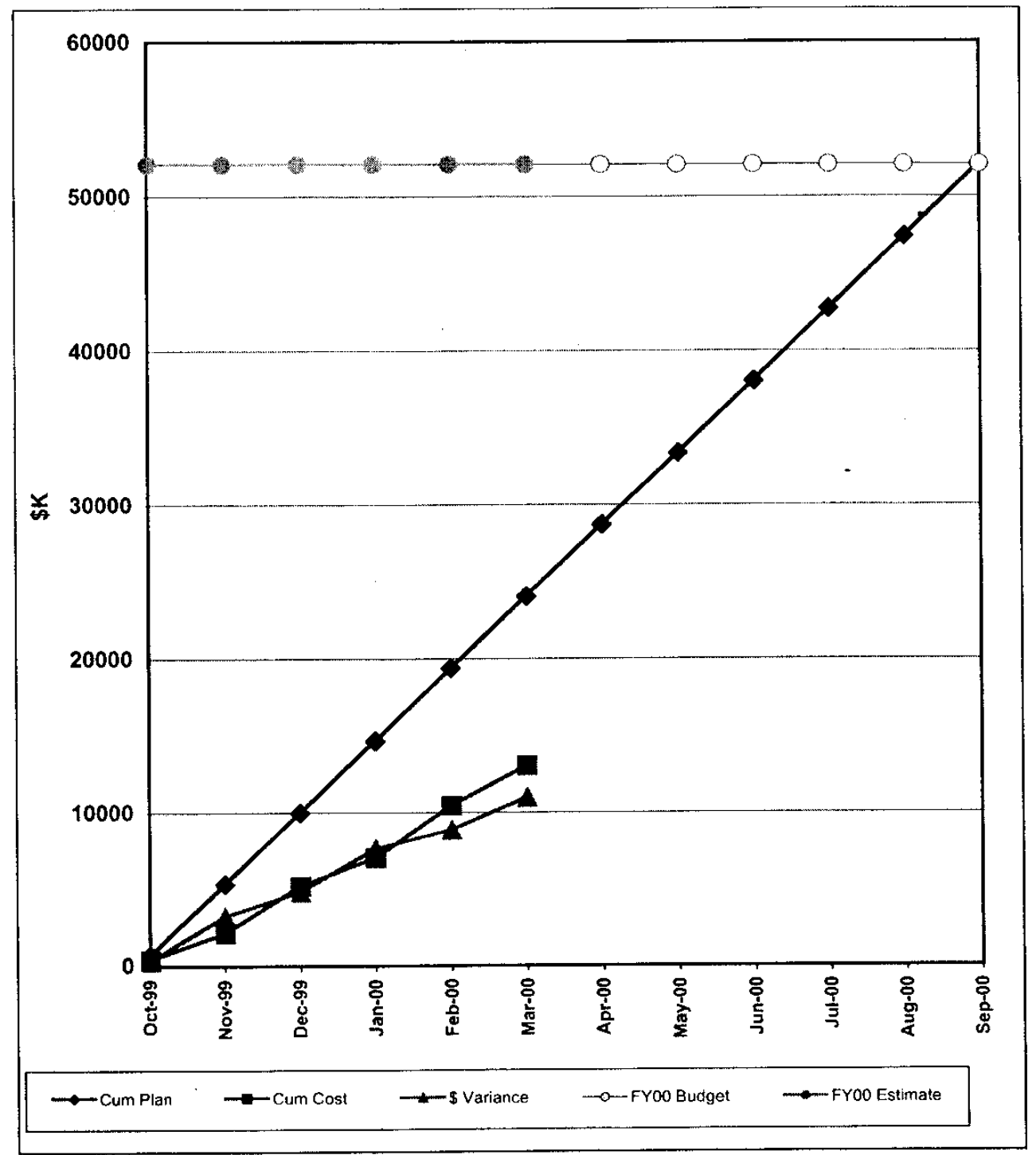

\begin{tabular}{|c|c|c|c|c|c|c|c|c|}
\hline \multirow[b]{2}{*}{ Month } & \multicolumn{2}{|c|}{ Monthly } & \multicolumn{4}{|c|}{ Cumulative } & \multirow{2}{*}{$\begin{array}{l}\text { FY2000 } \\
\text { Budget }\end{array}$} & \multirow{2}{*}{$\begin{array}{c}\text { FY2000 } \\
\text { Estimate }\end{array}$} \\
\hline & Planned & Actual & Planned & Actual & \$ Var & $\%$ Var & & \\
\hline Oct-98 & 664 & 363 & 664 & 363 & 301 & $45 \%$ & 52,090 & 52,090 \\
\hline Nov-98 & 4,675 & 1,767 & 5,339 & 2,130 & 3,209 & $60 \%$ & 52,090 & 52,090 \\
\hline Dec-98 & 4,675 & 3,057 & 10,014 & 5,187 & 4.827 & $48 \%$ & 52,090 & 52,090 \\
\hline Jan-99 & 4,675 & 1,852 & 14,689 & 7,040 & 7,650 & $52 \%$ & 52,090 & 52,090 \\
\hline$F e b-99$ & 4,675 & 3.442 & 19,364 & 10,481 & 8,883 & $46 \%$ & 52,090 & 52,090 \\
\hline Mar-99 & 4,675 & 2,567 & 24.040 & 13,048 & 10,991 & $46 \%$ & 52,090 & 52,090 \\
\hline Apr -99 & 4,675 & & 28,715 & & & & 52,090 & \\
\hline May-99 & 4,675 & & 33,390 & & & & 52,090 & \\
\hline Jun-99 & 4,675 & & 38,065 & & & & 52,090 & \\
\hline Jut-99 & 4,675 & & 42,740 & & & & 52,090 & \\
\hline Aug-99 & 4,675 & & 47,415 & & & & 52,090 & \\
\hline Sep-99 & 4,675 & & 52,090 & & & & 52,090 & \\
\hline
\end{tabular}


FY2000 Cost and Commitment Plan to Actual

DRAFT WBS 1.2 - Site and Conventional Facilities (\$K)

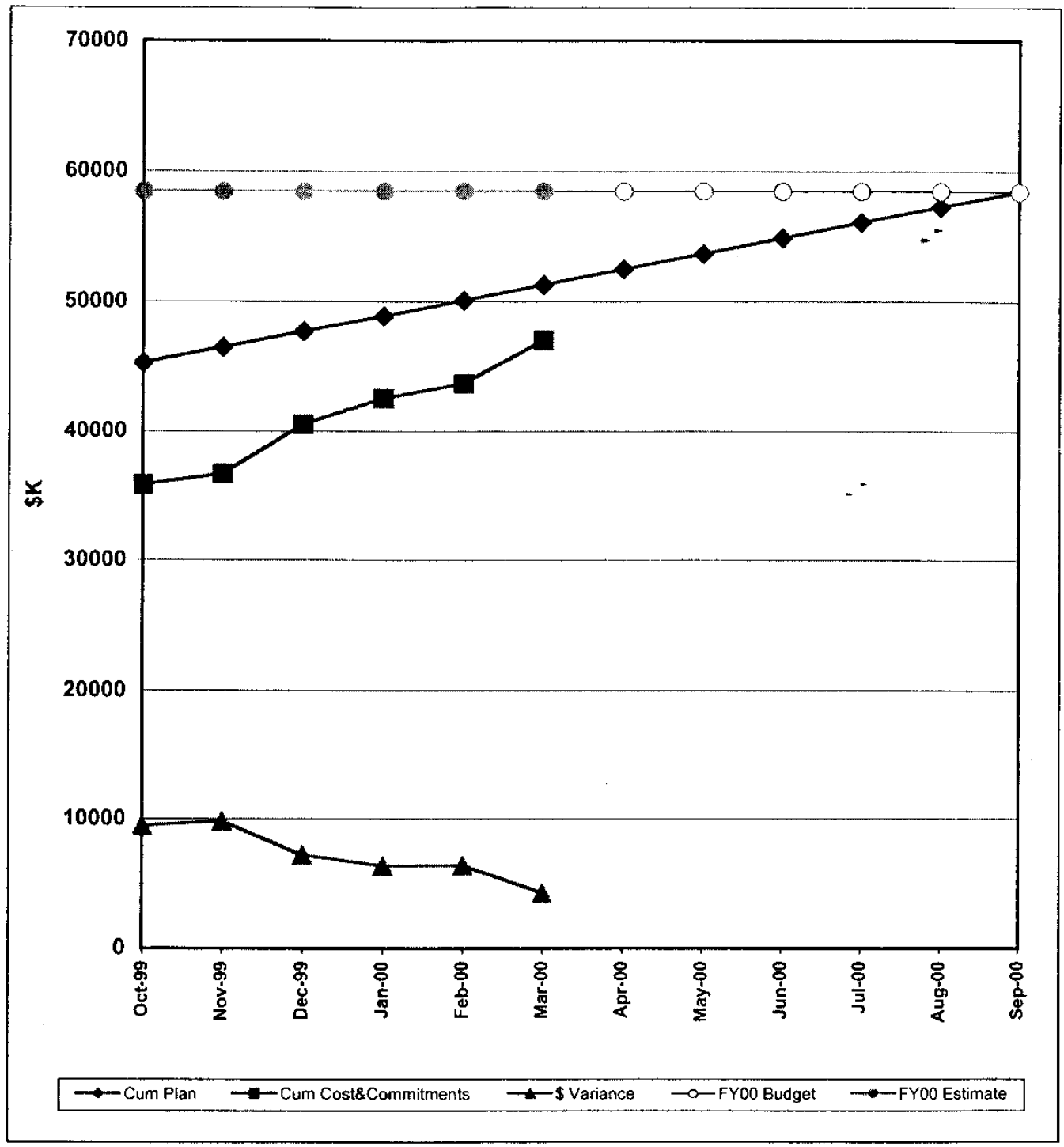

\begin{tabular}{|c|c|c|c|c|c|c|c|c|}
\hline \multirow[b]{2}{*}{ Month } & \multicolumn{2}{|c|}{ Monthly } & \multicolumn{4}{|c|}{ Cumulative } & \multirow{2}{*}{$\begin{array}{l}\text { FY2000 } \\
\text { Budget }\end{array}$} & \multirow{2}{*}{$\begin{array}{c}\text { FY2000 } \\
\text { Estimate }\end{array}$} \\
\hline & Planned & Actual & Planned & Actual & \$ Var & $\%$ Var & & \\
\hline $0 c t .98$ & $45,320^{*}$ & 35.825 & $45,320^{\circ}$ & 35,825 & 9,495 & $21 \%$ & 58,466 & 58,466 \\
\hline Nov-98 & 1,195 & 860 & 46,515 & 36,685 & 9,830 & $21 \%$ & 58,466 & 58,466 \\
\hline Dec-98 & 1,195 & 3,842 & 47,710 & 40,527 & 7,184 & $15 \%$ & 58,466 & 58,466 \\
\hline Jan-99 & 1,195 & 2,016 & 48,905 & 42,543 & 6,363 & $13 \%$ & 58,466 & 58,466 \\
\hline Feb.99 & 1,195 & 1,143 & 50,100 & 43,685 & 6,415 & $13 \%$ & 58,466 & 58,466 \\
\hline Mar-99 & 1,195 & 3,372 & 51.296 & 47,057 & 4,239 & $8 \%$ & 58,466 & 58,466 \\
\hline Apr-99 & 1,195 & & 52.491 & & & & 58,466 & \\
\hline May-99 & 1,195 & & 53.686 & & & & 58,466 & \\
\hline Jun-99 & 1,195 & & 54,881 & & & & 58,466 & \\
\hline$J u l-99$ & 1,195 & & 56,076 & & & & 58,466 & \\
\hline Aug.99 & 1,195 & & 57.271 & & & & 58,466 & \\
\hline Sep-99 & 1,195 & & 58,466 & & & & 58,466 & \\
\hline
\end{tabular}

- Includes $\$ 34,968 \mathrm{~K}$ of uncosted obligations from FY99. 
as of March 2000

WBS 1.3 - Lasers Systems (\$K)

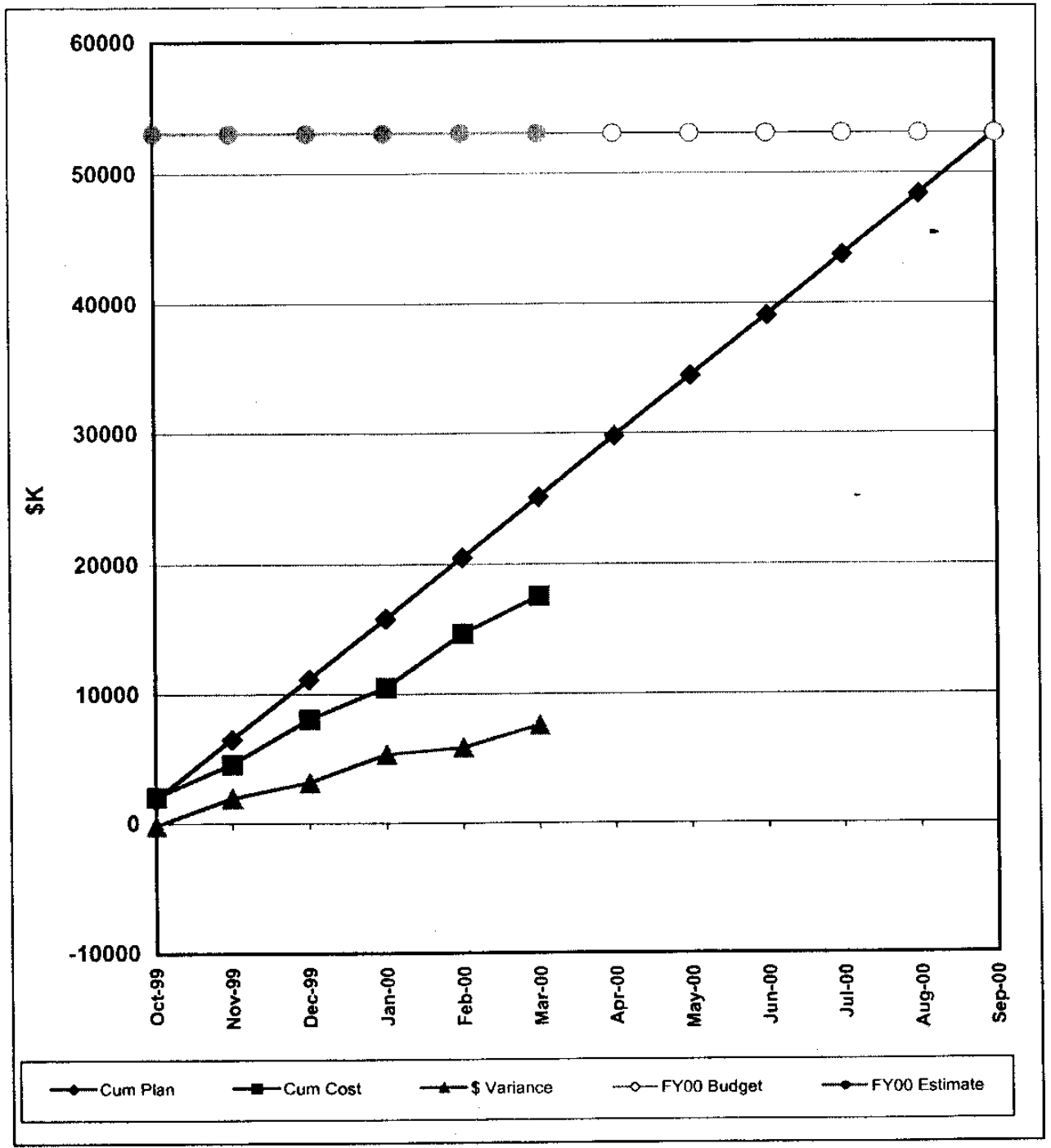

\begin{tabular}{|c|c|c|c|c|c|c|c|c|}
\hline \multirow[b]{2}{*}{ Month } & \multicolumn{2}{|c|}{ Monthly } & \multicolumn{4}{|c|}{ Cumulative } & \multirow{2}{*}{$\begin{array}{l}\text { FY2000 } \\
\text { Budget }\end{array}$} & \multirow{2}{*}{$\begin{array}{c}\text { FY2000 } \\
\text { Estimate }\end{array}$} \\
\hline & Planned & Actual & Planned & Actual & $\$$ Var & $\%$ Var & & \\
\hline $0 c t-98$ & 1,849 & 2,050 & 1,849 & 2,050 & -201 & $-11 \%$ & 53,083 & 53,083 \\
\hline Nov-98 & 4,658 & 2,517 & 6,507 & 4,567 & 1,939 & $30 \%$ & 53.083 & 53,083 \\
\hline$D e c-98$ & 4,658 & 3,455 & 11,164 & 8,023 & 3,142 & $28 \%$ & 53,083 & 53,083 \\
\hline Jan-99 & $4,65.8$ & 2,463 & 15,822 & 10,485 & 5,336 & $34 \%$ & 53,083 & 53,083 \\
\hline Feb-99 & 4,658 & 4,157 & 20,479 & 14,642 & 5,837 & $29 \%$ & 53,083 & 53,083 \\
\hline Mar-99 & 4,658 & 2,904 & 25,137 & 17,546 & 7,591 & $30 \%$ & 53,083 & 53,083 \\
\hline Apr-99 & 4,658 & & 29,795 & & & & 53,083 & \\
\hline May-99 & 4,658 & & 34,452 & & & & 53,083 & \\
\hline Jun-99 & 4,658 & & 39,110 & & & & 53,083 & \\
\hline Jul-9g & 4,658 & & 43,767 & & & & 53,083 & \\
\hline Aug. 99 & 4,658 & & 48,425 & & & & 53,083 & \\
\hline Sep-99 & 4,658 & & 53,083 & & & & 53.083 & \\
\hline
\end{tabular}


FY2000 Cost and Commitment Plan to Actual

as of March 2000

DRAFT

WBS 1.3 - Lasers Systems (\$K)
Project Number 96-D-111

March 2000

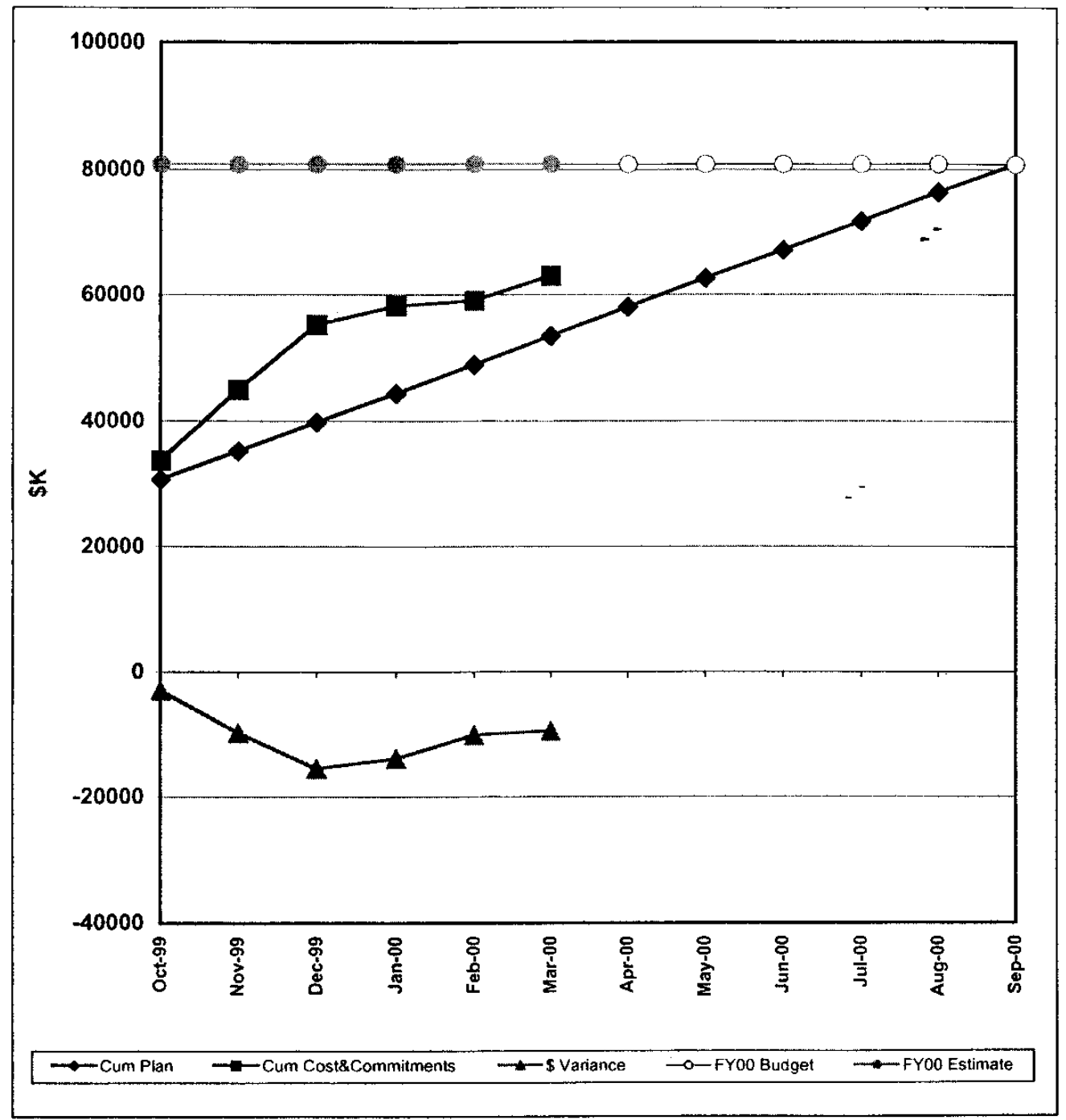

\begin{tabular}{|c|c|c|c|c|c|c|c|c|}
\hline \multirow[b]{2}{*}{ Month } & \multicolumn{2}{|c|}{ Monthly } & \multicolumn{4}{|c|}{ Cumulative } & \multirow{2}{*}{$\begin{array}{l}\text { Fr2000 } \\
\text { Budget }\end{array}$} & \multirow{2}{*}{$\begin{array}{l}\text { Fr2000 } \\
\text { Estimate }\end{array}$} \\
\hline & Planned & Actual & Planned & Actual & \$Var & $\%$ Var & & \\
\hline Oct -98 & $30,66.1$ & 33,683 & $30,661 *$ & 33,683 & $-3,022$ & $-10 \%$ & 80,840 & 80.840 \\
\hline Nov -98 & 4,562 & 11,269 & 35,223 & 44,952 & $.9,729$ & $-28 \%$ & 80.840 & 80.840 \\
\hline Dec- 98 & 4,562 & 10,316 & 39.784 & 55,268 & $-15,484$ & $-39 \%$ & 80,840 & 80.840 \\
\hline $\operatorname{Jan-99}$ & 4,562 & 2,990 & 44,346 & 58,259 & $-13,912$ & $-31 \%$ & 80,840 & 80,840 \\
\hline$F_{e b-99}$ & 4,562 & 775 & 48,908 & 59,033 & $-10,125$ & $-21 \%$ & 80,840 & 80,840 \\
\hline Mar-99 & 4,562 & 3,947 & 53,470 & 62,980 & $-9,511$ & $-18 \%$ & 80,840 & 80,840 \\
\hline Apr -99 & 4,562 & & 58,031 & & & & 80,840 & \\
\hline May.99 & 4,562 & & 62,593 & & & & 80,840 & \\
\hline Jun-99 & 4,562 & & 67,155 & & & & 80,840 & \\
\hline Jul-gg & 4,562 & & 71,716 & & & & 80,840 & \\
\hline$A u g-99$ & 4,562 & & 76,278 & & & & 80,840 & \\
\hline Sep.99 & 4,562 & & 80,840 & & & & 80,840 & \\
\hline
\end{tabular}

- includes $\$ 25,645 \mathrm{~K}$ of uncosted obligations from FY99. 


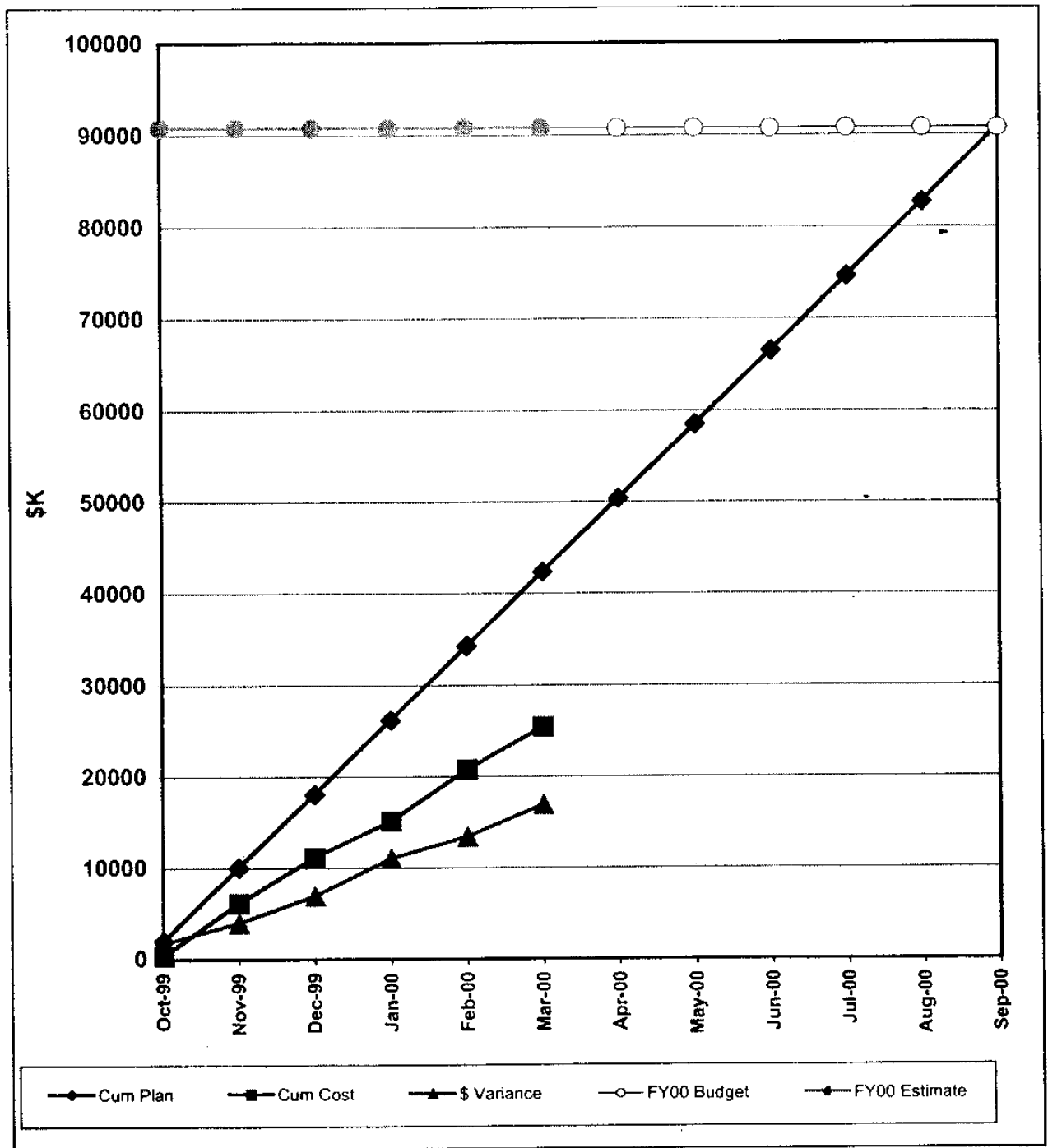

\begin{tabular}{|c|c|c|c|c|c|c|c|c|}
\hline \multirow[b]{2}{*}{ Month } & \multicolumn{2}{|c|}{ Monthly } & \multicolumn{4}{|c|}{ Cumulative } & \multirow{2}{*}{$\begin{array}{l}\text { FY2000 } \\
\text { Budget }\end{array}$} & \multirow{2}{*}{$\begin{array}{l}\text { FY2000 } \\
\text { Estlmate }\end{array}$} \\
\hline & Planned & Actual & Planned & Actual & $\$$ Var & $\%$ Var & & \\
\hline Oct-99 & 1.993 & 312 & 1,993 & 312 & 1,681 & $84 \%$ & 90,764 & 90,764 \\
\hline Nov-99 & 8,070 & 5,793 & 10,063 & 6,106 & 3,957 & $39 \%$ & 90,764 & 90,764 \\
\hline Dec-99 & 8,070 & 5,116 & 18,133 & 11,222 & 6,912 & $38 \%$ & 90.764 & 90,764 \\
\hline $\operatorname{Jan}-00$ & 8,070 & 3,928 & 26,203 & 15,150 & 11.054 & $42 \%$ & 90,764 & 90,764 \\
\hline Feb-0o & 8,070 & 5,692 & 34,273 & 20,842 & 13,431 & $39 \%$ & 90,764 & 90,764 \\
\hline Mar-00 & 8,070 & 4,586 & 42,344 & 25,428 & 16,915 & $40 \%$ & 90,764 & 90,764 \\
\hline Apr -00 & 8,070 & & 50,414 & & & & 90,764 & \\
\hline May -00 & 8,070 & & 58,484 & & & & 90,764 & \\
\hline Jun-00 & 8,070 & & 66,554 & & & & 90,764 & \\
\hline$J u l-00$ & 8,070 & & 74,624 & & & & 90,764 & \\
\hline Aug.00 & 8,070 & & 82,694 & & & & 90,764 & \\
\hline Sep-00 & 8.070 & & 90,764 & & & & 90,764 & \\
\hline
\end{tabular}


FY2000 Cost and Commitment Plan to Actual as of March 2000

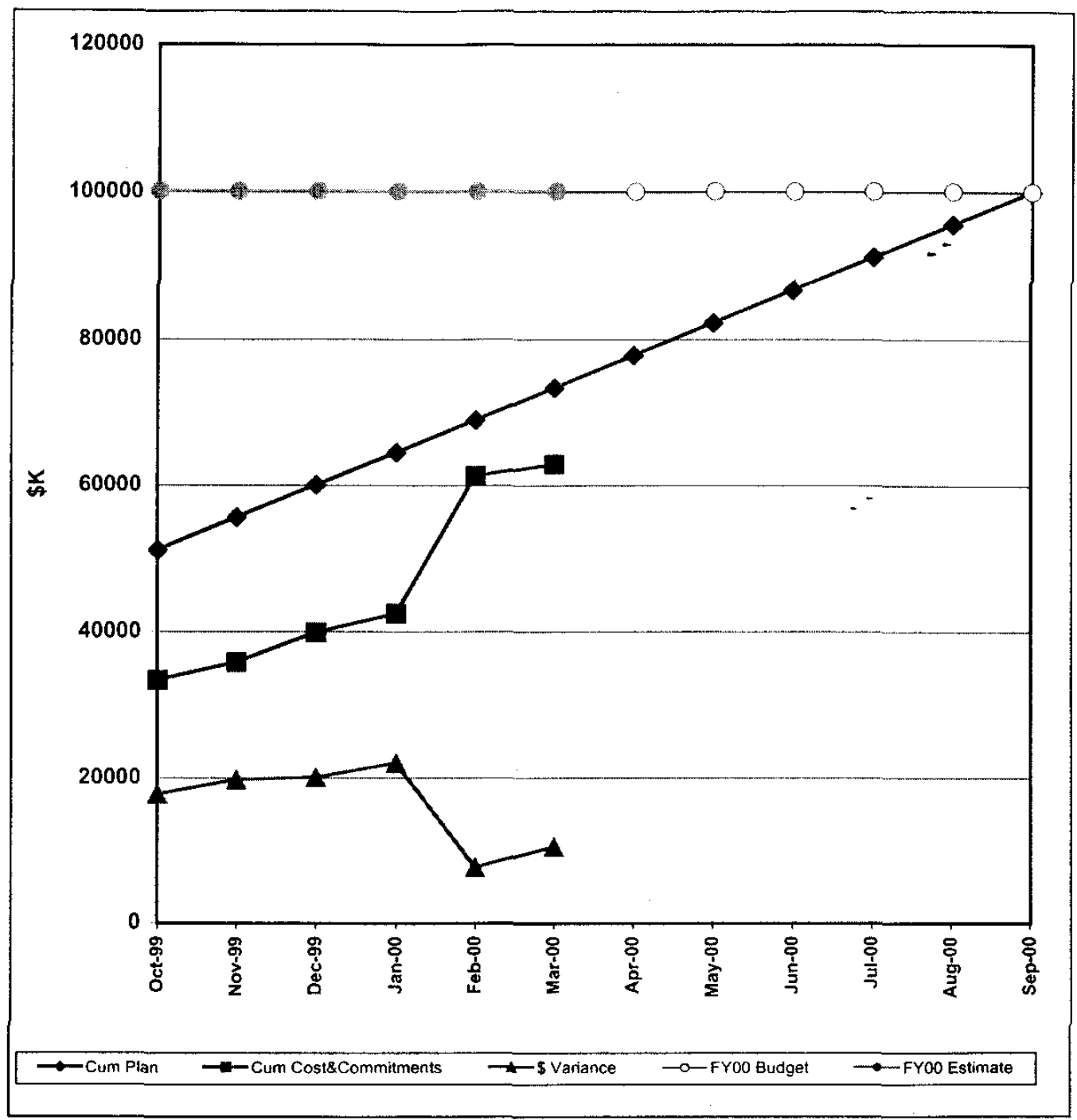

\begin{tabular}{|c|c|c|c|c|c|c|c|c|}
\hline \multirow[b]{2}{*}{ Month } & \multicolumn{2}{|c|}{ Monthly } & \multicolumn{4}{|c|}{ Cumulative } & \multirow{2}{*}{$\begin{array}{l}\text { FY2000 } \\
\text { Budget }\end{array}$} & \multirow{2}{*}{$\begin{array}{l}\text { Fr2000 } \\
\text { Estimate }\end{array}$} \\
\hline & Planned & Actual & Planned & Actual & $\$$ Var & $\%$ Var & & \\
\hline Oct-99 & 51,134 & 33,394 & $51,134^{\circ}$ & 33,394 & 17,740 & $35 \%$ & 100,106 & 100,106 \\
\hline Nov-99 & 4,452 & 2,457 & 55,586 & 35,850 & 19.736 & $36 \%$ & 100,106 & 100,106 \\
\hline Dec-99 & 4,452 & 4,109 & 60,038 & 39,960 & 20,078 & $33 \%$ & 100,106 & 100,106 \\
\hline Jan-OO & 4,452 & 2,535 & $64 ; 490$ & 42,495 & 21,995 & $34 \%$ & 100,106 & 100,106 \\
\hline$F e b-O O$ & 4,452 & 18,832 & 68,942 & 61,327 & 7,615 & $11 \%$ & 100,106 & 100,106 \\
\hline Mar.00 & 4,452 & 1,602 & 73,394 & 62,929 & 10,465 & $14 \%$ & 100,106 & 100,106 \\
\hline Apr-00 & 4,452 & & 77,846 & & & & 100,106 & \\
\hline May-00 & 4,452 & & 82,298 & & & & 100,106 & \\
\hline Jun-00 & 4,452 & & 86,750 & & & & 100,106 & \\
\hline Jul-00 & 4,452 & & 91,202 & & & & 100,106 & \\
\hline Aug-00 & 4,452 & & 95,654 & & & & 100,106 & \\
\hline Sep-00 & 4,452 & & 100,106 & & & & 100,106 & \\
\hline
\end{tabular}

\footnotetext{
- Includes $\$ 34,782 \mathrm{~K}$ of uncosted obligations from FY99.
} 
FY2000 Cost Plan to Actual

as of March 2000

DRAFT

WBS 1.5 - Integrated Computer Control (\$K)
Project Number 96-0-111 March 2000

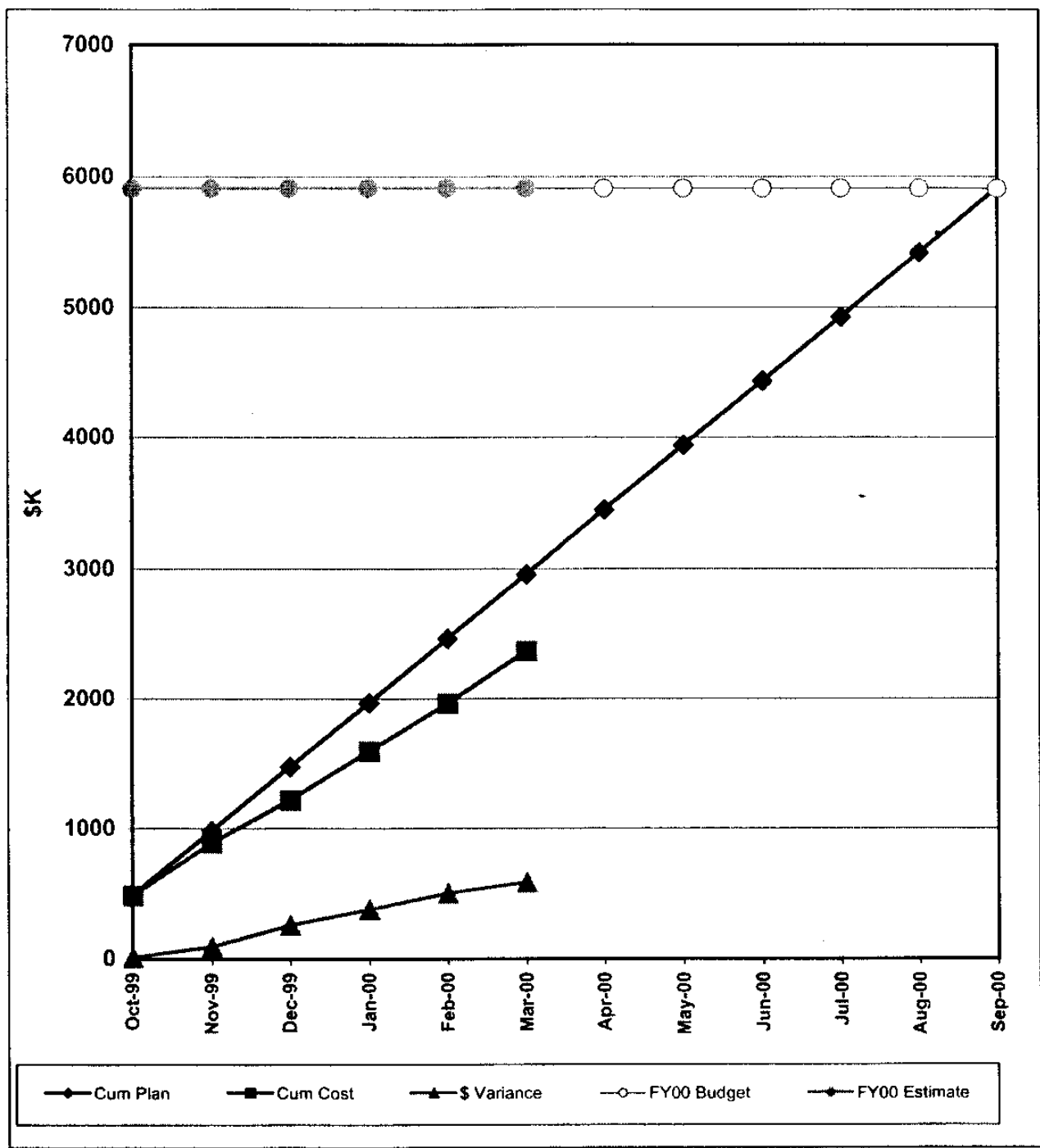

\begin{tabular}{|c|c|c|c|c|c|c|c|c|}
\hline \multirow[b]{2}{*}{ Month } & \multicolumn{2}{|c|}{ Monthly } & \multicolumn{4}{|c|}{ Cumulative } & \multirow{2}{*}{$\begin{array}{l}\text { FY2000 } \\
\text { Budget }\end{array}$} & \multirow{2}{*}{$\begin{array}{c}\text { FY2000 } \\
\text { Estimate }\end{array}$} \\
\hline & Planned & Actual & Planned & Actual & $\$$ Var & $\%$ Var & & \\
\hline Oct-99 & 489 & 482 & 489 & 482 & 7 & $1 \%$ & 5,914 & 5,914 \\
\hline Nov-99 & 493 & 407 & 982 & 889 & 93 & $10 \%$ & 5,914 & 5,914 \\
\hline$D e c-99$ & 493 & 328 & 1,475 & 1,217 & 258 & $17 \%$ & 5,914 & 5,914 \\
\hline Jan-00 & 493 & 374 & 1,969 & 1,591 & 377 & $19 \%$ & $5,9+4$ & 5,914 \\
\hline$F_{\Theta b}-O O$ & 493 & 369 & 2,462 & 1,960 & 502 & $20 \%$ & 5,914 & 5.914 \\
\hline Mar-00 & 493 & 409 & 2.955 & 2,369 & 586 & $20 \%$ & 5.914 & 5,914 \\
\hline Apr-OO & 493 & & 3,448 & & & & 5,914 & \\
\hline May-00 & 493 & & 3,941 & & & & 5,914 & \\
\hline Jun-00 & 493 & & 4,435 & & & & 5.914 & \\
\hline$J u l-00$ & 493 & & 4,928 & & & & 5,914 & \\
\hline Aug -00 & 493 & & 5.421 & & & & 5,914 & \\
\hline Sep-00 & 493 & & 5,914 & & & & 5,914 & \\
\hline
\end{tabular}




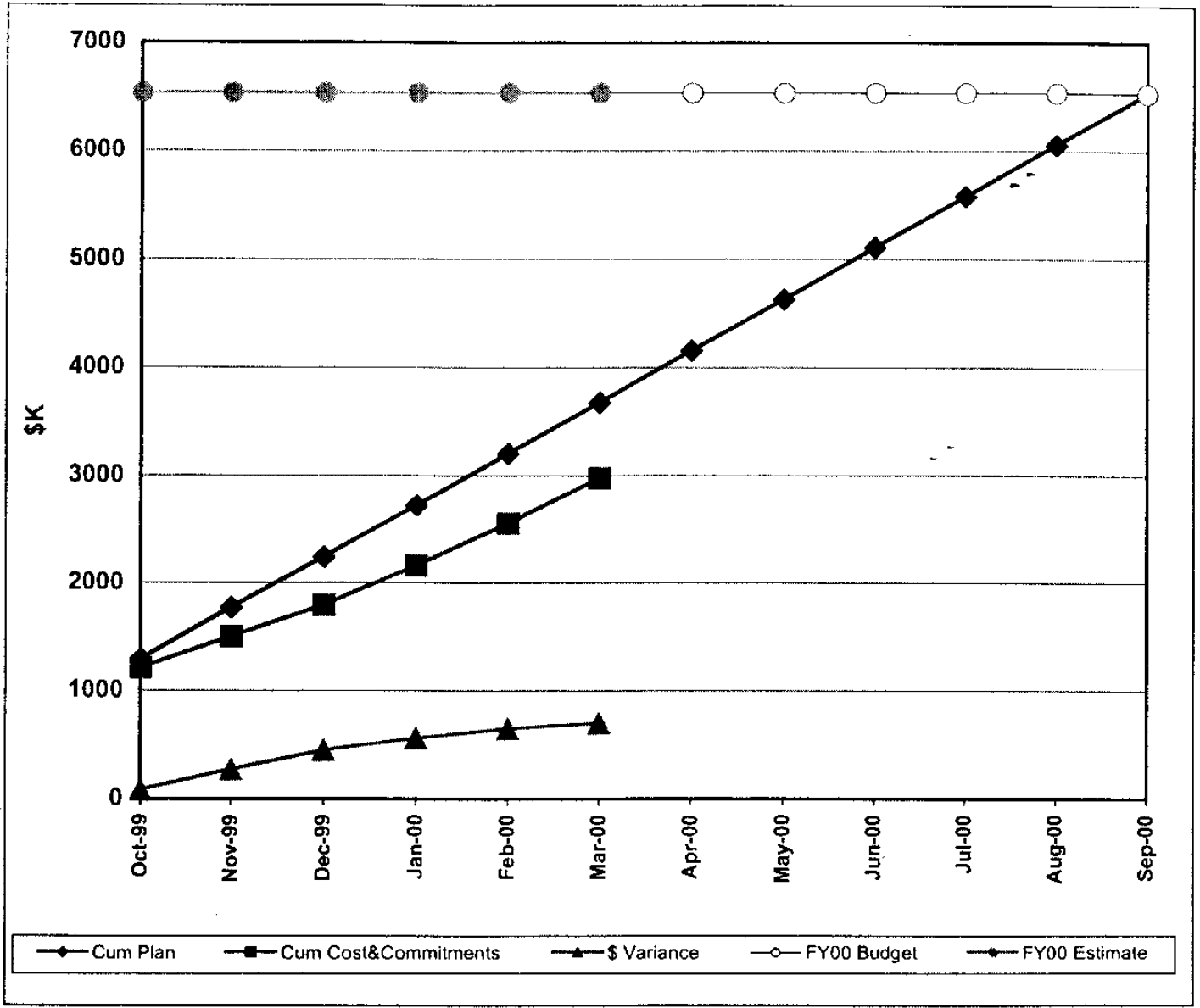

\begin{tabular}{|c|c|c|c|c|c|c|c|c|}
\hline \multirow[b]{2}{*}{ Month } & \multicolumn{2}{|c|}{ Monthly } & \multicolumn{4}{|c|}{ Cumulative } & \multirow{2}{*}{$\begin{array}{l}\text { FY2000 } \\
\text { Budget }\end{array}$} & \multirow{2}{*}{$\begin{array}{c}\text { FY2000 } \\
\text { Estimate }\end{array}$} \\
\hline & Planned & Actual & Planned & Actual & $\$$ Var & $\%$ Var & & \\
\hline Oct-99 & $1,294 *$ & 1,211 & $1,294^{*}$ & 1,211 & 83 & $6 \%$ & 6,536 & 6,536 \\
\hline Nov-99 & 477 & 287 & 1,771 & 1,498 & 273 & $15 \%$ & 6,536 & 6.536 \\
\hline Dec-99 & 477 & 299 & 2,247 & 1,797 & 450 & $20 \%$ & 6,536 & 6,536 \\
\hline Jan-00 & 477 & 369 & 2,724 & 2,166 & 557 & $20 \%$ & 6,536 & 6,536 \\
\hline$F e b-00$ & 477 & 388 & 3,200 & 2,554 & 646 & $20 \%$ & 6,536 & 6,536 \\
\hline Mar-00 & 477 & 422 & 3,677 & 2,976 & 701 & $19 \%$ & 6,536 & 6.536 \\
\hline Apr -00 & 477 & & 4.153 & & & & 6,536 & \\
\hline May-0O & 477 & & 4,630 & & & & 6,536 & \\
\hline Jun-00 & 477 & & 5,106 & & & & 6,536 & \\
\hline Jul.00 & 477 & & 5.583 & & & & 6.536 & \\
\hline Aug-00 & 477 & & 6,059 & & & & 6,536 & \\
\hline Sep-00 & 477 & & 6,536 & & & & 6,536 & \\
\hline
\end{tabular}

\footnotetext{
- Includes $\$ 750 \mathrm{~K}$ of uncosted obligations from FY99.
} 
FY2000 Cost Plan to Actual

as of March 2000

WBS 1.6 - Optical Components (\$K)

DRAFT

Project Number 96-D-111 March 2000

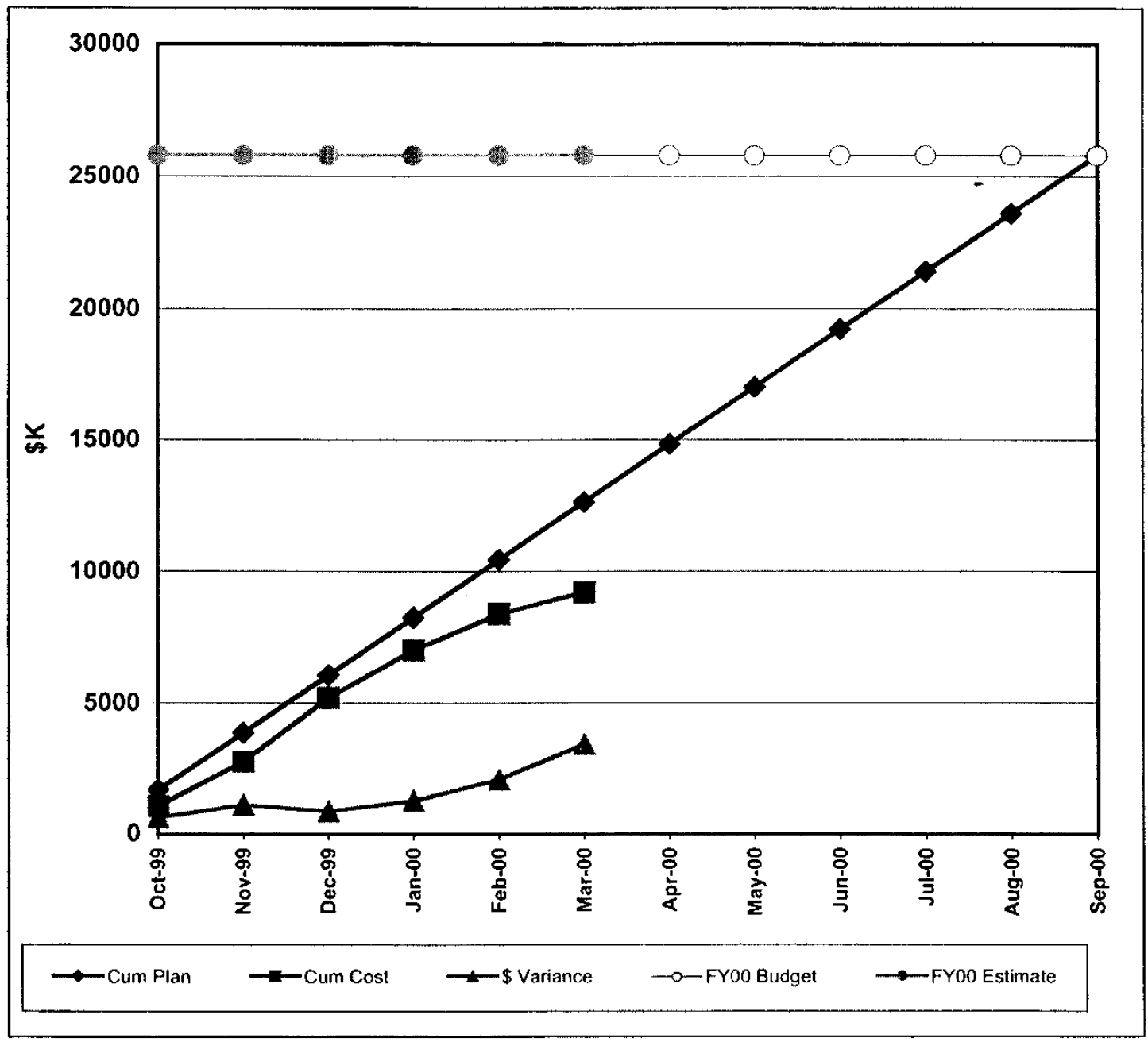

\begin{tabular}{|c|c|c|c|c|c|c|c|c|}
\hline \multirow[b]{2}{*}{ Month } & \multicolumn{2}{|c|}{ Monthly } & \multicolumn{4}{|c|}{ Cumulative } & \multirow{2}{*}{$\begin{array}{l}\text { FY2000 } \\
\text { Budget }\end{array}$} & \multirow{2}{*}{$\begin{array}{l}\text { FY2000 } \\
\text { Estimate }\end{array}$} \\
\hline & Planned & Actual & Planned & Actual & \$ Var & $\%$ Var & & \\
\hline Oct-99 & 1,681 & 1,067 & 1,681 & 1,067 & 614 & $37 \%$ & 25,798 & 25,798 \\
\hline Nov-99 & 2,192 & 1,704 & 3,873 & 2,771 & 1,102 & $28 \%$ & 25,798 & 25.798 \\
\hline Dec-99 & 2,193 & 2,422 & 6,066 & 5,193 & 873 & $14 \%$ & 25,798 & 25,798 \\
\hline Jan-0O & 2,193 & 1,810 & 8,258 & 7,003 & 1,255 & $15 \%$ & 25,798 & 25,798 \\
\hline $\mathrm{Feb}-00$ & 2,193 & 1,377 & 10.451 & 8,380 & 2,071 & $20 \%$ & 25,798 & 25,798 \\
\hline Mar $=00$ & 2,193 & 824 & 12,643 & 9,204 & 3,439 & $27 \%$ & 25,798 & 25,798 \\
\hline Apr-OO & 2,193 & & 14,836 & & & & 25,798 & \\
\hline May-oo & 2,193 & & 17,028 & & & & 25,798 & \\
\hline Jun-OO & 2,193 & & 19,221 & & & & 25,798 & \\
\hline$J u l-00$ & 2,193 & & 21.413 & & & & 25,798 & \\
\hline Aug-OO & 2,193 & & 23,606 & & & & 25,798 & \\
\hline Sep-00 & 2,193 & & 25,798 & & & & 25,798 & \\
\hline
\end{tabular}


FY2000 Cost and Commitment Plan to Actual

as of March 2000

WBS 1.6 - Optical Components (\$K)

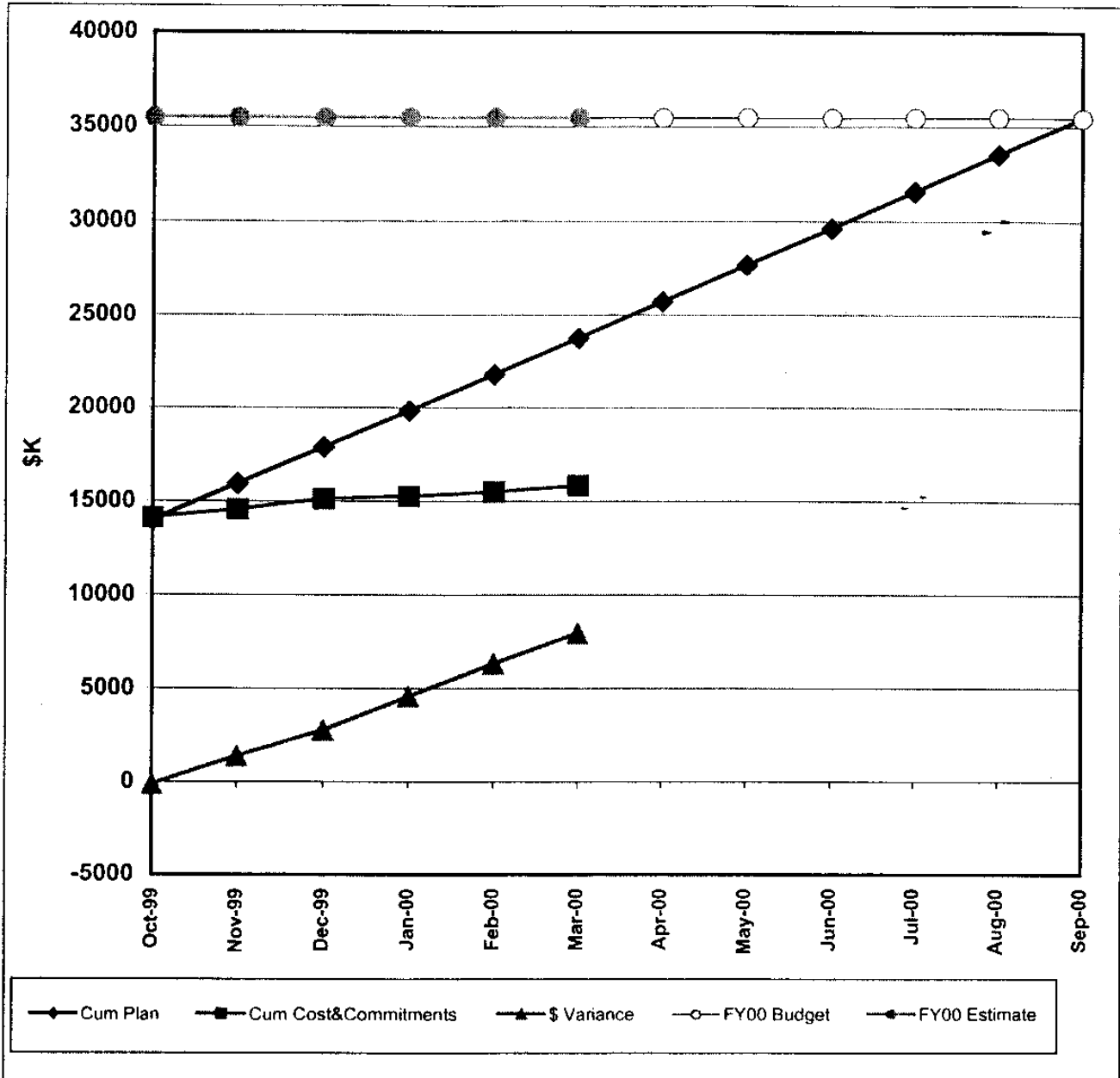

\begin{tabular}{|c|c|c|c|c|c|c|c|c|}
\hline \multirow[b]{2}{*}{ Month } & \multicolumn{2}{|c|}{ Monthly } & \multicolumn{4}{|c|}{ Cumulative } & \multirow{2}{*}{$\begin{array}{l}\text { Fr2000 } \\
\text { Budget }\end{array}$} & \multirow{2}{*}{$\begin{array}{l}\text { FY2000 } \\
\text { Estimate }\end{array}$} \\
\hline & Planned & Actual & Planned & Actual & \$ Var & $\%$ Var & & \\
\hline Oct-99 & $13,984^{*}$ & 14,124 & $13,984^{*}$ & 14,124 & -140 & $-1 \%$ & 35,473 & 35,473 \\
\hline Nov -99 & 1,954 & 441 & 15,938 & 14,565 & 1,373 & $9 \%$ & 35,473 & 35,473 \\
\hline Dec-99 & 1,954 & 570 & $17,89 t$ & 15,135 & 2,756 & $15 \%$ & 35,473 & 35,473 \\
\hline Jan-00 & 1,954 & 131 & 19,845 & 15,266 & 4,579 & $23 \%$ & 35,473 & 35,473 \\
\hline$F a b \cdot 00$ & 1.954 & 223 & 21,798 & 15,489 & 6,309 & $29 \%$ & 35,473 & 35,473 \\
\hline Mar-00 & 1,954 & 326 & 23,752 & 15,815 & 7,937 & $33 \%$ & 35,473 & 35,473 \\
\hline Apr-DO & 1,954 & & 25,705 & & & & 35,473 & \\
\hline May-OO & 1,954 & & 27,659 & & & & 35,473 & \\
\hline Jun-00 & 1,954 & & 29,612 & & & & 35,473 & \\
\hline$J u t-00$ & 1,954 & & 31,566 & & & & 35,473 & \\
\hline Aug-OO & 1,954 & & 33,519 & & & & 35,473 & \\
\hline Sep-00 & 1,954 & & 35,473 & & & & 35.473 & \\
\hline
\end{tabular}

\footnotetext{
- Includes $\$ 12,620 \mathrm{~K}$ of uncosted obligations from FY99.
} 


\section{DRAFT}

FY2000 Cost Plan to Actual as of March 2000 WBS 1.7 - Laser Control (\$K)
Project Number 96-D- 111 March 2000

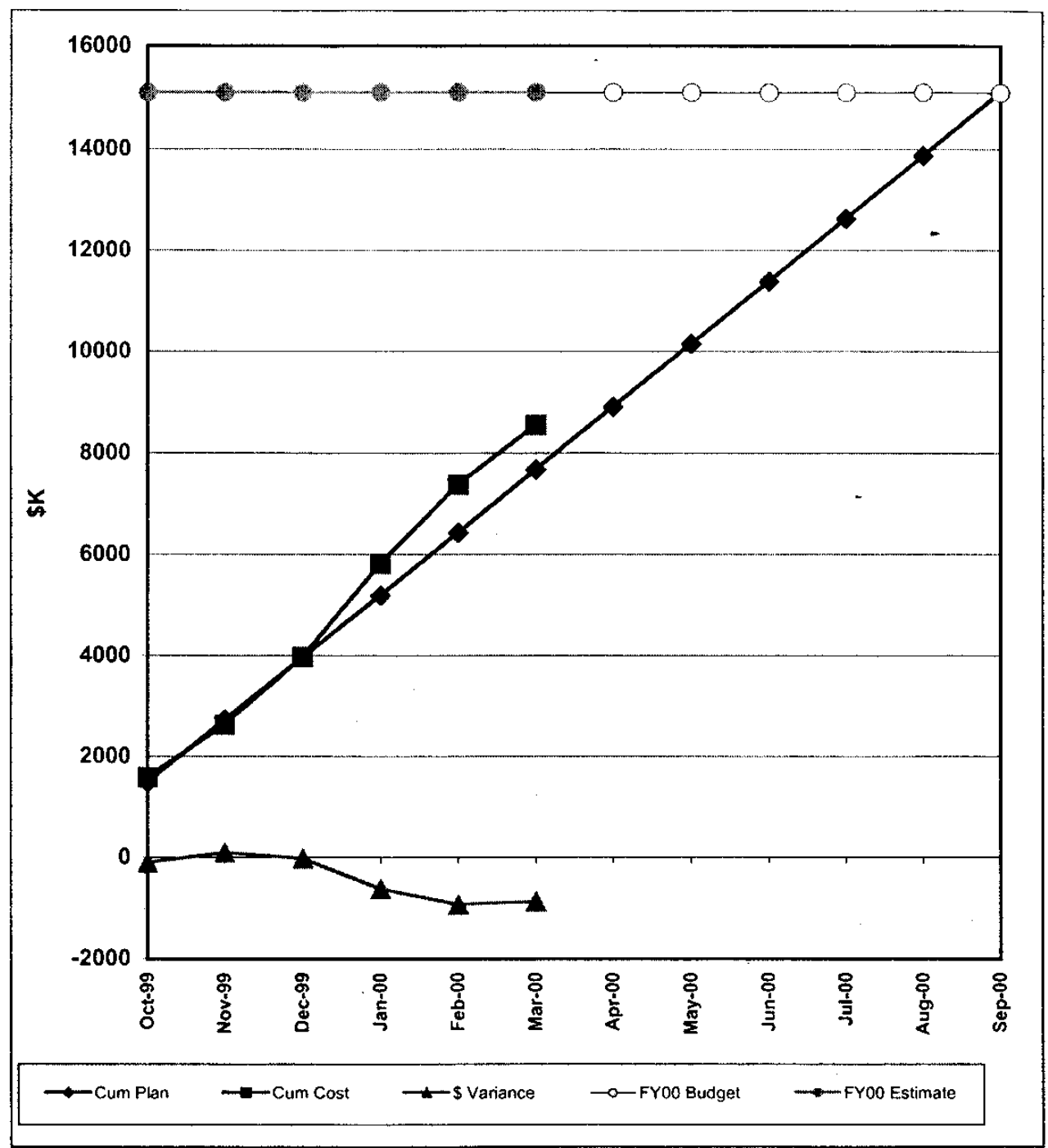

\begin{tabular}{|c|c|c|c|c|c|c|c|c|}
\hline \multirow[b]{2}{*}{ Month } & \multicolumn{2}{|c|}{ Monthly } & \multicolumn{4}{|c|}{ Cumulative } & \multirow{2}{*}{$\begin{array}{l}\text { FY2000 } \\
\text { Budget }\end{array}$} & \multirow{2}{*}{$\begin{array}{c}\text { FY2000 } \\
\text { Estimate }\end{array}$} \\
\hline & Planned & Actual & Planned & Actual & $\$$ Var & $\%$ Var & & \\
\hline Oct-99 & 1,483 & 1,582 & 1,483 & 1,582 & -99 & $-7 \%$ & 15,103 & 15,103 \\
\hline Nov.99 & 1,238 & 1,042 & 2,721 & 2,625 & 97 & $4 \%$ & 15,103 & 15,103 \\
\hline Dec.99 & 1,238 & 1,351 & 3,959 & 3,976 & -17 & $0 \%$ & 15,103 & 15,103 \\
\hline Jan-0O & 1,238 & 1,851 & 5,198 & 5,827 & -629 & $-12 \%$ & 15,103 & 15,103 \\
\hline Feb-oo & 1,238 & 1,547 & 6,436 & 7,374 & -938 & $-15 \%$ & 15,103 & 15,103 \\
\hline Mar-oo & 1,238 & 1,176 & 7,674 & 8,550 & -876 & $-11 \%$ & 15,103 & 15,103 \\
\hline Apr-OO & 1,238 & & 8,912 & & & & 15,103 & \\
\hline May-0o & 1,238 & & 10,150 & & & & 15,103 & \\
\hline Jun-oo & 1,238 & & 11,389 & & & & 15,103 & \\
\hline Jut-0O & 1,238 & & 12,627 & & & & 15,103 & \\
\hline Aug-00 & 1.238 & & 13,865 & & & & 15,103 & \\
\hline Sep-00 & 1,238 & & 15,103 & & & & 15,103 & \\
\hline
\end{tabular}


FY2000 Cost and Commitment Plan to Actual as of March 2000

WBS 1.7 - Laser Control (\$K)

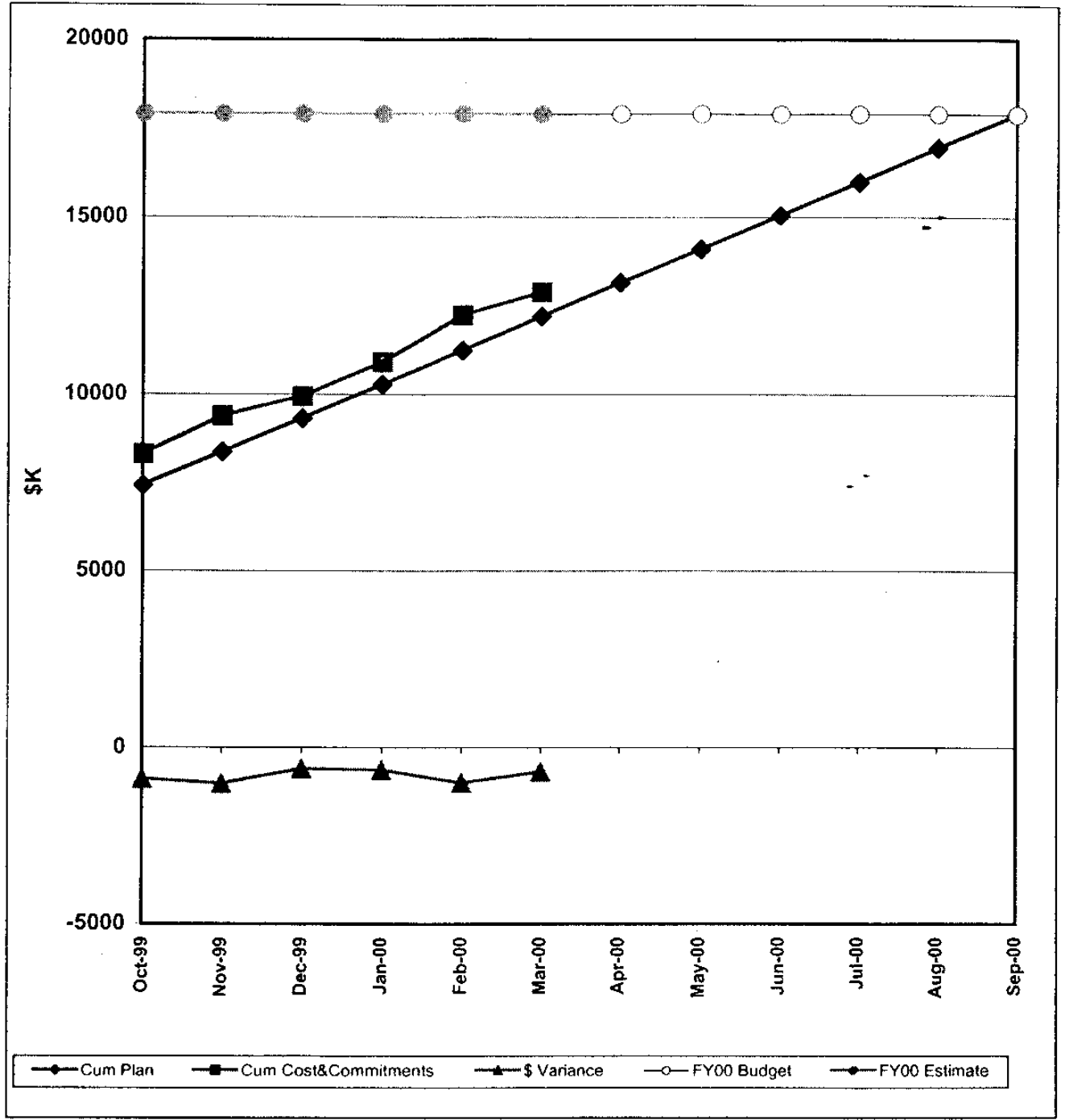

\begin{tabular}{|c|c|c|c|c|c|c|c|c|}
\hline \multirow[b]{2}{*}{ Month } & \multicolumn{2}{|c|}{ Monthly } & \multicolumn{4}{|c|}{ Cumulative } & \multirow{2}{*}{$\begin{array}{l}\text { FY2000 } \\
\text { Budget }\end{array}$} & \multirow{2}{*}{$\begin{array}{c}\text { FY2000 } \\
\text { Estimate }\end{array}$} \\
\hline & Planned & Actual & Planned & Actual & $\$$ Var & $\%$ Var & & \\
\hline Oct-99 & $7,429^{*}$ & 8,309 & $7,429 *$ & 8,309 & -880 & $-12 \%$ & 17.914 & 17,914 \\
\hline Nov -99 & 953 & 1.089 & 8,382 & 9,398 & $-1,016$ & $-12 \%$ & 17,914 & 17,914 \\
\hline Dec-99 & 953 & 544 & 9,335 & 9,942 & -607 & $-6 \%$ & 17,914 & 17,914 \\
\hline Jan-00 & 953 & 982 & 10,289 & 10,924 & -636 & $-6 \%$ & 17,914 & 17,914 \\
\hline$F e b-00$ & 953 & 1.312 & 11,242 & 12,236 & -994 & $-9 \%$ & 17.914 & 17,914 \\
\hline Mar-00 & 95.3 & 641 & 12,195 & 12,877 & -682 & $-6 \%$ & 17.914 & 17,914 \\
\hline Apr-OO & 953 & & 13,148 & & & & 17.914 & \\
\hline May-OO & 953 & & 14.101 & & & & 17,914 & \\
\hline Jun-00 & 953 & & 15,055 & & & & 17.914 & \\
\hline Sul-00 & 953 & & 16,008 & & & & 17,914 & \\
\hline Aug-00 & 953 & & 16.961 & & & & 17,914 & \\
\hline Sep.00 & 953 & & 17,914 & & & & 17.914 & \\
\hline
\end{tabular}

- Includes $\$ 4,136 \mathrm{~K}$ of uncosted obligations from FY99. 
as of March 2000

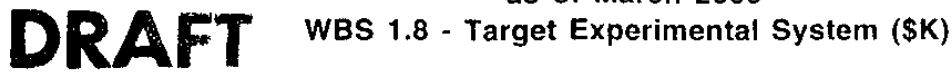

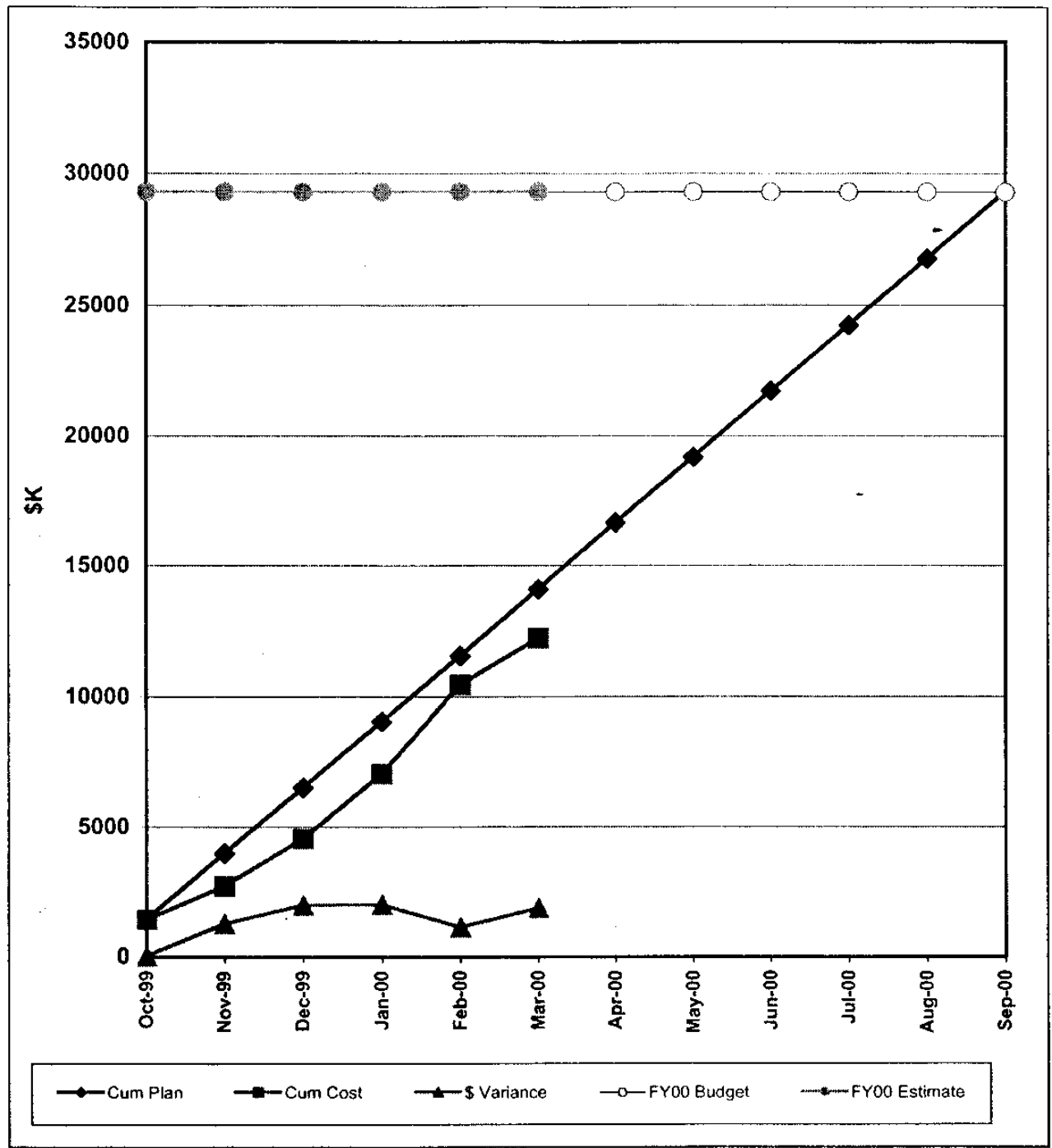

\begin{tabular}{|c|c|c|c|c|c|c|c|c|}
\hline \multirow[b]{2}{*}{ Month } & \multicolumn{2}{|c|}{ Monthly } & \multicolumn{4}{|c|}{ Cumulative } & \multirow{2}{*}{$\begin{array}{l}\text { FY2000 } \\
\text { Budget } \\
\end{array}$} & \multirow{2}{*}{$\begin{array}{l}\text { Fr2000 } \\
\text { Estimate }\end{array}$} \\
\hline & Planned & Actual & Planned & Actual & \$ Var & $\% \operatorname{Var}$ & & \\
\hline Oct-9g & 1,458 & 1,429 & 1,458 & 1,429 & 29 & $2 \%$ & 29.303 & 29,303 \\
\hline Nov-99 & 2,531 & 1,296 & 3,989 & 2,725 & 1,264 & $32 \%$ & 29,303 & 29,303 \\
\hline$D e c-99$ & 2,531 & 1,806 & 6,521 & 4,531 & 1,990 & $31 \%$ & 29,303 & 29,303 \\
\hline $\operatorname{Jan-00}$ & 2,531 & 2,521 & 9,052 & 7,052 & 2,000 & $22 \%$ & 29,303 & 29,303 \\
\hline Feb-OO & 2,531 & 3,410 & 11,584 & 10,462 & 1,122 & $10 \%$ & 29,303 & 29,303 \\
\hline Mar-oo & 2,531 & 1,782 & 14,115 & 12,243 & 1.872 & $13 \%$ & 29,303 & 29,303 \\
\hline Apr.0O & 2,531 & & 16,646 & & & & 29,303 & \\
\hline May.00 & 2,531 & & 19.178 & & & & 29,303 & \\
\hline Jun-00 & 2,531 & & 21.709 & & & & 29,303 & \\
\hline$J u t-\infty O$ & 2,531 & & 24.241 & & & & 29,303 & \\
\hline Aug-00 & 2,531 & & 26,772 & & & & 29,303 & \\
\hline Sep.00 & 2,531 & & 29,303 & & & & 29,303 & \\
\hline
\end{tabular}




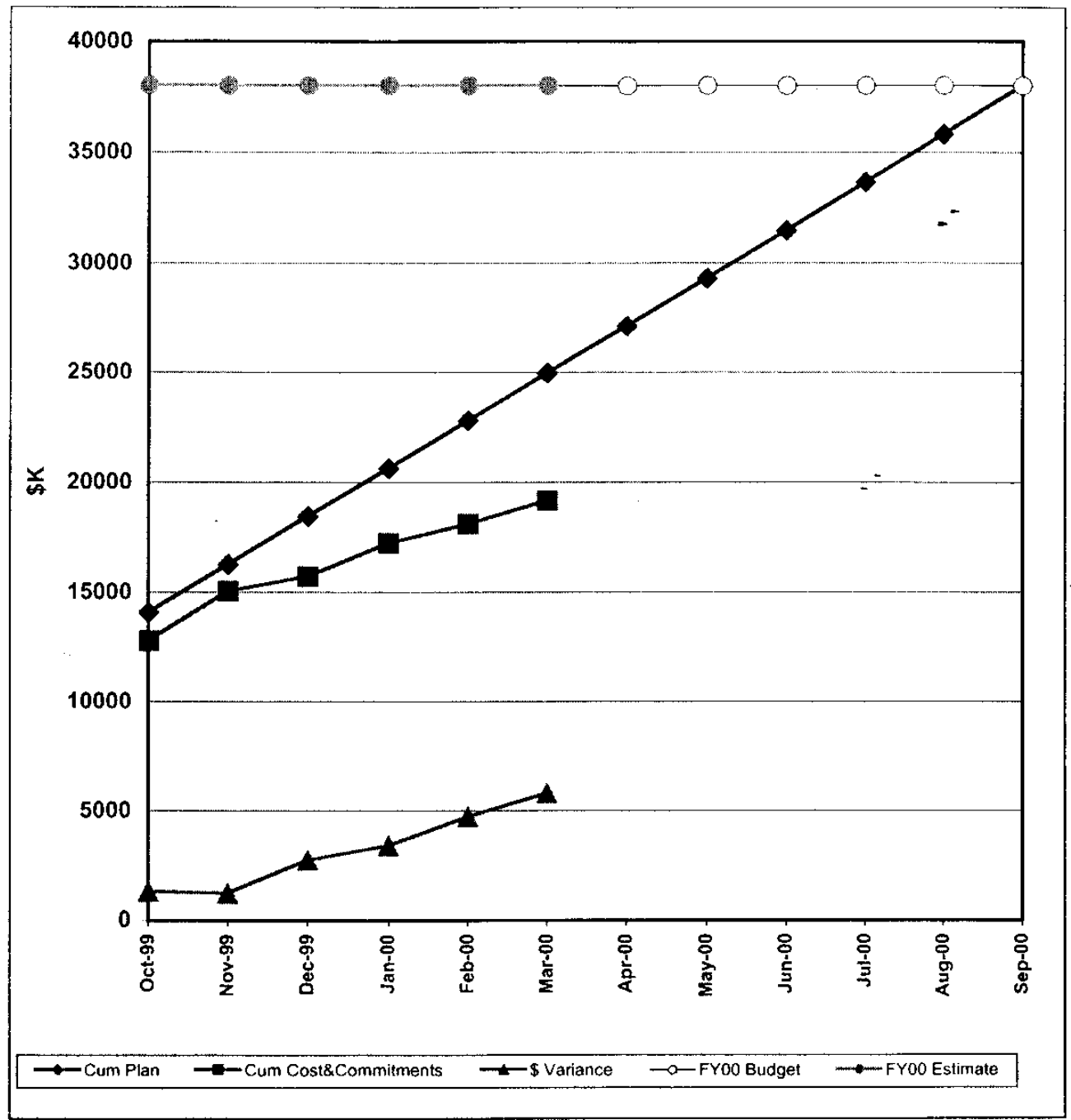

\begin{tabular}{|c|c|c|c|c|c|c|c|c|}
\hline \multirow[b]{2}{*}{ Month } & \multicolumn{2}{|c|}{ Monthly } & \multicolumn{4}{|c|}{ Cumulative } & \multirow{2}{*}{$\begin{array}{l}\text { FY2000 } \\
\text { Budget }\end{array}$} & \multirow{2}{*}{$\begin{array}{l}\text { FY2000 } \\
\text { Estimate }\end{array}$} \\
\hline & Planned & Actual & Planned & Actual & \$ Var & $\%$ Var & & \\
\hline Oct-99 & 14,093 * & 12,805 & $14,093^{*}$ & 12,805 & 1,288 & $9 \%$ & 38,008 & 38,008 \\
\hline Nov-99 & 2,174 & 2,246 & 16,267 & 15,050 & 1,217 & $7 \%$ & 38,008 & 38,008 \\
\hline Dec-99 & 2,174 & 670 & 18,441 & 15.720 & 2,721 & $15 \%$ & 38,008 & 38,008 \\
\hline Jan-0o & 2,174 & 1,496 & 20,615 & 17,216 & 3,399 & $16 \%$ & 38,008 & 38,008 \\
\hline Feb-0o & 2,174 & 855 & 22,789 & 18,071 & 4,718 & $21 \%$ & 38,008 & 38,008 \\
\hline Mar-00 & 2,174 & 1,091 & 24,964 & 19,162 & 5,802 & $23 \%$ & 38,008 & 38,008 \\
\hline Apr-OO & 2,174 & & 27,138 & & & & 38,008 & \\
\hline May-00 & 2,174 & & 29,312 & & & & 38,008 & \\
\hline Jun-00 & 2,174 & & 31,486 & & & & 38,008 & \\
\hline$J u t-00$ & 2,174 & & 33,660 & & & & 38,008 & \\
\hline Aug-00 & 2.174 & & 35,834 & & & & 38,008 & \\
\hline Sep-0O & 2,174 & & 38,008 & & & & 38,008 & \\
\hline
\end{tabular}

\footnotetext{
- Includes $\$ 6,252 K$ of uncosted obligations from FY99.
} 
FY2000 Cost Plan to Actual

as of February 2000

DRAFT

WBS 1.9 - Operations Special Equipment (\$K)
Project Number 96-D-111

February 2000

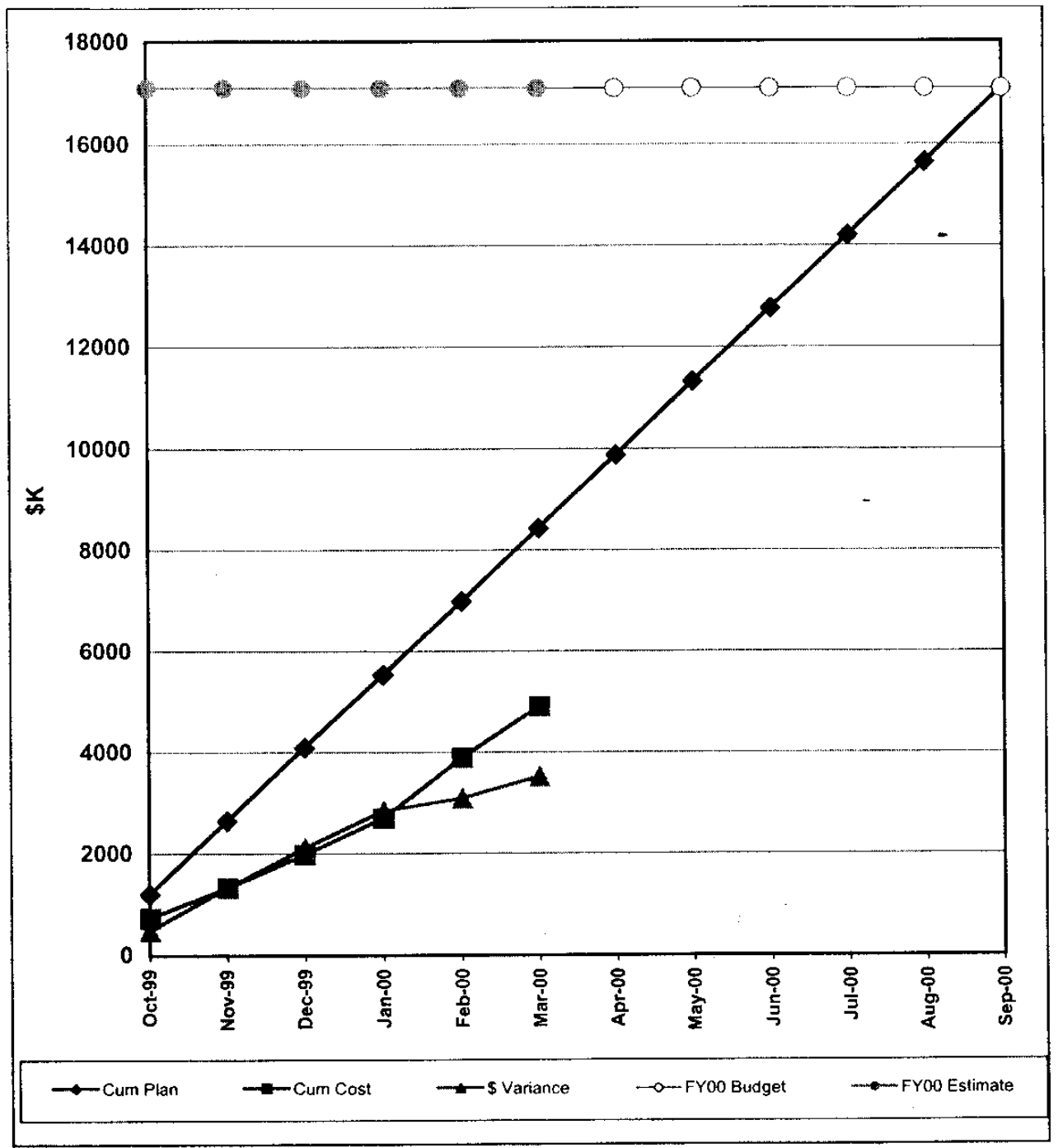

\begin{tabular}{|c|c|c|c|c|c|c|c|c|}
\hline \multirow[b]{2}{*}{ Month } & \multicolumn{2}{|c|}{ Monthly } & \multicolumn{4}{|c|}{ Cumulative } & \multirow{2}{*}{$\begin{array}{l}\text { Fr2000 } \\
\text { Eudget }\end{array}$} & \multirow{2}{*}{$\begin{array}{l}\text { FY2000 } \\
\text { Estimate }\end{array}$} \\
\hline & Planned & Actual & Planned & Actual & $\$$ Var & $\%$ Var & & \\
\hline Oct-99 & 1,209 & 728 & 1,209 & 728 & 481 & $40 \%$ & 17,091 & 17.091 \\
\hline Nov.99 & 1,444 & 601 & 2,653 & 1,329 & 1,324 & $50 \%$ & 17,091 & 17,091 \\
\hline Dec-99 & 1,444 & 653 & 4,097 & 1,982 & 2,115 & $52 \%$ & 17,091 & 17,091 \\
\hline Jan-00 & 1,444 & 716 & 5,540 & 2,698 & 2,843 & $51 \%$ & 17,091 & 17,091 \\
\hline Feb-00 & 1,444 & 1,191 & 6,984 & 3,889 & 3,095 & $44 \%$ & 17,091 & 17.091 \\
\hline Mar-OO & 1,444 & 1,019 & 8,428 & 4,908 & 3,520 & $42 \%$ & 17,091 & 17,091 \\
\hline Apr-OO & 1,444 & & 9,872 & & & & 17.091 & \\
\hline May-OO & 1,444 & & 11,316 & & & & 17,091 & \\
\hline Jun-0O & 1,444 & & 12.759 & & & & 17,091 & \\
\hline Jul-0o & 1,444 & & 14,203 & & & & 17,091 & \\
\hline Aug-OO & 1,444 & & 15,647 & & & & 17,091 & \\
\hline Sep.0o & 1,444 & & 17,091 & & & & 17,091 & \\
\hline
\end{tabular}


FY2000 Cost and Commitment Plan to Actual

as of March 2000

WBS 1.9 - Operations

ERAFT
Project Number 96-D-111

March 2000

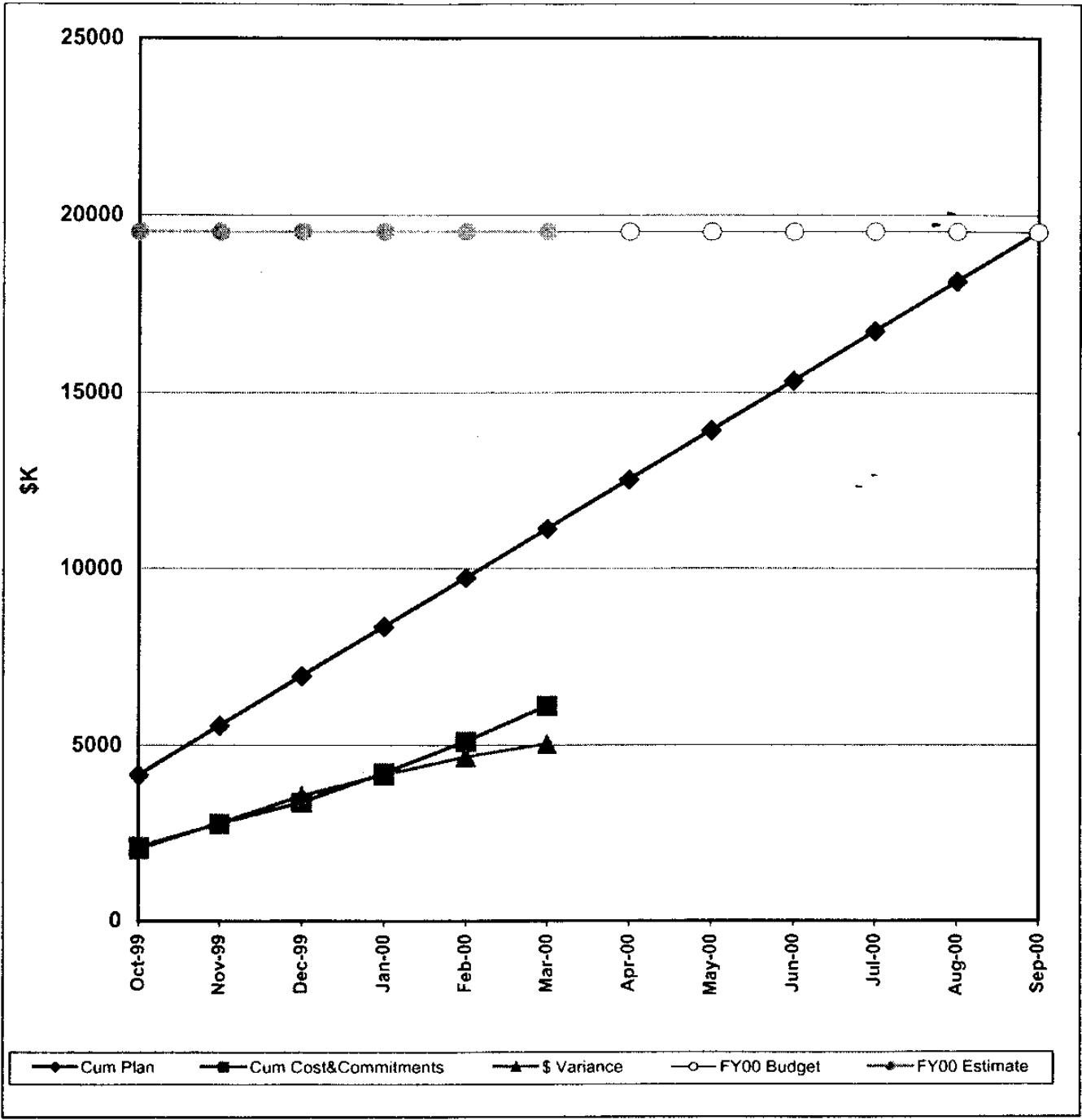

\begin{tabular}{|c|c|c|c|c|c|c|c|c|}
\hline \multirow[b]{2}{*}{ Month } & \multicolumn{2}{|c|}{ Monthly } & \multicolumn{4}{|c|}{ Cumulative } & \multirow{2}{*}{$\begin{array}{l}\text { FY2000 } \\
\text { Budget }\end{array}$} & \multirow{2}{*}{$\begin{array}{l}\text { FY2000 } \\
\text { Estimate }\end{array}$} \\
\hline & Ptanned & Actual & Planned & Actual & $\$$ Var & $\%$ Var & & \\
\hline Oct-99 & $4,144^{\prime}$ & 2,102 & $4,144^{*}$ & 2,102 & 2,042 & $49 \%$ & 19,537 & 19,537 \\
\hline Nov.99 & 1,399 & 657 & 5,543 & 2,759 & 2,784 & $50 \%$ & 19,537 & 19.537 \\
\hline Dec.99 & 1,399 & 618 & 6,943 & 3,377 & 3,566 & $51 \%$ & 19,537 & $\$ 9,537$ \\
\hline $\operatorname{Jan} \cdot 00$ & 1,399 & 817 & 8,342 & 4,194 & 4,148 & $50 \%$ & 19,537 & 19,537 \\
\hline $\mathrm{Feb}-00$ & 1,399 & 894 & 9,742 & 5,088 & 4,654 & $48 \%$ & 19.537 & 19,537 \\
\hline Mar.00 & 1,399 & 1,027 & 11,141 & 6,115 & 5,026 & $45 \%$ & 19,537 & 19,537 \\
\hline$A p r .00$ & 1,399 & & 12,540 & & & & 19,537 & \\
\hline May-00 & 1,399 & & 13,940 & & & & 19,537 & \\
\hline Jun-00 & 1,399 & & 15,339 & & & & 19,537 & \\
\hline$s u t-00$ & 1,399 & & 16,739 & & & & 19,537 & \\
\hline Aug-0o & 1,399 & & 18,138 & & & & 19,537 & \\
\hline Sep.00 & 1,399 & & 19,537 & & & & 19,537 & \\
\hline
\end{tabular}

- Includes $\$ 1,404 \mathrm{~K}$ of uncosted obligations from FY99. 
FY2000 Cost Plan to Actual

as of March 2000

WBS 1.10 - Start-up Activities (\$K)

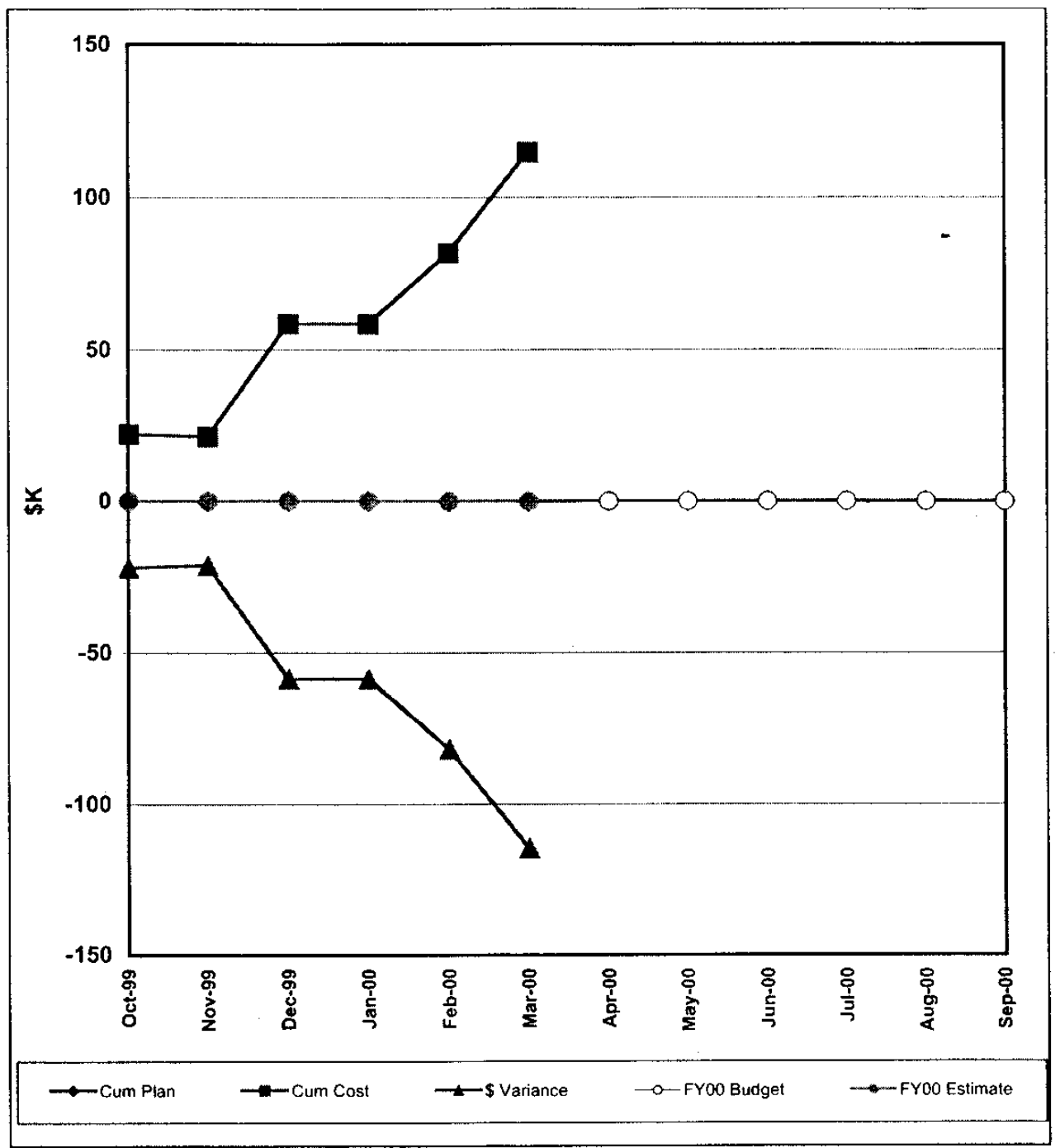

\begin{tabular}{|c|c|c|c|c|c|c|c|c|}
\hline \multirow[b]{2}{*}{ Month } & \multicolumn{2}{|c|}{ Monthly } & \multicolumn{4}{|c|}{ Cumulative } & \multirow{2}{*}{$\begin{array}{l}\text { FY2000 } \\
\text { Budget }\end{array}$} & \multirow{2}{*}{$\begin{array}{c}\text { FY2000 } \\
\text { Estimate }\end{array}$} \\
\hline & Planned* & Actual & Planned & Actual & $\$$ Var & $\%$ Var & & \\
\hline Oct-99 & 0 & 22 & 0 & 22 & -22 & \#D|V/0! & 0 & - \\
\hline Nov-99 & 0 & -1 & 0 & 21 & -21 & \#DIV/0! & 0 & - \\
\hline$D e c-99$ & 0 & 37 & 0 & 59 & -59 & \#DIV/O! & 0 & - \\
\hline Jan-00 & 0 & 0 & 0 & 59 & -59 & \#DIV/O! & 0 & - \\
\hline$F e b-0 O$ & 0 & 23 & 0 & 82 & -82 & \#DIV/O! & 0 & \\
\hline Mar-oo & 0 & 33 & 0 & 115 & .115 & \#DIV/O! & 0 & \\
\hline Apr.oO & 0 & & 0 & & & & 0 & \\
\hline May-OO & 0 & & 0 & & & & 0 & \\
\hline Jun.00 & 0 & & 0 & & & & 0 & \\
\hline Jut.00 & 0 & & 0 & & & & 0 & \\
\hline Aug. 00 & 0 & & 0 & & & & 0 & \\
\hline Sep-00 & 0 & & 0 & & & & 0 & \\
\hline
\end{tabular}

- Plan will be prepared and budgeted. 
FY2000 Cost and Commitment Plan to Actual

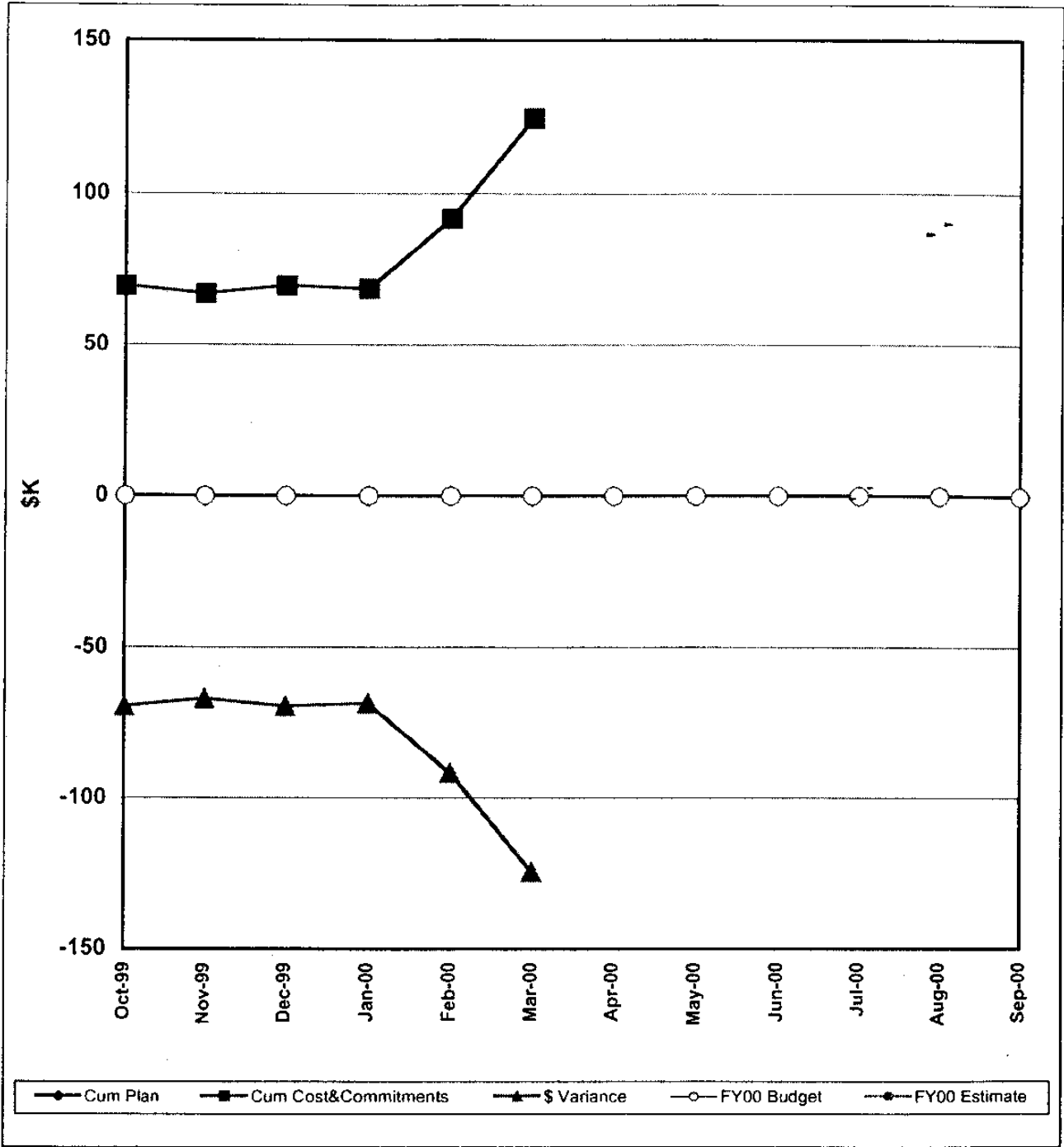

\begin{tabular}{|c|c|c|c|c|c|c|c|c|}
\hline \multirow[b]{2}{*}{ Month } & \multicolumn{2}{|c|}{ Monthly } & \multicolumn{4}{|c|}{ Cumulative } & \multirow{2}{*}{$\begin{array}{l}\text { FY2000 } \\
\text { Budget* }\end{array}$} & \multirow{2}{*}{$\begin{array}{c}\text { FY2000 } \\
\text { Estimate }\end{array}$} \\
\hline & Planned* & Actual & Planned & Actual & $\$$ Var & $\%$ Var & & \\
\hline Oct -99 & 0 & 70 & 0 & 70 & -70 & \#DIV/O! & 0 & 0 \\
\hline Nov.99 & 0 & -2 & 0 & 67 & -67 & \#DIV/0! & 0 & 0 \\
\hline Dec-99 & 0 & 3 & 0. & 70 & -70 & \#DIV/O! & 0 & 0 \\
\hline $\operatorname{Jan}-00$ & 0 & -1 & 0 & 69 & -69 & \#DIV/0! & 0 & 0 \\
\hline Feb-00 & 0 & 23 & 0 & 92 & -92 & \#DIV/0! & 0 & 0 \\
\hline Mar.0o & 0 & 33 & 0 & 125 & -125 & \#DIV/O! & 0 & 0 \\
\hline Apr.0O & 0 & & 0 & & & & 0 & \\
\hline May.0o & 0 & & 0 & & & & 0 & \\
\hline Jun-oo & 0 & & 0 & & & & 0 & \\
\hline JuI.0O & 0 & & 0 & & & & 0 & \\
\hline Aug.00 & 0 & & 0 & & & & 0 & \\
\hline Sep-00 & 0 & & 0 & & & & 0 & \\
\hline
\end{tabular}

\footnotetext{
- Plan will be prepared and budgeted.
} 
FY2000 Cost Plan to Actual

as of March 2000

WBS 1.11 (\$K)
Project Number 96-D-111 March 2000

DRAFT

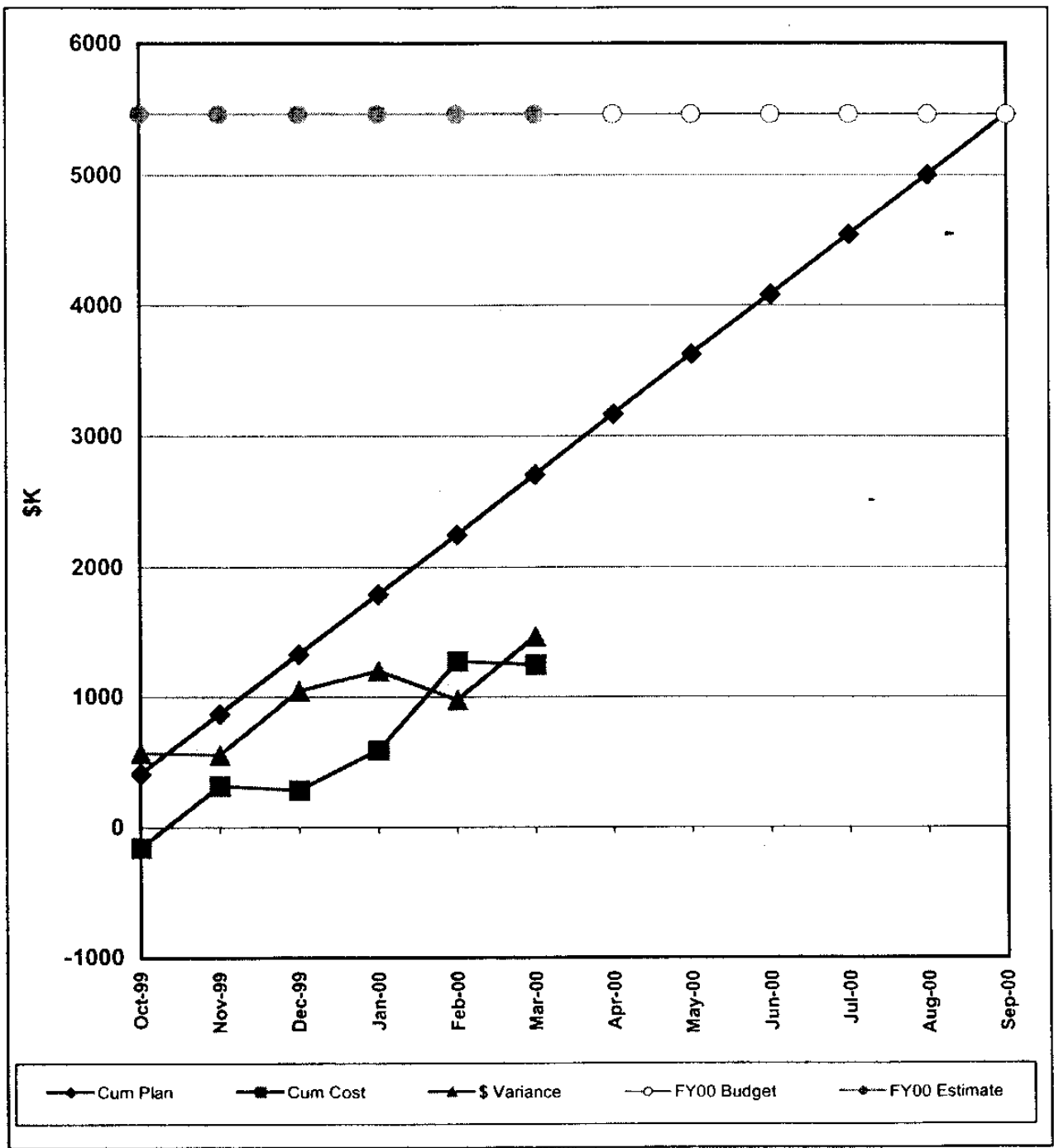

\begin{tabular}{|c|c|c|c|c|c|c|c|c|}
\hline \multirow[b]{2}{*}{ Month } & \multicolumn{2}{|c|}{ Monthly } & \multicolumn{4}{|c|}{ Cumulative } & \multirow{2}{*}{$\begin{array}{l}\text { FY2000 } \\
\text { Budget* }\end{array}$} & \multirow{2}{*}{$\begin{array}{l}\text { FY2000 } \\
\text { Estimate }\end{array}$} \\
\hline & Planned * & Actual & Planned & Actual & $\$$ Var & $\%$ Var & & \\
\hline Oct.99 & 410 & -157 & 410 & -157 & 567 & $138 \%$ & 5,466 & 5,466 \\
\hline Nov-99 & 460 & 474 & 870 & 317 & 553 & $64 \%$ & 5,466 & 5,466 \\
\hline$D e c-99$ & 460 & -33 & 1,329 & 284 & 1,046 & $79 \%$ & 5,466 & 5,466 \\
\hline Jan-00 & 460 & 306 & 1,789 & 589 & 1,200 & $67 \%$ & 5,466 & 5,466 \\
\hline Feb-oo & 460 & 682 & 2.248 & 1.272 & 977 & $43 \%$ & 5,466 & 5,466 \\
\hline Mar-OO & 460 & -29 & 2,708 & 1,243 & 1,465 & $54 \%$ & 5.466 & 5,466 \\
\hline Apr-00 & 460 & & 3.168 & & & & 5,466 & \\
\hline May-00 & 460 & & 3,627 & & & & 5,466 & \\
\hline Jun-00 & 460 & & 4,087 & & & & 5,466 & \\
\hline$J u t-00$ & 460 & & 4,546 & & & & 5,466 & \\
\hline$A u g \cdot 0 O$ & 460 & & 5,006 & & & & 5.466 & \\
\hline Sep-00 & 460 & & 5,466 & & & & 5.466 & \\
\hline
\end{tabular}




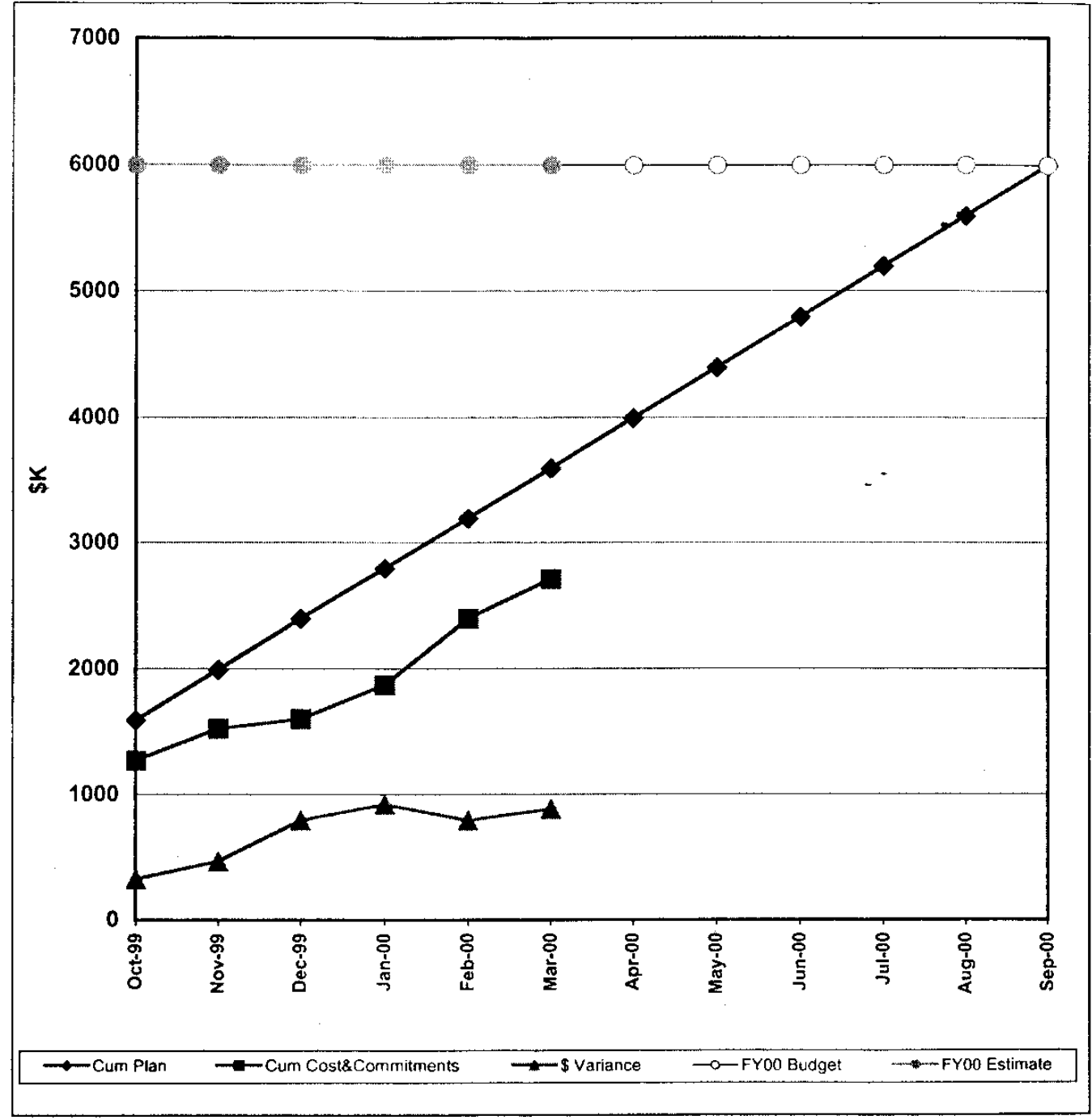

\begin{tabular}{|r|cc|cc|cc|r|r|}
\hline & \multicolumn{3}{|c|}{ Monthly } & \multicolumn{4}{c|}{ Cumulative } & FY2000 \\
Month & Planned & Actual & Planned & Actual & S Var & $\%$ Var & Fudget \\
Estimate
\end{tabular}

- includes $\$ 1,423 \mathrm{~K}$ of uncosted obligations from FY99. 


\section{$2 \mathrm{Q} 00$ NIF Contingency Log (\$BA)}

\begin{tabular}{|c|c|c|c|c|c|c|}
\hline Month & \multirow{2}{*}{$\frac{\text { Request \# }}{\text { BCP00-004 }}$} & WBS element & \multicolumn{2}{|c|}{ Total } & \multirow[b]{2}{*}{$\$$} & \multirow{2}{*}{$\begin{array}{l}\text { Contingency } \\
23,686,988\end{array}$} \\
\hline \multirow[t]{11}{*}{ Jan-00 } & & 1.1 .5 & $\$$ & 362,500 & & \\
\hline & & 1.4.1.2 & & 100,000 & $\$$ & $23,586,988$ \\
\hline & & 1.5.4.1 & & 10,000 & $\$$ & $23,576,988$ \\
\hline & & 1.7.1.4 & $\$$ & 95,000 & $\$$ & $23,481,988$ \\
\hline & BCP00-006 & 1.4.2.4 & $\$$ & 609,000 & $\$$ & $22,872,988$ \\
\hline & CTR344 & 1.4 .4 .2 & $\$$ & 311,000 & $\$$ & $22,561,988$ \\
\hline & ECR1316 & 1.2 .2 .1 & $\$$ & 20,000 & $\$$ & $22,541,988$ \\
\hline & & 1.2.2.4.9 & $\$$ & 15,000 & $\$$ & $22,526,988$ \\
\hline & ECR1356 & 1.4 .1 .3 & $\$$ & 69,300 & $\$$ & $22,457,688$ \\
\hline & ECR1357 & 1.4 .1 .3 & $\$$ & 94,900 & $\$$ & $22,362,788$ \\
\hline & ECR1364 & 1.3 .2 & $\$$ & 4,000 & $\$$ & $22,358,788$ \\
\hline \multirow[t]{8}{*}{ Feb-00 } & BCP00-011 & 1.4 .3 .2 & & $2,600,000$ & $\$$ & $19,758,788$ \\
\hline & CTR335 & 1.1 .4 & $\$$ & 185,000 & $\$$ & $19,573,788$ \\
\hline & CTR343 & 1.2 .2 .4 .6 & $\$$ & 250,000 & $\$$ & $19,323,788$ \\
\hline & CTR345 & 1.2 .2 .4 .9 & $\$$ & 88,000 & $\$$ & $19,235,788$ \\
\hline & CTR346 & 1.2 .2 .1 & $\$$ & 125,000 & $\$$ & $19,110,788$ \\
\hline & CTR349 & 1.2 .2 .4 .6 & $\$$ & 450,000 & $\$$ & $18,660,788$ \\
\hline & CTR350 & 1.2 .2 .4 & $\$$ & 302,000 & $\$$ & $18,358,788$ \\
\hline & ECR1408 & 1.4 .4 .3 & $\$$ & 50,000 & $\$$ & $18,308,788$ \\
\hline \multirow[t]{9}{*}{ Mar-00 } & CTR351 & 1.2.2.4.9 & $\$$ & 145,000 & $\$$ & $18,163,788$ \\
\hline & CTR353 & 1.3 .1 .3 & $\$$ & 375,000 & $\$$ & $17,788,788$ \\
\hline & ECR1437 & 1.8 .7 & $\$$ & 100,000 & $\$$ & $17,688,788$ \\
\hline & ECR1473 & 1.4 .2 .4 & $\$$ & 170,000 & $\$$ & $17,518,788$ \\
\hline & ECR1515 & 1.4 .4 .2 & $\$$ & 5,700 & $\$$ & $17,513,088$ \\
\hline & ECR1535 & 1.1 .5 & $\$$ & 54,000 & $\$$ & $17,459,088$ \\
\hline & ECR1554 & 1.4 .1 & $\$$ & 55,000 & $\$$ & $17,404,088$ \\
\hline & & 1.6.10.1 & & 50,000 & $\$$ & $17,354,088$ \\
\hline & & 1.7 .1 & $\$$ & 25,000 & $\$$ & $17,329,088$ \\
\hline
\end{tabular}




\section{DRAFT \\ FY00 - Manpower Plan to Actual by Month* \\ as of March 2000 \\ (LLNL and Supplemental Labor Manmonths)}

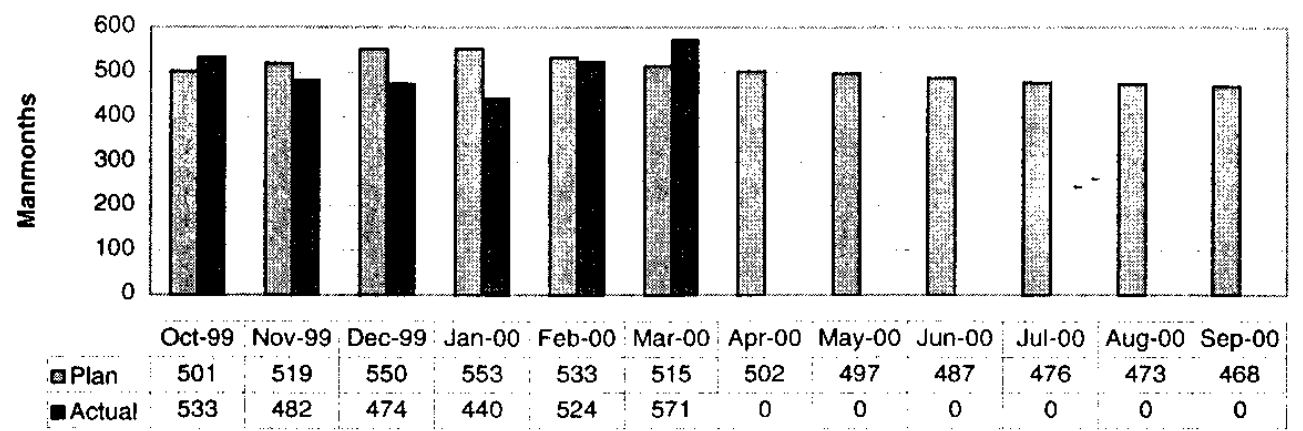

* FYO0 manpower plan will be in draft until the rebaselining effort is complete and the FYO0 Cost Account Plans are approved. 